Tese apresentada ao Departamento de Economia da Universidade de Brasília, como requisito parcial para obtenção do título de Doutor em Economia.

\title{
Ensaios em macroeconomia aberta
}

Orientador: Joaquim Pinto de Andrade

\author{
Autor: Adonias Evaristo da Costa Filho \\ Brasília, 19 janeiro de 2015
}

Universidade de Brasília

Faculdade de Economia, Administração e Contabilidade

Departamento de Economia 



\section{Sumário}

1 Introdução 9

2 Fatores Determinantes do Ciclo de Negócios no Brasil 11

2.1 Introdução . . . . . . . . . . . . . . . . . . . . . 11

2.2 Modelo . . . . . . . . . . . . . . . . . . 15

2.2.1 Estado Estacionário . . . . . . . . . . . . . . . . . 21

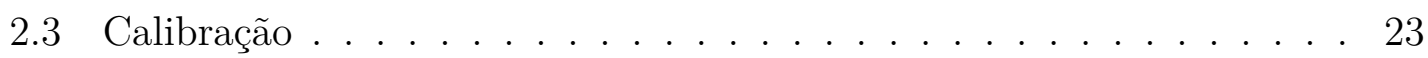

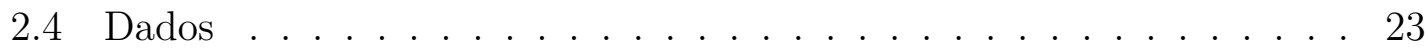

2.5 Resultados . . . . . . . . . . . . . . . . . . . . 24

2.6 Conclusão . . . . . . . . . . . . . . . . . . . . . . . . . . . . . . 28

Referências Bibliográficas $\quad 35$

2.7 Apêndice . . . . . . . . . . . . . . . . . . . . . . 36

3 Fricções financeiras em um modelo de economia aberta estimado para o Brasil

3.1 Introdução . . . . . . . . . . . . . . . . . . . . . . . . . . . . . 41

3.2 Modelo . . . . . . . . . . . . . . . . . . . . 43

3.2.1 Empreendedores. . . . . . . . . . . . . . . . . 44

3.2.2 Produtores de capital . . . . . . . . . . . . . . . . . . . . . . . . . . . . . 47

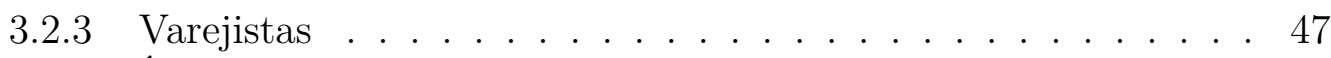

3.2.4 Índices de consumo e de preços . . . . . . . . . . . . . . . . . 50

3.2.5 Economia externa . . . . . . . . . . . . . . . 51

3.2 .6 Consumidores . . . . . . . . . . . . . . . . . 51

3.2 .7 Governo . . . . . . . . . . . . . . . . . . 54

3.3 Modelo log-linearizado . . . . . . . . . . . . . . . . . . . 54

3.4 Calibração . . . . . . . . . . . . . . . . . 56

3.5 Dados . . . . . . . . . . . . . . . . . . 57

3.6 Resultados . . . . . . . . . . . . . . . . . 57

3.6.1 Parâmetros estimados . . . . . . . . . . . . . 57

3.6.2 Decomposição da variância . . . . . . . . . . . . . . . . 61

3.6.3 Funções de impulso resposta . . . . . . . . . . . . . . . . . 63

3.7 Conclusão . . . . . . . . . . . . . . . . . . . . . . 64

$\begin{array}{ll}\text { Referências Bibliográficas } & \mathbf{7 3}\end{array}$

3.8 Apêndice. . . . . . . . . . . . . . . . . . . . 74 
4 O papel das variáveis externas no período 1999-2013 em um modelo DSGE estimado para o Brasil

4.1 Introdução . . . . . . . . . . . . . . . . . . . . . . . . . 79

4.2 Revisão da Literatura . . . . . . . . . . . . . . . . . . . . . . 80

4.2.1 Termos de troca . . . . . . . . . . . . . . . 80

4.2.2 Petróleo . . . . . . . . . . . . . . . . . . . . . 80

4.2.3 Modelos DSGE aplicados à economia brasileira . . . . . . . . 83

4.3 Modelo . . . . . . . . . . . . . . . . . . . . 85

4.3.1 Estrutura geral do modelo . . . . . . . . . . . . . . . . 85

4.3.2 Modelo na forma log-linear: . . . . . . . . . . . . . . . . 99

4.4 Dados . . . . . . . . . . . . . . . . . . . . . 103

4.5 Calibração . . . . . . . . . . . . . . . . . . . . . 103

4.6 Resultados . . . . . . . . . . . . . . . . . . . . 105

4.6 .1 Parâmetros estimados . . . . . . . . . . . . . . 105

4.6 .2 Distribuições posteriores . . . . . . . . . . . . . . . 106

4.6.3 Decomposição da Variância . . . . . . . . . . . . . . . . . . 107

4.6.4 Decomposição histórica . . . . . . . . . . . . . . . . . . . 108

4.6.5 Funções de impulso resposta . . . . . . . . . . . . . . . . . . . 111

4.7 Conclusão . . . . . . . . . . . . . . . . . . . . . . . . . . . 123

$\begin{array}{ll}\text { Referências Bibliográficas } & 125\end{array}$

5 Apêndice - Estimação Bayesiana $\quad 129$

$\begin{array}{ll}\text { Referências Bibliográficas } & 137\end{array}$ 


\section{Lista de Figuras}

2.1 Séries originais . . . . . . . . . . . . . . . . . . . . . 24

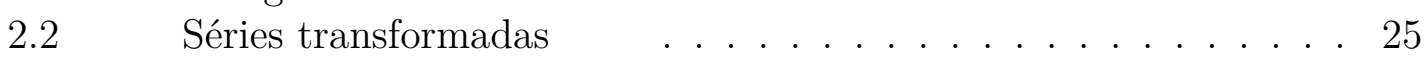

2.3 IRF choque de produtividade . . . . . . . . . . . 27

$2.4 \quad$ IRF - choque no prêmio de risco $\ldots \ldots \ldots . \ldots 28$

2.5 IRF - choque nos juros mundiais _ . . . . . . . . . . . 29

2.6 IRF- choque específico no investimento . . . . . . . . 30

2.7 Priors e posteriores $-1 \quad \ldots \ldots \ldots$. . . . . . . . . 30

2.8 Priors e posteriores $-2 \quad \ldots \ldots \ldots . \ldots . \ldots . \ldots 32$

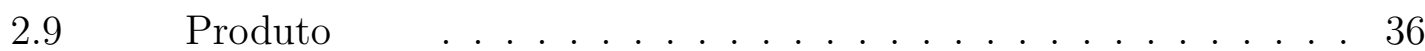

2.10 Consumo $\ldots \ldots \ldots \ldots \ldots$

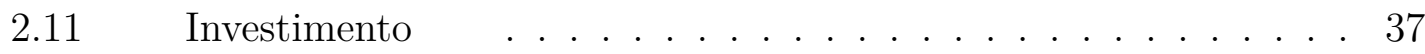

2.12 Balança comercial . . . . . . . . . . . . 37

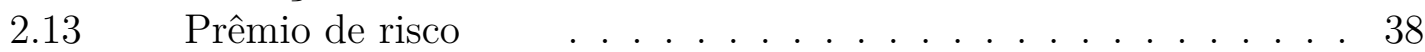

2.14 Converência multivariada f . . . . . . . . . . . 38

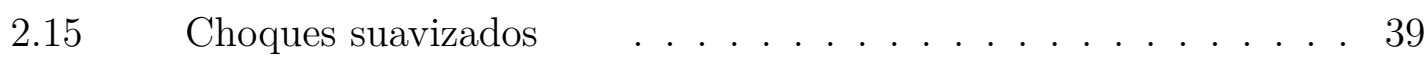

2.16 Identificação . . . . . . . . . . . . . . . . . . 39

3.1 Dados utilizados nas estimações _. . . . . . . . . 57

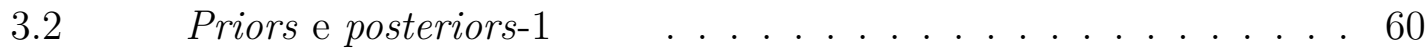

3.3 Priors e posteriors $-2 \quad \ldots \ldots \ldots \ldots$. . . . . . . 61

3.4 Priors e posteriors $-3 \quad \ldots \ldots \ldots \ldots 62$

3.5 Priors e posteriors $-4 \quad \ldots \ldots \ldots \ldots 6 . \ldots \ldots 6$

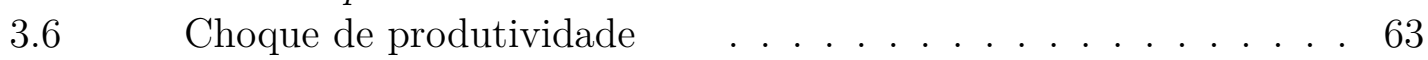

3.7 Choque na taxa de juros mundial f. . . . . . . . . . . 64

3.8 Choque na taxa de juros doméstica f . . . . . . . . . 65

3.9 Choque na inflação mundial _. . . . . . . . . . . 66

3.10 Choque nos gastos do governo f............ 66

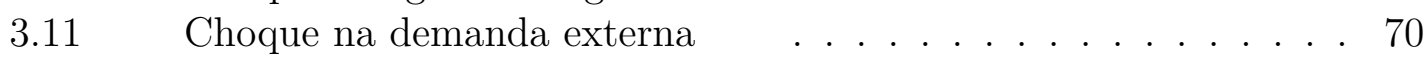

3.12 Choque no prêmio de risco f . . . . . . . . . . 70

3.13 Choque específico no investimento . . . . . . . . . . . 71

3.14 Funções de resposta ao impulso após um choque na taxa de juros, com e sem prêmio de financiamento externo _. . . . . . . . . . 71

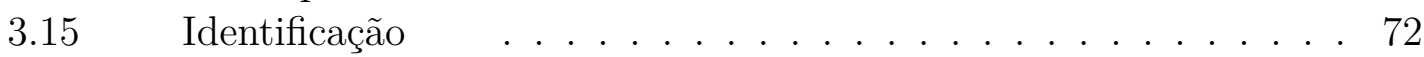

3.16 Convergência f...................... 72

3.17 Decomposição histórica do produto $\quad \ldots \ldots$. . . . . . 75 
3.18 Decomposição histórica do consumo … . . . . . . . 75

3.19 Decomposição histórica do investimento … . . . . . 76

3.20 Decomposição histórica das exportações líquidas . . . . . . 76

3.21 Decomposição histórica da inflação f . . . . . . . . . . 76

3.22 Decomposição histórica do prêmio de financiamento externo $\quad 77$

4.1 Saldo comercial de produtos relacionados ao petroleo . . . . . . . . 79

$4.2 \quad$ Firmas no modelo f. . . . . . . . . . . . 86

4.3 Séries utilizadas . . . . . . . . . . . . . . . . . . . . 103

$4.4 \quad$ Priors $\mathrm{x}$ posteriores dos parâmetros estimados $-1 \quad \ldots 106$

$4.5 \quad$ Priors $\mathrm{x}$ posteriores dos parâmetros estimados $-2 \quad$. . . . . 107

4.6 Priors $\mathrm{x}$ posteriores dos parãmetros estimados $-3 \quad$. . . . . . 108

4.7 Priors x posteriores dos parâmetros estimados $-4 \quad$. . . . . 109

4.8 Priors $\mathrm{x}$ posteriores dos parâmetros estimados $-5 \quad$. . . . . 110

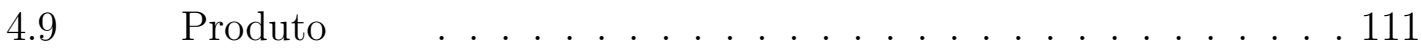

4.10 Inflação … . . . . . . . . . . . . . . . . . 112

4.11 Conta-Corrente . . . . . . . . . . . . . . . 112

4.12 Câmbio Real ． . . . . . . . . . . . . . 116

4.13 Choque de produtividade f. . . . . . . . . . 118

4.14 Choque na produção de commodities . . . . . . . . . 118

4.15 Choque no preço das commodities exportadas _. . . . . . 119

4.16 Choque no produto mundial _. . . . . . . . . . . 119

4.17 Choque na taxa de juros doméstica . . . . . . . . . . . 120

4.18 Choque na taxa de juros externa $\quad \ldots \ldots . . \ldots 120$

4.19 Choque na oferta de trabalho . . . . . . . . . . . . 121

4.20 Choque no preço do petróleo . . . . . . . . . . . . . . . 121

4.21 Choque no custo de ajustamento do investimento . . . . . 122

4.22 Choque no preço das importações . . . . . . . . . . . . . . . . . . . . 122

4.23 Choque na inflação mundial . . . . . . . . . . . . 123

4.24 Identificação ． . . . . . . . . . . . . . . . . . 123 


\section{Lista de Tabelas}

2.1 Parâmetros calibrados . . . . . . . . . . . . 23

2.2 Parâmetros estimados- média da posterior … . . . . . 31

2.3 Decomposição da variância-Modelo Base . . . . . . . . . 32

2.4 Decomposição da variância do produto, balança comercial e prêmio de risco para diferentes especificações _ . . . . . . . . 33

$3.1 \quad$ Valores calibrados f. . . . . . . . . . . 67

3.2 Resultado da estimação f. . . . . . . . . . . . . . 68

3.3 Decomposição da variância . . . . . . . . . . . . . 69

3.4 Estimações da rigidez de preços e salários para o Brasil . . 77

4.1 Principais choques do petróleo f . . . . . . . . . . . . . . 81

4.2 Descrição das séries . . . . . . . . . . . . . . . . . . . . . . . . . 113

4.3 Descrição dos parâmetros estimados . . . . . . . . . . . . . . . . . . 114

4.4 Parâmetros estimados . . . . . . . . . . . . . 115

4.5 Decomposição da Variância - contribuição \% de cada tipo de

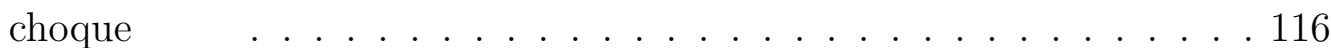

4.6 Decomposição da variância condicional - contribuição \% de cada tipo de choque ....................... 117 



\section{Dedicação}

Dedico este trabalho para os meus pais. 



\section{Introdução}

Esta tese é composta de 4 capítulos, além desta introdução. O capítulo 2 explica sucintamente a estimação Bayesiana, que foi utilizada na estimação dos modelos, e que está sendo cada vez mais utilizada em macroeconomia. Ao todo, 3 modelos são utilizados na tese. Além da estimação Bayesiana, os modelos têm em comum o fato de serem de economia aberta. Segue a seguir uma pequena descrição da estrutura de cada modelo e dos resultados obtidos.

O capítulo 3 utiliza um modelo de ciclos econômicos reais (RBC) para analisar o papel de 4 tipos de choques na economia brasileira entre 1997 e 2014: choques específicos no investimento - entendidos como choques no preço relativo do investimento - , choques no prêmio de risco, na taxa de juros externa e na produtividade.

Encontra-se um papel bastante relevante para os choques no preço relativo do investimento quando o modelo é estimado com todos os choques. Entretanto, um modelo sem choques no investimento apresenta um melhor ajuste as dados. Encontra-se também evidências de endogeneidade do prêmio de risco - como função da produtividade -, em linha com a evidência para outros países emergentes, apontando para a interação entre a produtividade e fatores de origem financeira.

O capítulo 4 estima um modelo DSGE com fricções financeiras em um contexto de economia aberta para o Brasil, contemplando rigidez de preços, custos de ajustamento do capital, hábito no consumo e o acelerador financeiro no bloco do investimento.

Os resultados obtidos apontam para uma grande relevãncia dos choques de origem financeira - choques na taxa de juros externa, no prêmio de risco e na taxa de juros doméstica - com a interação da taxa de câmbio com os fatores financeiros sendo fundamental para os resultados obtidos. Mostra-se que o prêmio de financiamento externo amplia os efeitos da política monetária no produto e no investimento.

Por fim, o capítulo 5 estima para o Brasil o modelo de Soto e Medina (2007), um DSGE de grande porte, que embute rigidez de salários, 4 tipos de rigidez de preços, custos de ajustamento do capital e diversos choques. A interesse na estimação do modelo para o Brasil reside na sua estrutura, que considera o papel do petróleo no consumo e investimento, e da presença de um setor exportador de commodities, uma vez que no Brasil elas representam em média $60 \%$ da pauta de exportações. Adicionalmente, o modelo contempla o papel dos termos de troca, representados pelo preço das importações. 
Os resultados obtidos apontam para uma grande importância dos choques de origem externa neste modelo mais complexo. Os choques de oferta têm grande importância na variância de curto prazo do produto, mas à medida em que o horizonte de previsão aumenta, os fatores externos passam a predominar. Novamente, os resultados apontam para a importância da dinâmica da taxa de câmbio na economia brasileira ao longo do período considerado, haja vista que ela é explicada majoritariamente por choques de origem externa no modelo. 


\section{Fatores Determinantes do Ciclo de Negócios no Brasil}

\subsection{Introdução}

Os ciclos econômicos nos países emergentes são caracterizados por elevada volatilidade de várias variáveis macroeconômicas (produto, consumo e taxa de juros), e pelo caráter contracíclico das exportações líquidas e dos juros reais, conforme apontado por ampla evidência empírica, como em Fernandez e Gulan (2012), Neumayer e Perri (2005), Aguiar e Gopinath (2007) e Uribe (2014).

No intuito de explicar os ciclos econômicos nos países emergentes, conforme apontado por Chang e Fernández (2013), a literatura em geral se divide entre o foco em choques na taxa de juros, em particular no componente do prêmio de risco dos juros reais, como em Neumeyer e Perri (2005), Uribe e Yue (2006) e García-Cicco et al. (2010), ou em choques permanentes na produtividade, como em Aguiar e Gopinath (2007) e Fernandez e Gulán (2012).

Neumeyer e Perri (2005) tentam explicar estes fatos estilizados principalmente através de choques nas taxas de juros com que os países emergentes se deparam. Com esta finalidade, utilizam um modelo de ciclos reais de economia aberta, caracterizado pela presença preferências GHH (Greenwood et al. (1988)), custos de ajustamento do capital e working capital, i.e., as firmas precisam financiar a sua folha de pagamento antes de efetivamente produzirem. O modelo também inclui choques na taxa de juros externa, choques no prêmio de risco e choques na produtividade. Os choques no prêmio de risco são modelados tanto de forma exógena (i.e., de forma independente dos fatores domésticos) quanto de forma endógena (i.e., como função da produtividade). O modelo foi calibrado para a Argentina para o período 1983 e 2001, e os resultados encontrados apontam para um papel importante para os choques no prêmio de risco nos ciclos econômicos dos países emergentes, pois no modelo em que o prêmio de risco dependente endogenamente e de forma negativa da produtividade, o choque no prêmio de risco contribui com cerca de $27 \%$ da variação do produto argentino. A restrição de working capital se mostra importante para ampliar os efeitos de choques de produtividade na economia. Sem a presença de working capital, o modelo gera uma correlação positiva entre juros reais e produto, e pouca volatilidade no produto em comparação com a encontrada nos dados.

Aguiar e Gopinath (2007) argumentam que choques permanentes na produtividade do trabalho explicam boa parte das características dos ciclos nos países emergentes, 
em particular as variâncias e correlações envolvendo o consumo, produto e exportações líquidas. A análise foi efetuada para o México e Canadá, em um modelo RBC com choques temporários e permanentes na produtividade para o período compreendido entre 1980 e 2003. Os autores encontram que choques na tendência da produtividade explicam $82 \%$ da variância do produto mexicano. Entretanto, uma deficiência do modelo é que ele não consegue explicar as correlações envolvendo taxas de juros, produto e exportações líquidas.

García-Cicco et al. (2010) contestam a interpretação de que choques permanentes na produtividade são os mais importantes nos ciclos de negócios de países emergentes. Os autores utilizaram séries longas ( de 1900 até 2005) para a Argentina e o México, argumentando que o modelo RBC não consegue reproduzir o excesso de volatilidade do consumo em relação ao produto nos países mencionados, e também produzindo um excesso de volatilidade da balança comercial e correlações errôneas entre a balança comercial e os componentes da demanda agregada. Estimando um modelo RBC aumentado por choques no prêmio de risco, os autores não encontram relevância para choques permanentes na produtividade, em contraste com choques no prêmio de risco e nas preferências.

Buscando conciliar as duas vertentes teóricas dos ciclos econômicos em países emergentes, Chang e Fernández (2013) desenvolvem um modelo que engloba tanto fricções financeiras quanto choques temporários e permanentes na produtividade. Duas fricções financeiras são consideradas: working capital e prêmio de risco endógeno, como função da produtividade. Os demais ingredientes do modelo são os usualmente encontrados na literatura relevante, como preferências GHH e custo de ajustamento do capital, utilizado para reduzir a volatilidade do investimento. O modelo foi estimado com métodos Bayesianos para o México, utilizando os mesmos dados utilizados em Aguiar e Gopinath (2007). Os autores concluem favoravelmente para a fricção financeira modelada por meio de spreads endógenos à produtividade, encontrando que os choques de produtividade convencionais (temporários) são os mais relevantes para o México. Os choques na tendência da produtividade têm um papel bastante reduzido. A fricção financeira, conjugada com os choques de produtividade, tem papel fundamental na ampliação dos choques.

Conclusão semelhante foi alcançada por Fernandez (2010) para a Colômbia. Em um modelo RBC ampliado, contemplando choques temporários e permanentes na produtividade, choques na taxa de juros mundial, choques nos termos de troca e nos gastos do governo, os choques na taxa de juros e temporários na produtividade se mostraram os mais relevantes. Outra conclusão do artigo é que a restrição de working capital se torna pouco relevante quando o prêmio de risco é modelado de forma endógena à produtividade.

Fernandez e Gulan (2012) inovam ao incorporar o acelerador financeiro de Bernanke, Gertler and Gilchrist (doravante BGG) (1999) em um modelo RBC de economia aberta. O artigo investiga se o acelerador financeiro consegue explicar o caráter contracíclico do prêmio de risco e da alavancagem em países emergentes, provendo 
assim uma estrutura microfundamentada para explicar a dinâmica da taxa de juros nos países emergentes. O modelo foi estimado com base em um painel com 12 países emergentes, utilizando séries de produto (sem consumo do governo), consumo privado, investimento, balança comercial e taxa de juros doméstica, utilizando GMM, logrando reproduzir o caráter contraciclico da taxa de juros e da balança comercial nos países emergentes, e também as respectivas volatilidades.

Entretanto, o choque permanente na produtividade também se mostra relevante na dinâmica do modelo, tendo em vista que quando o modelo considera apenas choques na taxa de juros externa, passa a não replicar de forma satisfatória os momentos de interesse. Dessa forma, a interação entre prêmio de risco, alavancagem e produtividade é essencial no modelo desenvolvido. Assim, os resultados encontrados se inclinam para os de Aguiar e Gopinath (2007), com as fricções financeiras desempenhando o papel de amplificador dos choques de produtividade, em detrimento do papel dos choques na taxa de juros enfatizados pela outra vertente da literatura.

No Brasil, Kanczuk (2004) estudou o papel da taxa de juros real em um modelo $\mathrm{RBC}$ de economia fechada, com custos de ajustamento de capital e firmas sujeitas à restrição de working capital. A taxa de juros real é determinada de forma exógena no modelo pelo governo, dependendo do seu valor defasado e do hiato do produto. Os dados utilizados abrangem os anos entre 1980 e 2001.

Souza-Sobrinho (2011) utilizou um modelo RBC de economia aberta, com working capital, preferências GHH e custos de ajustamento de portfólio para explicar a dinâmica da taxa de juros nos ciclos de negócios do Brasil. O autor utilizou dados trimestrais do $4^{\mathrm{O}}$ trimestre de 1994 até o $1^{\mathrm{O}}$ trimestre de 2010 para calibrar o modelo. Três choques foram contemplados no modelo: i) choque temporário na produtividade, ii) choque na taxa de juros internacional e iii) choque no prêmio de risco doméstico, todos modelados por meio de processos $\mathrm{AR}(1)$. O modelo com apenas choques no prêmio de risco consegue explicar cerca de um terço da variação do produto, e reproduz o caráter contra-cíclico da taxa de juros e da balança comercial. Assim, choques no prêmio de risco tiveram um papel importante para explicar o ciclo de negócios do Brasil no período em questão.

Os resultados encontrados para o Brasil ecoam os encontrados para a Argentina por Neumeyer e Perri (2005), tendo em vista a importância da caracteristica de working capital no modelo e o papel do prêmio de risco. A restrição de working capital, que conforme apontado por Kanczuk (2004) atua como uma restrição de cash-in-advance do lado da produção, é essencial para gerar uma correlação negativa entre os juros reais e o produto, uma vez que com esta característica a demanda por trabalho inequivocamente cai após uma elevação na taxa de juros.Por outro lado, SouzaSobrinho (2011) enfatiza o papel de choques no prêmio de risco, resultado também encontrado por Neumeyer e Perri (2005) para a Argentina, sobretudo quando o prêmio de risco depende endogenamente da produtividade.

Silva (2008) explorou o papel relativo de choques nos termos de troca, na taxa de juros mundial, no prêmio de risco, e choques temporários e permanentes na 
produtividade para o Brasil, usando um modelo RBC e dados trimestrais de 1994 a 2007. O autor encontrou que a variância do produto no período foi explicada majoritariamente por choques temporários na produtividade, seguido por choques permanentes na produtividade (em torno de 14\%) e choques no prêmio de risco. Os choques nos termos de troca e na taxa de juros mundial não se mostraram de grande relevância. O prêmio de risco foi modelado de forma endógena aos fundamentos (i.e., como função da produtividade e dos termos de troca), com evidências favoráveis a esta especificação em comparação com uma em que o prêmio de risco é modelado de forma exógena (determinado por fatores políticos, efeito contágio, etc.).

Mais recentemente, Araújo (2012) analisou o papel de choques específicos no investimento, que atuam como choques tecnológicos no investimento, no contexto de um modelo RBC para o Brasil. Os resultados encontrados mostraram um papel importante para o componente permanente de choques específicos no investimento para o Brasil no período compreendido entre 1947 e 2007, ecoando assim os resultados de Aguiar e Gopinath (2007). Entretanto, o modelo não conseguiu reproduzir o caráter contra-cíclico da balança comercial, produzindo também um excesso de volatilidade desta variável em relação aos dados.

O objetivo deste artigo é contrapor choques específicos no investimento, explorados em Araújo (2012), e choques na taxa de juros, explorados por Kanczuk (2004) e Souza-Sobrinho (2011) para o ciclo de negócios brasileiro. Nesse sentido, o artigo estima um modelo RBC de economia aberta, com as características usualmente encontradas na literatura (working capital, preferencias GHH, prêmio de risco endógeno à dívida) por meio de métodos bayesianos. Ao todo 4 choques são considerados: i) choque temporário na tecnologia, ii) choque na taxa de juros mundial, iii) choque no prêmio de risco e iv) choque específico no investimento.

A contribuição reside no fato de que Kanczuk (2004) considerou um modelo de economia fechada e calibrado, enquanto Souza-Sobrinho (2011) considerou um modelo de economia aberta, mas calibrado. Por sua vez, Araújo (2012) considerou um modelo de economia aberta, mas sem explorar o papel de choques na taxa de juros e no prêmio de risco, ao passo que Silva (2008) não considerou o papel dos choques específicos no investimento como determinantes dos ciclos de negócios no Brasil.

Assim, seguindo a literatura mais recente, o objetivo é averiguar empiricamente o papel relativo de choques de produtividade, choques na eficiência do investimento, na taxa de juros externa e no prêmio de risco no ciclo de negócios do Brasil, dado que por um lado Souza-Sobrinho (2011) encontra que choques no prêmio de risco são fundamentais para que o modelo consiga reproduzir adequadamente os momentos selecionados, enquanto que em Kanczuk (2004) a fricção financeira do working capital tem papel essencial para que o modelo produza uma correlação negativa entre os juros reais e o produto. 


\subsection{Modelo}

O modelo é de uma pequena economia aberta, seguindo basicamente a estrutura de Uribe (2014, p. 81), com a adição de utilização variável do capital, working capital, e choques específicos no investimento.

Um número infinito de consumidores idênticos maximiza a seguinte função utilidade, onde $c_{t}$ é o consumo, $h_{t}$ são as horas trabalhadas, $\beta \epsilon(0,1)$ é o fator de desconto intertemporal e U é a função utilidade:

$$
E_{o} \sum_{t=0}^{\infty} \beta^{t} U\left(c_{t}, h_{t}\right)
$$

Restrição orçamentária do consumidor representativo:

$$
d_{t}=\left(1+r_{t-1}\right) d_{t-1}-y_{t}+c_{t}+i_{t}+\Phi\left(k_{t+1}-k_{t}\right)
$$

onde $d_{t}$ é a dívida do consumidor no fim do período t, $r_{t}$ é a taxa de juros pela qual os residentes domésticos tomam emprestado no período t, $y_{t}$ é o produto, $i_{t}$ é o investimento e, $k_{t}$ é o capital e $\Phi$ é a função dos custos de ajustamento de capital, $\operatorname{com} \Phi(0)=\Phi^{\prime}(0)=0$.

Função de produção toma os serviços de capital $\left(k_{t} u_{t}\right)$ - onde $u_{t}$ é a utilização do capital-, e o trabalho $\left(h_{t}\right)$ como argumentos:

$$
y_{t}=A_{t} F\left(k_{t} u t i_{t}, h_{t}\right)
$$

Acumulação de capital, onde $x_{t}$ é um choque especifico no investimento, podendo ser interpretado como o inverso do preço relativo do investimento em termos do bem de consumo:

$$
k_{t+1}=x_{t} i_{t}+(1-\delta(u t i)) k_{t}
$$

A depreciação depende endogenamente da utilização do capital. Com plena utilização do capital (uti=1), a depreciação é igual a 0,025 (10\% anuais).

$$
\delta(u t i)=\bar{\delta} \frac{u t i^{\eta}}{\eta}
$$


Substituindo na restrição orçamentária:

$$
d_{t}=\left(1+r_{t-1}\right) d_{t-1}-A_{t} F\left(k_{t} u t i_{t}, h_{t}\right)+c_{t}+k_{t+1}-(1-\delta(u t i)) k_{t}+\Phi\left(k_{t+1}-k_{t}\right)
$$

Lagrangeano:

$$
L=E_{o} \sum_{t=0}^{\infty} \beta^{t}\left\{U\left(c_{t}, h_{t}\right)+\lambda_{t}\left[d_{t}-\left(1+r_{t-1}\right) d_{t-1}+A_{t} F\left(k_{t} u t i_{t}, h_{t}\right)-c_{t}-\frac{k_{t+1}}{x_{t}}+(1-\delta(u t i)) \frac{k_{t}}{x_{t}}-\Phi\left(k_{t+1}-k_{t}\right)\right]\right\}(2.7)
$$

Como mencionado, o choque específico no investimento pode ser interpretado como um choque no preço relativo do capital. Assim, denotando por $q_{t}$ o preço relativo do capital, temos:

$$
q_{t}=\frac{1}{x_{t}}
$$

Substituindo no lagrangeano:

$$
L=E_{o} \sum_{t=0}^{\infty} \beta^{t}\left\{U\left(c_{t}, h_{t}\right)+\lambda_{t}\left[d_{t}-\left(1+r_{t-1}\right) d_{t-1}+y_{t}-c_{t}-q_{t} k_{t+1}+\left(1-\delta\left(u t i_{t}\right)\right) q_{t} k_{t}-\Phi\left(k_{t+1}-k_{t}\right)\right.\right.
$$

Nas derivações adiante o operador esperança foi omitido por simplificação.

Derivando em relação a $c_{t}$ :

$$
\begin{aligned}
& \frac{\partial L}{\partial c_{t}}=\beta^{t} \frac{\partial U\left(c_{t}, h_{t}\right)}{\partial c_{t}}-\beta^{t} \lambda_{t}=0 \\
& \frac{\partial U\left(c_{t}, h_{t}\right)}{\partial c_{t}}=\lambda_{t}
\end{aligned}
$$

Derivando em relação a $h_{t}$ :

$$
\beta^{t} \frac{\partial U\left(c_{t}, h_{t}\right)}{\partial h_{t}}+\beta^{t} \lambda_{t} A_{t} \frac{\partial F\left(k_{t} u t i_{t}, h_{t}\right)}{\partial h_{t}}=0
$$


Derivando em relação a $d_{t}$ :

$$
\begin{aligned}
& \frac{\partial U\left(c_{t}, h_{t}\right)}{\partial d_{t}}=\beta^{t} \lambda_{t}-E_{0} \beta^{t+1} \lambda_{t+1}\left(1+r_{t}\right)=0 \\
& \lambda_{t}=E_{0} \beta \lambda_{t+1}\left(1+r_{t}\right)
\end{aligned}
$$

Derivando em relação a $u t i_{t}$ :

$$
\begin{aligned}
& \beta^{t} \lambda_{t} k_{t} A_{t} \frac{\partial F\left(k_{t} u t i_{t}, h_{t}\right)}{\partial u t i}-\beta^{t} \lambda_{t} k_{t} \delta^{\prime}(u t i) q_{t}=0 \\
& A_{t} \frac{\partial F\left(k_{t} u t i_{t}, h_{t}\right)}{\partial u t i}=\delta^{\prime}(u t i) q_{t}
\end{aligned}
$$

Derivando em relação a $k_{t+1}$ :

$$
\begin{gathered}
\beta^{t+1} \lambda_{t+1} u t i_{t+1} A_{t+1} \frac{\partial F\left(k_{t+1}, h_{t+1}\right)}{\partial k_{t+1}}-\beta^{t} \lambda_{t} q_{t}+\beta^{t+1} \lambda_{t+1}\left(1-\delta\left(u t i_{t+1}\right)\right)-\beta^{t} \lambda_{t} \frac{\partial \Phi\left(k_{t+1}-k_{t}\right)}{\partial k_{t+1}}+\beta^{t+1} \lambda_{t+1} \frac{\partial \Phi\left(k_{t+2}-k_{t+1}\right)}{\partial k_{t+1}}=0 \\
(2.16) \\
\beta^{t+1} \lambda_{t+1}\left(u t i_{t+1} A_{t+1} \frac{\partial F\left(k_{t+1}, h_{t+1}\right)}{\partial k_{t+1}}+\left(1-\delta\left(u t i_{t+1}\right)\right)+\frac{\partial \Phi\left(k_{t+2}-k_{t+1}\right)}{\partial k_{t+1}}\right)=\beta^{t} \lambda_{t}\left(q_{t}+\frac{\partial \Phi\left(k_{t+1}-k_{t}\right)}{\partial k_{t+1}}\right) \\
\beta \lambda_{t+1}\left(u t i_{t+1} A_{t+1} \frac{\partial F\left(k_{t+1}, h_{t+1}\right)}{\partial k_{t+1}}+q_{t+1}\left(1-\delta\left(u t i_{t+1}\right)\right)+\frac{\partial \Phi\left(k_{t+2}-k_{t+1}\right)}{\partial k_{t+1}}\right)=\lambda_{t}\left(q_{t}+\frac{\partial \Phi\left(k_{t+1}-k_{t}\right)}{\partial k_{t+1}}\right)
\end{gathered}
$$

A taxa de juros real é elástica em relação ao tamanho da dívida, i.e., a taxa de juros com a qual os agentes se deparam é função crescente do nível de divida médio (cross-section) $\bar{d}_{t}$.

$$
r_{t}=r^{*}+p\left(\overline{d_{t}}\right)
$$

Onde $r^{*}$ é a taxa de juros do mundo e $p($.$) é um prêmio de risco específico do país. Os$ consumidores tomam a evolução de $d_{t}$ como exógena. Em equilíbrio, como os agentes são todos iguais, o nível médio de divida da economia é igual ao nível individual de divida, $\overline{d_{t}}=d_{t}$. No estado estacionário o prêmio é igual a zero. 
Balança comercial $\left(t b_{t}\right)$ :

$$
t b_{t} \equiv y_{t}-c_{t}-i_{t}-\Phi\left(k_{t+1}-k_{t}\right)
$$

A conta-corrente é definida como a variação do passivo externo líquido:

$$
c a_{t}=d_{t-1}-d_{t}
$$

As firmas operam em um ambiente perfeitamente competitivo, produzindo com capital e trabalho, mas estao sujeitas à restrição de working capital, precisando tomar emprestado um fração $\theta$ da folha de pagamento. Assim, o problema de maximização de lucros é dado por:

$$
\pi_{t}=A_{t} F\left(k_{t} u t i_{t}, h_{t}\right)-w_{t} h_{t}-u_{t} k_{t} u t i_{t}-\theta r_{t-1} w_{t} h_{t}
$$

Denotando $\tilde{k}_{t}=k_{t} u t i_{t}$ os serviços de capital, derivando em relação ao primeiro argumento obtemos a remuneração dos serviços de capital:

$$
u_{t}=\frac{\partial F\left(k_{t} u t i_{t}, h_{t}\right)}{\partial \tilde{k}_{t}}
$$

Derivando em relação a $h_{t}$ :

$$
w_{t}\left(1+\theta r_{t-1}\right)=\frac{\partial F\left(k_{t}, h_{t}\right)}{\partial h_{t}}
$$

Onde $r_{t-1}$ é a taxa de juros real em termos líquidos. Pela expressão acima, um aumento dos juros reais leva a uma queda da demanda de trabalho. A restrição faz com que o salário real não seja igual ao produto marginal do trabalho.

Assumindo uma função de produção Cobb-Douglas:

$$
y_{t}=A_{t}\left(k_{t} u t i_{t}\right)^{\alpha} l^{(1-\alpha)}, \alpha \epsilon(0,1)
$$

Remuneração dos serviços de capital:

$$
u_{t}=\frac{\partial F\left(k_{t} u t i_{t}, h_{t}\right)}{\partial \tilde{k}_{t}}=\alpha \frac{y_{t}}{k_{t} u t i_{t}}
$$


Remuneração do trabalho:

$$
w_{t}\left(1+\theta r_{t-1}\right)=\frac{\partial F\left(k_{t}, h_{t}\right)}{\partial h_{t}}=(1-\alpha) \frac{y_{t}}{h_{t}}
$$

Por conta das expressões, 15 e 18, também é útil encontrar as derivadas da função de produção em relação a $u t i_{t}$ e $k_{t}$ :

$$
\frac{\partial F\left(k_{t}, h_{t}\right)}{\partial u t i_{t}}=\alpha A_{t}\left(k_{t} u t i_{t}\right)^{\alpha-1} l_{t}^{1-\alpha} k_{t}=\alpha \frac{y_{t}}{u t i_{t}}
$$

Assim, pela expressão 15:

$$
\begin{aligned}
& \alpha \frac{y_{t}}{u t i_{t}}=q_{t} k_{t} \bar{\delta} u t i_{t}^{\eta-1} \\
& \frac{\partial F\left(k_{t}, h_{t}\right)}{\partial k_{t}}=\alpha A_{t}\left(k_{t} u t i_{t}\right)^{\alpha-1} l_{t}^{1-\alpha} u t i=\alpha \frac{y_{t}}{k_{t}}
\end{aligned}
$$

Para a função utilidade assumimos a forma GHH, que é bastante frequente nos estudos de ciclos econômicos nos países emergentes ${ }^{1}$ :

$$
\begin{aligned}
& U(c, h)=\frac{G(c, h)^{1-\sigma}-1}{1-\sigma}, \sigma>0 \\
& G(c, h)=c-\frac{h^{\omega}}{\omega}, \omega>1
\end{aligned}
$$

Derivando em relação a c:

$$
\frac{\partial U(c, h)}{\partial c}=G(c, h)^{-\sigma} \frac{\partial G(c, h)}{\partial c}=\left[c-\frac{h^{\omega}}{\omega}\right]^{-\sigma}
$$

\footnotetext{
${ }^{1}$ Correia, Neves e Rebelo (1995) encontram que a utilidade GHH é essencial para gerar um caráter contra-cíclico da balança comercial e para que o modelo RBC consiga reproduzir a volatilidade relativa do consumo nos ciclos de negócios de Portugal.
} 
Derivando em relação a h:

$$
\frac{\partial U(c, h)}{\partial h}=G(c, h)^{-\sigma} \frac{\partial G(c, h)}{\partial h}=-h^{\omega-1}\left[c-\frac{h^{\omega}}{\omega}\right]^{-\sigma}
$$

Combinando as duas expressões acima na condição de 1a ordem para h temos:

$$
w_{t}=h_{t}^{\omega-1}
$$

Nesta especificação a oferta de trabalho depede apenas do salário real, o que decorre da função de utilidade GHH considerada. Por outro lado, a demanda de trabalho passa a depender da taxa de juros. Aumentos na taxa de juros reduzem a demanda por trabalho para um determinado salário real (Neumeyer e Perri, 2005, p.2).

A elasticidade da oferta de trabalho em relação ao salário real é igual a $\frac{1}{\omega-1}$.

O custo de ajustamento do capital é dado por uma função quadrática:

$$
\Phi(x)=\frac{\phi x^{2}}{2}, \phi>0
$$

De forma que a condição de 1a ordem em relação ao capital fica:

$\beta \lambda_{t+1}\left(u t i_{t+1} A_{t+1} \frac{\partial F\left(k_{t+1}, h_{t+1}\right)}{\partial k_{t+1}}+q_{t+1}\left(1-\delta\left(u t i_{t+1}\right)\right)+\phi\left(k_{t+2}-k_{t+1}\right)\right)=\lambda_{t}\left(q_{t}+\phi\left(k_{t+1}-k_{t}\right)\right)$

O prêmio de risco é uma função crescente do passivo externo líquido:

$$
\begin{aligned}
& p\left(d_{t}\right)=\psi(\exp (d-\bar{d})-1)+\exp \left(\text { prêmio }_{t}\right)-1 \\
& \psi>0
\end{aligned}
$$

Os choques do modelo seguem um $\mathrm{AR}(1)$.

Choque tecnológico:

$$
\ln A_{t}=\rho_{A} \ln A_{t-1}+\varepsilon_{A t}
$$


Choque no prêmio de risco:

$\ln$

$$
\ln \left(\text { prêmio }_{t}\right)=\rho_{p} \ln \left(\text { prêmio } o_{t-1}\right)+\varepsilon_{p t}
$$

Choque na taxa de juros mundial:

$$
r_{t}^{*}=\rho_{r^{*}} r_{t-1}^{*}+\varepsilon_{r_{t}^{*}}
$$

Choque específico no investimento:

$$
x_{t}=\rho_{x} x_{t-1}+\varepsilon_{x t}
$$

Segundo Greenwood et al. (88), choques específicos no investimento podem ser interpretados como mudanças tecnológicas que afetam o capital no período subsequente $(t+1)$, ou seja, na eficiência marginal do capital. Greenwood et al. (2000) encontram que choques tecnológicos no setor de investimento da economia americana são responsáveis por cerca de $30 \%$ da variação do PNB, apesar do setor responder por apenas 7\% do PNB dos EUA, sugerindo um importante papel para este tipo de choque no ciclo de negócios americano. Justiniano et al. (2010) encontram uma grande importância para choques específicos no investimento para o ciclo de negócios americano, mas o resultado em larga medida depende da presença de rigidez nominal no modelo. Por sua vez, Fisher (2006) também encontra um grande importância para choques específicos no investimento - interpretados como choques no preço relativo do investimento - no produto e nas horas trabalhadas nos EUA.

\subsubsection{Estado Estacionário}

Pela equação de Euler, de número 13, no estado estacionário $\lambda_{t}=\lambda_{t+1}$, logo:

$$
\beta=\frac{1}{1+r}
$$

Da condição de 1a ordem em relação ao capital (equação 36) e da derivada da função de produção em relação ao capital, no estacionário o custo de ajustamento do capital é zero, $\phi=0$. Adicionalmente, $q=1$, uti $=1, A=1 \mathrm{e} \lambda_{t}=\lambda_{t+1}$. Assim:

$$
\beta\left(\alpha k^{\alpha-1} l^{1-\alpha}+(1-\bar{\delta})\right)=1
$$


Rearranjando:

$$
\frac{1}{\beta}-(1-\bar{\delta})=\alpha k^{\alpha-1} l^{1-\alpha}
$$

Relação capital-trabalho de estado estacionário:

$$
\begin{aligned}
& \left(\frac{k}{l}\right)^{\alpha-1}=\frac{\frac{1}{\beta}-(1-\bar{\delta})}{\alpha} \\
& \left(\frac{k}{l}\right)^{s s}=\left(\frac{\frac{1}{\beta}-(1-\bar{\delta})}{\alpha}\right)^{1-\alpha}
\end{aligned}
$$

Remuneração do trabalho no estado estacionário:

$$
\begin{aligned}
& w(1+\theta r)=(1-\alpha)\left(\frac{k}{l}\right)^{\alpha} \\
& w^{s s}=\frac{(1-\alpha)\left(\frac{k}{l}\right)^{\alpha}}{(1+\theta r)}
\end{aligned}
$$

Remuneração do capital:

$$
u^{s s}=\alpha\left(\frac{k}{l}\right)^{\alpha-1}
$$

Da equação 28, segue que no estado estacionário, com $u t i=1$ :

$$
\alpha \frac{y_{t}}{k_{t} u t i_{t}}=\bar{\delta}
$$

De forma que a depreciação é igual ao produto marginal dos serviços de capital.

As demais relações de estado estacionário podem ser derivadas a partir das apresentadas acima. A partir do salário de estado estacionário é possivel derivar as horas trabalhadas -pela equação de oferta de trabalho dos agentes-, e, por consequência, o capital de estado estacionário. 


\subsection{Calibração}

Alguns parâmetros foram calibrados, por serem mais consensuais na literatura e/ou de difícil estimação. A escolha dos valores foi guiada basicamente pelos estudos prévios para o Brasil, em especial Souza-Sobrinho (2011) e Silva (2008).

- Inverso da elasticidade de substituição intertemporal $(\sigma)$ : foi utilizado um valor de 2. Este valor também foi utilizado em Silva (2008) e Souza-Sobrinho (2011) para o Brasil. Também foi utilizado por Garcia-Circco (2010), Aguiar e Gopinath (2007), Uribe e Yue (2006) e Fernández (2010);

- Parâmetro relacionado à elasticidade da oferta de trabalho em relação ao salário real $(\omega)$ : foi calibrado em 1,5, valor bem próximo ao utilizado na literatura. Silva (2008) utilizou 1,6 para o Brasil, Souza-Sobrinho (2011) utilizou 1,5. García-Cicco (2010) e Fernández (2010) utilizaram 1,6; Uribe e Yue (2006) 1,45

- Depreciação trimestral $(\delta)$ : foi calibrada em 2,5\%;

- Participação do capital no produto $(\alpha)$ : foi calibrada em 0,4;

- Dívida em estado estacionário foi calibrada em 0,65, valor utilizado em SouzaSobrinho (2011) ;

- Fator de desconto intertemporal foi calibrado em 0,98, correspondente a uma taxa de juros real trimestral de 1,5\%. O valor do fator de desconto utilizado foi um pouco superior aos estudos obtidos para o Brasil, no sentido de que o valor geralmente utilizado corresponde a uma taxa de juros real anualizada de $8 \%$;

Tabela 2.1: $\quad$ Parâmetros calibrados

\begin{tabular}{|c|c|c|}
\hline Parâmetro & Descrição & Valor \\
\hline \hline$\sigma$ & Inverso da elasticidade de substituição intertemporal & 2 \\
\hline$\varpi$ & Elasticidade da oferta de trabalho em relação ao salário real & 1,5 \\
\hline$\alpha$ & Participação do capital no produto & 0,4 \\
\hline$\beta$ & Fator de desconto intertemporal & 0,98 \\
\hline$\gamma$ & Depreciação & $2,5 \%$ \\
\hline $\bar{d}$ & Dívida em estado estacionário & 0,65 \\
\hline
\end{tabular}

\subsection{Dados}

Nas estimações, utilizou-se produto e investimento em diferenças logarítmicas. A série de prêmio de risco correspondeu ao EMBI+ Brasil, seguindo a literatura (Neumeyer e Frabizio (2005) e Uribe e Yun(2006)), HP-filtrado e posteriormente trimes- 
tralizado (dividido por 400) para a estimação. Os dados vão do 3o trimestre de 1997 até o 1o trimestre de 2014, compreendendo assim 67 observações.

Ao contrário de Neumeyer e Fabrizio (2005), para a taxa de juros real americana utilizou-se a série dos títulos indexados à inflação americanos ("TIPS"), para 5 anos. Este procedimento está em linha com o efetuado por Foley-Fisher e Guimarães (2013). Como exercício de robustez, utilizou-se também os juros reais para o prazo de 10 anos, mas os parâmetros estimados pouco se alteraram, conforme mostrado abaixo.

Figura 2.1: Séries originais
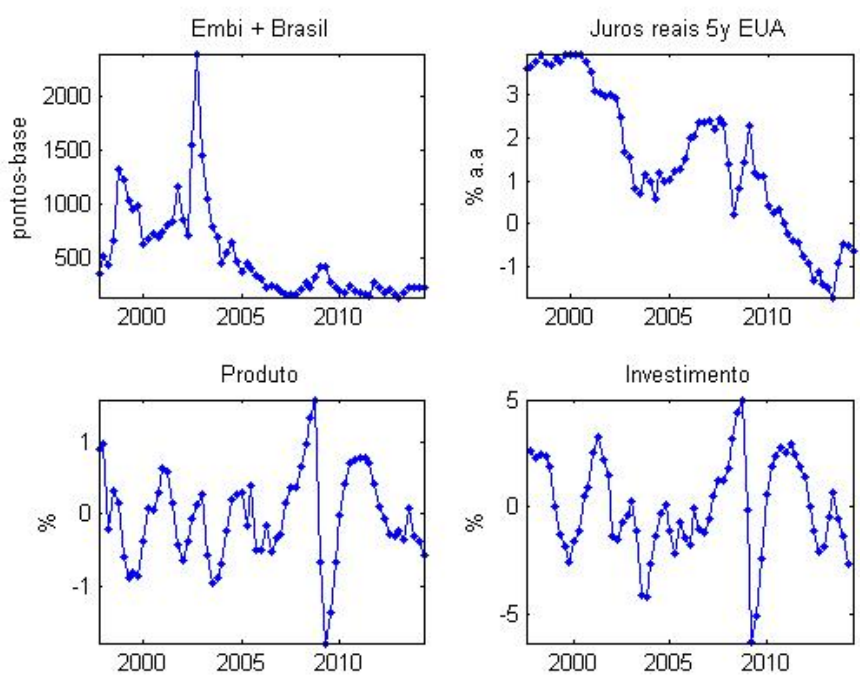

\subsection{Resultados}

O modelo foi estimado com 2 cadeias de 200.000 interações do algoritmo MCMC (Monte Carlo Markov Chain), resultando em uma taxa de aceitação de 39,06\% na primeira e 39,42\% na segunda. A média da posterior dos parâmetros estimados se encontra na tabela 2 abaixo, para o modelo base.

Quando o modelo foi estimado sem o choque específico no investimento, utilizou-se apenas 3 séries (produto, juros mundiais e prêmio de risco). O motivo pelo qual isto foi feito é que, com um choque a menos, devemos retirar uma série para a estimação, para evitar o problema conhecido como singularidade estocástica, que ocorre quando o número de choques é inferior ao número de séries utilizadas.

A última coluna da tabela 2 apresenta os resultados obtidos quando o modelo foi estimado considerando a taxa de juros real de 10 anos dos títulos americanos, ao invés da taxa de 5 anos utilizada nas demais estimações. Os resultados permanecem praticamente inalterados neste caso. 
Figura 2.2: $\quad$ Séries transformadas
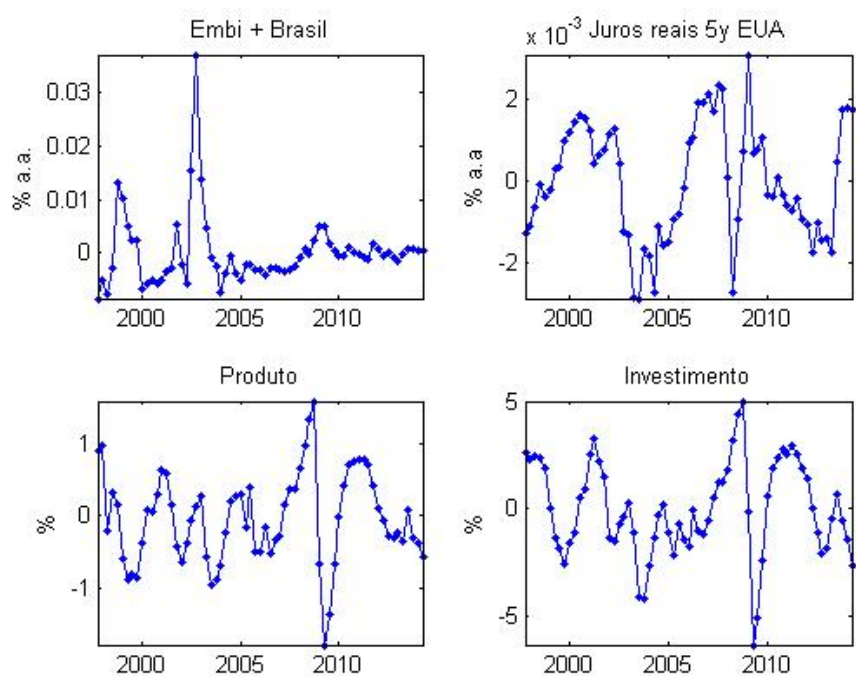

Em relação ao parâmetro associado à restrição de working capital, o valor estimado $(0,11)$ foi bem menor do que o obtido por Silva $(2008)$ para o Brasil, em que a média da posterior foi de 0,82. Entretanto, o valor estimado ficou próximo dos utilizados nos trabalhos de Kanczuk (2004) (0,11) e Souza-Sobrinho (2011) (0,2). A dispersão deste parâmetro é grande nos países emergentes. Chang e Fernández encontram um valor de 0,69 para o México, enquanto Fernández (2010) encontra um valor de 0,04 para a Colômbia. Entretanto, o critério de identificação, apresentado no final da seção, mostra que este parâmetro é de difícil identificação.

Seguindo Justiniano et al. (2010), utilizamos a verossimilhança marginal para avaliar o ajuste do modelo nas diferentes especificações utilizadas. Seguindo este procedimento, os resultados da tabela 2 indicam que a melhor especificação é a que não considera choques na eficiência marginal do investimento e nem utilização variável do capital. A verossimilhança marginal obtida segundo esta especificação -434-, é bastante superior à obtida nos demais modelos, mostrando um melhor ajuste do modelo quando choques específicos no investimento não são contemplados.

As funções de impulso resposta de choques no prêmio de risco e nos juros reais, apresentadas nas figuras 3 e 4, mostram um padrão qualitativo semelhante, no sentido de que o produto recua acentuadamente após a incidência do choque, o mesmo acontecendo com o consumo e o investimento. A balança comercial responde de forma contraciclica, melhorando após o choque. Assim como em Uribe e Yue (2006) e Foley-Fisher e Guimarães (2013), após a incidência do choque na taxa de juros mundial o prêmio de risco declina, indicando a correlação negativa entre juros mundias e prêmio de risco relatada na literatura.

Apesar de apresentarem um padrão qualitativo parecido, a magnitude da resposta a um choque no prêmio de risco é maior, o que pode ser atribuído ao maior desvio- 
padrão estimado para o prêmio de risco em comparação com os juros mundiais. Nesse sentido, o gráfico das priors e das posteriores estimadas mostra que a distribuição posterior do desvio-padrão do choque no prêmio de risco se situa dentro da prior considerada, enquanto para os juros mundiais a posterior se encontra à esquerda da prior.

A resposta da economia a um choque tecnológico, apresentada na figura 2, mostra que o produto, o consumo e o investimento aumentam após a incidência do choque. A divida diminui, levando a uma diminuição endógena do prêmio de risco e dos juros domésticos. Por sua vez, após a incidência de um choque na eficiência marginal do investimento, apresentado na figura 5, o produto, o consumo, o investimento e as horas se elevam, com a balança comercial respondento de forma contra-cíclica. A dívida então aumenta, levando a um aumento endógeno do prêmio de risco e dos juros.

Em relação aos parâmetros estimados, o procedimento de Ratto (2011) indicou que todos os parâmetros foram identificados nas estimações. O parâmetro relacionado à restrição de working capital (teta), de dificil identificação, foi estimado em torno de 0,11 , valor próximo à prior considerada, com os dados aparentemente não incorporando muitas informações na estimação, tendo em vista a proximidade da prior e da posterior na figura 7 .

Por outro lado, tanto o parâmetro associado ao custo de ajustamento de capital $(\phi)$, quanto o parâmetro da elasticidade do prêmio de risco em relação à dívida $(\psi)$ foram estimados em valores inferiores à prior considerada para cada parâmetro. Estes resultados podem ser considerados surpreendentes, pois indicam uma menor sensibilidade do prêmio de risco em relação à dívida do que a aventada na prior. Adicionalmente, o baixo valor estimado para o ajustamento do capital implica um uma maior volatilidade do investimento. 
Figura 2.3: $\quad$ IRF choque de produtividade

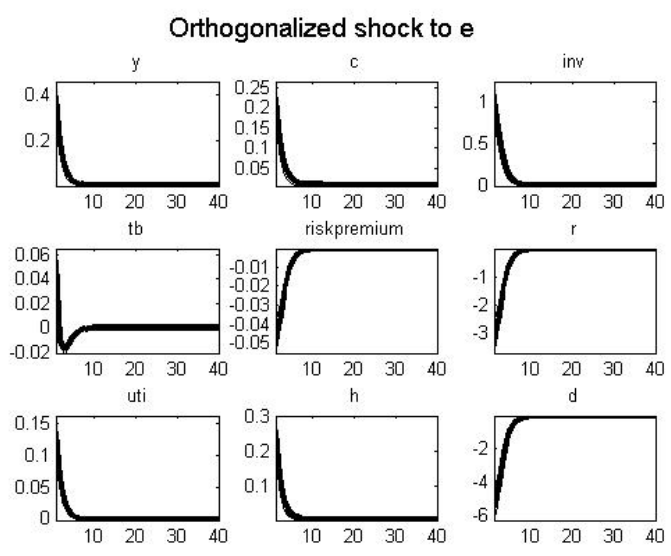

1a linha; produto, consumo e investimento, em desvios do estado estacionário 2a linha: balança comercial, prêmio de risco e taxa de juros

3a linha: utilização do capital, trabalho e dívida

Na especificação que inclui os 4 choques, o do investimento explica quase $90 \%$ da variabilidade do produto, valor superior ao encontrado para os EUA por Greenwood et al. (2000). O consumo e o investimento também são bastante afetados pelo choque especifico no investimento, uma vez cerca de $90 \%$ da variância dessas variáveis é explicada por este choque.

O choque no prêmio de risco tem papel relevante para explicar a balança comercial, com cerca de $75 \%$, e também os juros reais, respondendo por aproximadamente $41 \%$ da sua variação. O prêmio de risco é em larga medida explicado pelos choques tecnológicos, em torno de $56 \%$, e também pelos choques no próprio prêmio de risco, que contribuem com cerca de 40\%, conforme apresentado na tabela 3. Assim, os resultados apontam para a endogeneidade do prêmio de risco à produtividade dos fatores.

Por sua vez, o choque na taxa de juros real mundial tem baixa relevância para explicar o comportamento das variáveis.

Um passo natural é analisar como a decomposição da variância se alterna quando o choque específico no investimento não é considerado. Os resultados da tabela 2 mostram que, na ausência do choque especifico no investimento, a persistência do choque tecnológico aumenta, passando de 0,45 para 0,78, assim como o seu desviopadrão.

A tabela 4 apresenta as decomposições da variância do produto, da balança comercial e do prêmio de risco na média da posterior de cada modelo considerado. O choque tecnológico passa a explicar praticamente toda a variação do produto nesse caso. Por sua vez, o choque no prêmio de risco continua sendo de grande relevância para explicar a balança comercial. Por fim, em todas as especificações o prêmio de risco é 
Figura 2.4: $\quad$ IRF - choque no prêmio de risco
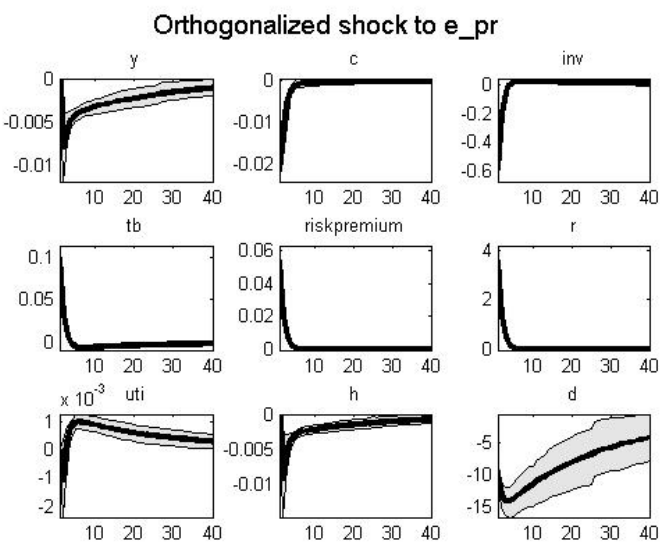

1a linha; produto, consumo e investimento, em desvios do estado estacionário 2a linha: balança comercial, prêmio de risco e taxa de juros

3a linha: utilização do capital, trabalho e dívida

explicado em boa medida pelos choques tecnológicos, com o percentual da variãncia explicada por estes choques oscilando entre 50 e $70 \%$.

\subsection{Conclusão}

O objetivo deste capítulo foi contrapor as diferentes vertentes sobre os determinantes do ciclo de negócios em países emergentes, com foco no caso brasileiro. Nesse sentido, estimou-se um modelo RBC de economia aberta, contemplando os principais componentes usualmente encontrados na literatura pertinente, e com 4 tipos de choques. No modelo base, que contempla todos os choques, os resultados apontam para um papel bastante significativo de choques no investimento para explicar as variáveis macroeconômicas consideradas. Os resultados são condizentes com os obtidos por Araújo (2012).

Entretanto, utilizando o critério da verossimilhança marginal, mostrou-se que um modelo mais parcimonioso, sem choques no investimento, produz um melhor ajuste dos dados. Na ausência de choques no investimento, o choque tecnológico explica praticamente a totalidade da variância do produto. Curiosamente, choques na taxa de juros real americana não se mostraram de grande relevância para explicar o ciclo de negócios brasileiro, resultado condizente com o obtido por Silva (2008).

Apesar de serem importantes para explicar o comportamento da balança comercial em todas as especificações contempladas, os choques no prêmio de risco não se mostraram relevantes para explicar a dinâmica do produto. No modelo sem choques específicos no investimento e sem utilização variável do capital, a decomposição da variância na média da posterior atribui $61 \%$ da variância do prêmio de risco 
Figura 2.5: $\quad$ IRF - choque nos juros mundiais
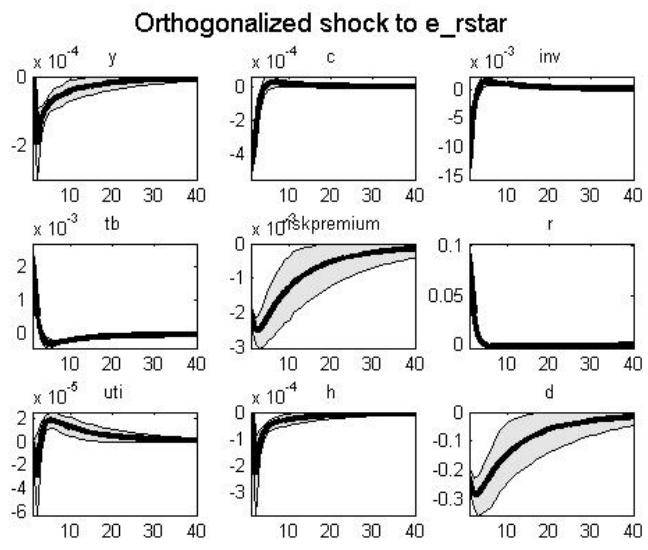

1a linha; produto, consumo e investimento, em desvios do estado estacionário 2a linha: balança comercial, prêmio de risco e taxa de juros

3a linha: utilização do capital, trabalho e divida

aos choques tecnológicos, $24 \%$ aos choques no próprio prêmio de risco e $13 \%$ aos choques nos juros reais americanos. Adicionalmente, a tecnologia tem correlação negativa e elevada com o prêmio de risco, -0.8. Desta forma, encontramos evidências de endogeneidade do prêmio de risco, em linha com Silva (2008), e boa parte da literatura para outros países.

A decomposição da variância do modelo sem choques no investimento favorece a interpretação de que o prêmio de risco é endógeno, uma vez que os choques tecnológicos explicam parte significante do prêmio de risco. Em função disso, concluímos que, em linha com a literatura recente sobre ciclos de negócios em países emergentes, o componente financeiro (ou fricção financeira, em um abuso de linguagem) atua ampliando o efeito de choques de produtividade na economia brasileira, condizente com Fernández (2010), Silva (2008), Chang e Fernández (2013) e Neumeyer e Perri (2005), trabalhos que consideram o prêmio de risco como função da produtividade. 
Figura 2.6: $\quad$ IRF- choque específico no investimento

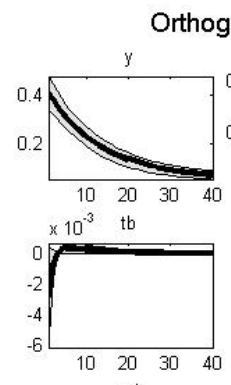

Orthogonalized shock to e_xinv
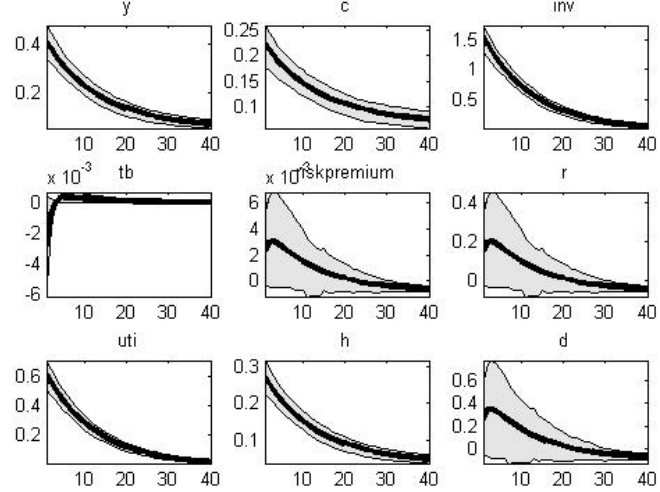

$\mathrm{h}$
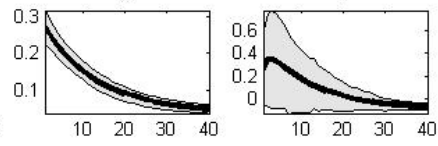

1a linha; produto, consumo e investimento, em desvios do estado estacionário 2a linha: balança comercial, prêmio de risco e taxa de juros

3a linha: utilização do capital, trabalho e dívida

Figura 2.7: $\quad$ Priors e posteriores - 1
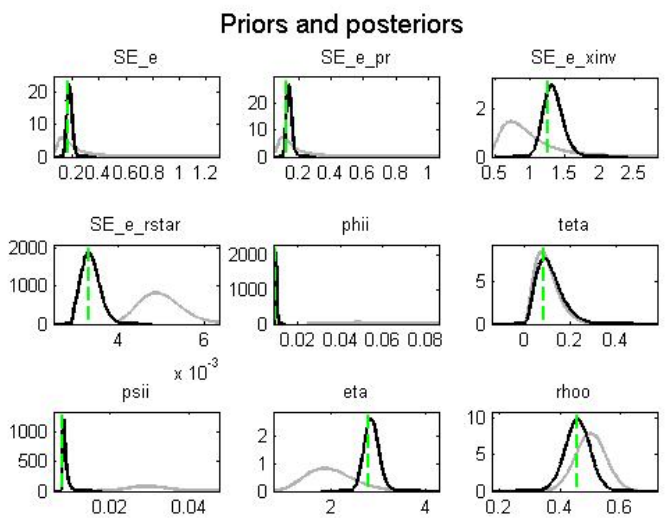
Tabela 2.2: $\quad$ Parâmetros estimados- média da posterior

\begin{tabular}{|c|c|c|c|c|c|c|}
\hline Parâmetro & Descrição & Prior & $\begin{array}{c}\text { Modelo } \\
\text { Base }\end{array}$ & $\begin{array}{c}\text { Sem } \\
\text { choque } \\
\text { xinv }\end{array}$ & $\begin{array}{l}\text { Sem xinv e } \\
\text { utilização }\end{array}$ & $\begin{array}{c}\text { Base } \\
\text {-Juros } \\
\text { mundiais } \\
10 \text { anos }\end{array}$ \\
\hline phii & $\begin{array}{c}\text { Custo de } \\
\text { ajustamento } \\
\text { do capital }\end{array}$ & 0.050 & 0.0098 & 0.0099 & 0.0096 & 0.0098 \\
\hline teta & $\begin{array}{c}\text { Restrição de } \\
\text { working } \\
\text { capital }\end{array}$ & 0.100 & 0.1112 & 0.1287 & 0.1078 & 0.1127 \\
\hline psii & $\begin{array}{l}\text { Elasticidade do } \\
\text { prêmio de risco } \\
\text { em relação à } \\
\text { dívida }\end{array}$ & 0.030 & 0.0087 & 0.0155 & 0.0322 & 0.0088 \\
\hline eta & $\begin{array}{l}\text { Elasticidade da } \\
\text { depreciação em } \\
\text { relação à } \\
\text { utilização }\end{array}$ & 2.000 & 2.8531 & 2.1246 & 1 & 2.8572 \\
\hline rhoo & $\begin{array}{c}\text { Persistência do } \\
\text { choque } \\
\text { tecnológico }\end{array}$ & 0.500 & 0.4564 & 0.7855 & 0.7871 & 0.4556 \\
\hline rho_pr & $\begin{array}{l}\text { Persistência do } \\
\text { choque no } \\
\text { prêmio de risco }\end{array}$ & 0.900 & 0.9620 & 0.9366 & 0.9251 & 0.9616 \\
\hline rho_xinv & $\begin{array}{l}\text { Persistência no } \\
\text { choque no } \\
\text { investimento }\end{array}$ & 0.900 & 0.9209 & - & & 0.9210 \\
\hline rho_rstar & $\begin{array}{l}\text { Persistência do } \\
\text { choque nos } \\
\text { juros mundiais }\end{array}$ & 0.900 & 0.8851 & 0.8845 & 0.8853 & 0.8871 \\
\hline $\mathrm{e}$ & $\begin{array}{c}\text { Desvio-padrão } \\
\text { do choque } \\
\text { tecnológico }\end{array}$ & 0.250 & 0.1810 & 0.2227 & 0.2772 & 0.1806 \\
\hline e_pr & $\begin{array}{c}\text { Desvio-padrão } \\
\text { do choque no } \\
\text { prêmio }\end{array}$ & 0.200 & 0.1398 & 0.1293 & 0.0454 & 0.1410 \\
\hline e_xinv & $\begin{array}{c}\text { Desvio-padrão } \\
\text { do choque no } \\
\text { investimento }\end{array}$ & 1.000 & 1.3369 & - & - & 1.3310 \\
\hline e_rstar & $\begin{array}{l}\text { Desvio-padrao } \\
\text { no choque nos } \\
\text { juros mundiais }\end{array}$ & 0.005 & 0.0034 & 0.0034 & 0.0034 & 0.0033 \\
\hline $\begin{array}{c}\text { Verossimilhas } \\
\text { marginal }\end{array}$ & ça & & 218.87 & 321.55 & 434.70 & 219.87 \\
\hline $\begin{array}{c}\text { Aceitação } \\
1:\end{array}$ & & & $39.06 \%$ & $37.57 \%$ & $31.63 \%$ & 33.10\% \\
\hline $\begin{array}{c}\text { Aceitação } \\
2:\end{array}$ & & & $39.42 \%$ & $38.00 \%$ & $31.66 \%$ & $37.15 \%$ \\
\hline
\end{tabular}


Figura 2.8: $\quad$ Priors e posteriores - 2

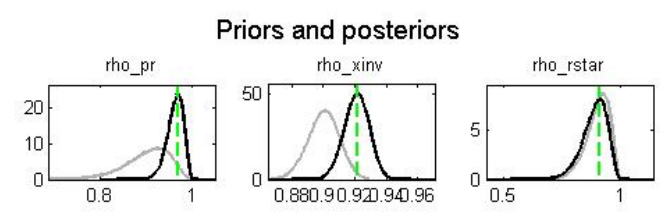

Tabela 2.3: $\quad$ Decomposição da variância-Modelo Base

\begin{tabular}{|c|c|c|c|c|}
\hline & Choque Tecnológico & Choque no risco & Choque no investimento & Choque nos juros mundiais \\
\hline \hline Produto & 9.91 & 0.02 & 90.07 & 0.00 \\
\hline Consumo & 6.51 & 0.05 & 93.44 & 0.00 \\
\hline Investimento & 9.35 & 2.23 & 88.41 & 0.00 \\
\hline Balança & 24.46 & 75.37 & 0.12 & 0.05 \\
\hline riskpremium & 56.17 & 40.53 & 2.56 & 0.74 \\
\hline Juros reais & 56.57 & 40.82 & 2.58 & 0.03 \\
\hline Utilização & 1.04 & 0.00 & 98.96 & 0.00 \\
\hline Trabalho & 10.02 & 0.02 & 89.96 & 0.00 \\
\hline Dívida & 1.59 & 98.32 & 0.07 & 0.02 \\
\hline
\end{tabular}


Tabela 2.4: $\quad$ Decomposição da variância do produto, balança comercial e prêmio de risco para diferentes especificações

\begin{tabular}{|c|c|c|c|c|}
\hline \multirow{2}{*}{ Especificação } & \multicolumn{5}{|c|}{ Choque } \\
\cline { 2 - 5 } & Tecnologia & Prêmio de risco & Investimento & Juros mundiais \\
\hline \hline \multirow{2}{*}{ Base } & \multicolumn{4}{|c|}{ Produto } \\
\hline Sem xinv e com utilização & 99.99 & 0.02 & 90.07 & 0.00 \\
\hline Sem xinv e utilização & 100.00 & 0.01 & - & 0.00 \\
\hline Base & & \multicolumn{5}{|c|}{ Balança comercial } & 0.00 \\
\hline Sem xinv e com utilização & 9.39 & 75.37 & 0.12 & 0.05 \\
\hline Sem xinv e utilização & 1.52 & 97.93 & - & 0.08 \\
\hline & & \multicolumn{2}{|c|}{ Prêmio de risco } & 0.55 \\
\hline Base & 56.17 & 40.53 & 2.56 & 0.74 \\
\hline Sem xinv e com utilização & 68.41 & 30.32 & - & 1.28 \\
\hline Sem xinv e utilização & 61.61 & 24.67 & - & 13.72 \\
\hline
\end{tabular}





\section{Referências Bibliográficas}

[1] Aguiar, Mark \& Gopinath, Gita 2007. "Emerging Market Business Cycles: The Cycle Is the Trend," Journal of Political Economy, University of Chicago Press, vol. 115, pages 69-102.

[2] Araújo, E. (2012), 'Investment-specific shocks and real business cycles in emerging economies: Evidence from brazil', Economic Modelling 29(3), 671-678.

[3] Chang, Roberto \& Andrés Fernández, 2013. "On The Sources Of Aggregate Fluctuations In Emerging Economies," International Economic Review, vol. 54, pages 1265-1293, November.

[4] Correia, Isabel H., Joao C. Neves and Sergio Rebelo. 1995. Business Cycles in a Small Open Economy. European Economic Review. 39(6): 1089-1113.

[5] Fernández, Andrés. 2010. ""Tropical” Real Business Cycles? A Bayesian Exploration." Ensayos sobre Política Económica, 28(61): 60-105.

[6] Fernández, Andrés \& Gulan, Adam, 2012. "Interest rates and business cycles in emerging economies: The role of financial frictions," Research Discussion Papers 23/2012, Bank of Finland.

[7] Fisher, Jonas D.M., 2006. The dynamic effects of neutral and specific technology shocks. Journal of Political Economy Vol. 114 (N. 3), 413-451 (June).

[8] Foley-Fisher, N. ; Guimarães, Bernardo . U.S. Real Interest Rates and Default Risk in Emerging Economies. Journal of Money, Credit and Banking, v. 45, p. 967-975, 2013.

[9] Garcíla-Cicco, Javier, Roberto Pancrazi, and Mart’ın Uribe. 2010. "Real Business Cycles in Emerging Countries?" American Economic Review, 100(5): $2510-31$.

[10] Greenwood, Jeremy, Hercowitz, Zvi, Huffman, Gregory W., 1988. Investment, capacity utilization, and the real business cycle. The American Economic Review Vol. 78 (N. 3), 402-417 (June).

[11] Greenwood, Jeremy, Hercowitz, Zvi, Krusell, Per, 2000. The role of investmentspecific technological change in the business cycle. European Economic Review Vol. 44 (N. 1), 91-115 (January).

[12] Justiniano, Alejandro, Primiceri, Giorgio, Tambalotti, Andrea, 2010. Investment shocks and business cycles. Journal of Monetary Economics Vol. 57 (N. 2), 132-145 (March). 
[13] Kanczuk, F. . Real Interest Rates and Brazilian Business Cycle. Review of Economics Dynamics, v. 7, p. 436-455, 2004.

[14] Neumeyer, Pablo A. \& Perri, Fabrizio, 2005. "Business cycles in emerging economies: the role of interet rates," Journal of Monetary Economics, Elsevier, vol. 52(2), pages 345-380, March.

[15] Ratto, Marco. (2011) Identification Analysis of DSGE models with Dynare. Disponível em: https://www.ifkcfs.de/fileadmin/downloads/events/conferences/monfispol2011/RATTO_IdentifFinal.pdfAce em 18 de julho de 2014 .

[16] Silva, Marcelo E. A. (2008) Accounting for Business Cycles in Emerging Market Economies. Manuscrito. Disponível em: http://www.unc.edu/ measilva/Paper_Marcelo_Silva_web.pdfAcesso em 4 de julho de 2014 .

[17] Souza-Sobrinho, Nelson F. 2011. "The Role of Interest Rates in the Brazilian Business Cycles," Revista Brasileira de Economia, FGV/EPGE Escola Brasileira de Economia e Finanças, Getulio Vargas Foundation (Brazil), vol. 65(3), pages 315-336, September.

[18] Uribe, Martin. (2014) Open Economy Macroeconomics. Disponível em: http://www.columbia.edu/ mu2166/book/

\subsection{Apêndice}

Apresentamos a decomposição histórica das principais variáveis do modelo, obtida a partir da especificação que considera os 4 tipos de choques.

Figura 2.9: $\quad$ Produto

Shock decomposition: $y$

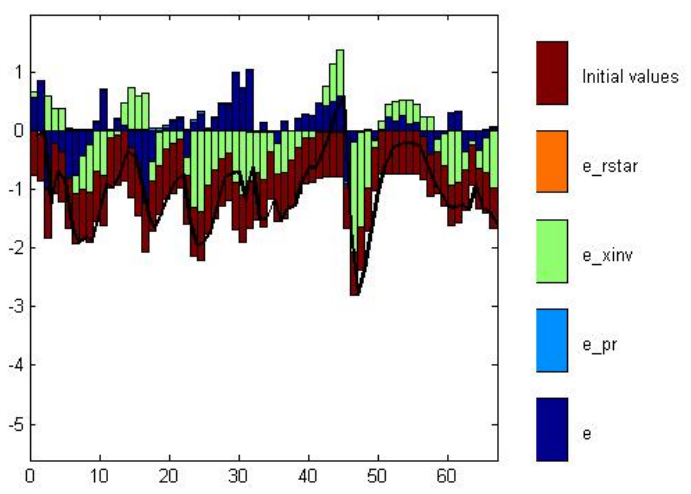


Figura 2.10: Consumo

Shock decomposition: c

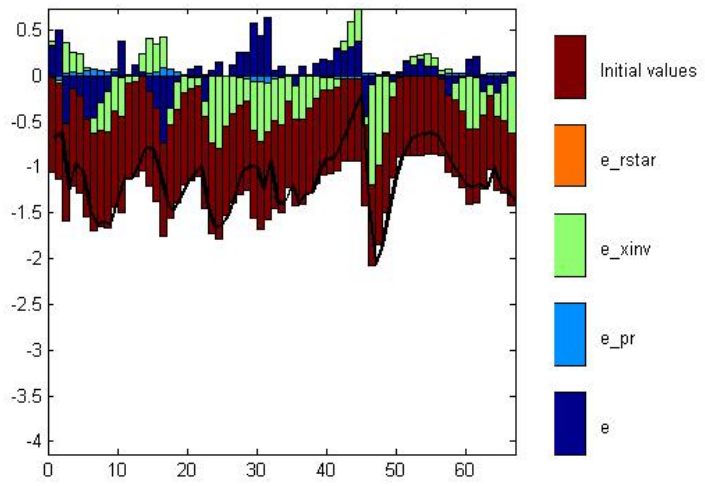

Figura 2.11: $\quad$ Investimento Shock decomposition: inv

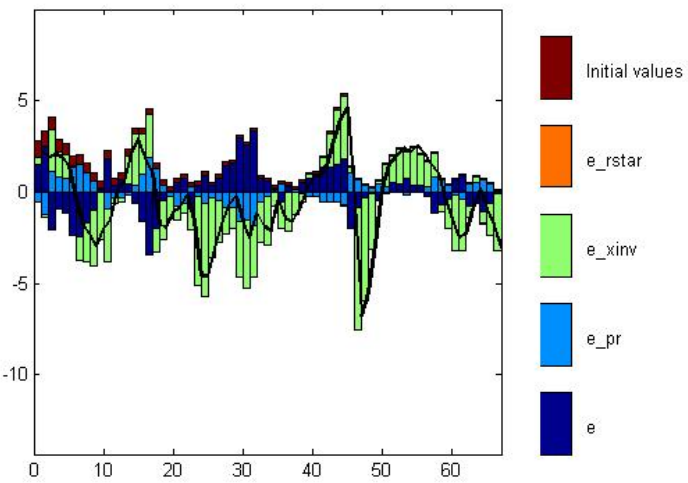

Figura 2.12: $\quad$ Balança comercial Shock decomposition: tb

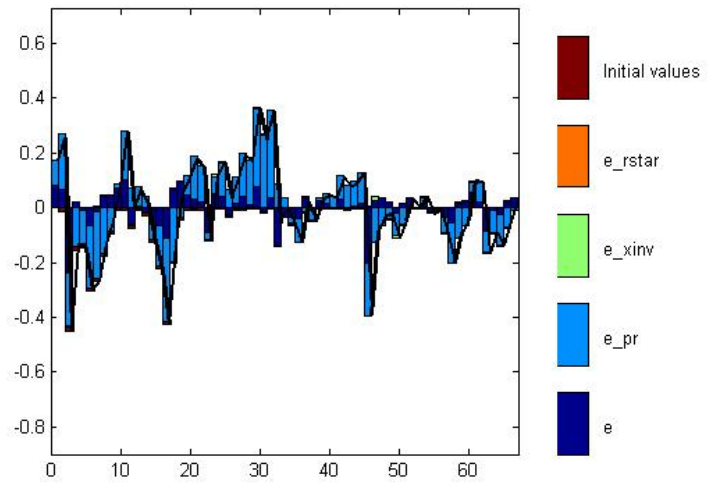


Figura 2.13: $\quad$ Prêmio de risco

Shock decomposition: riskpremium

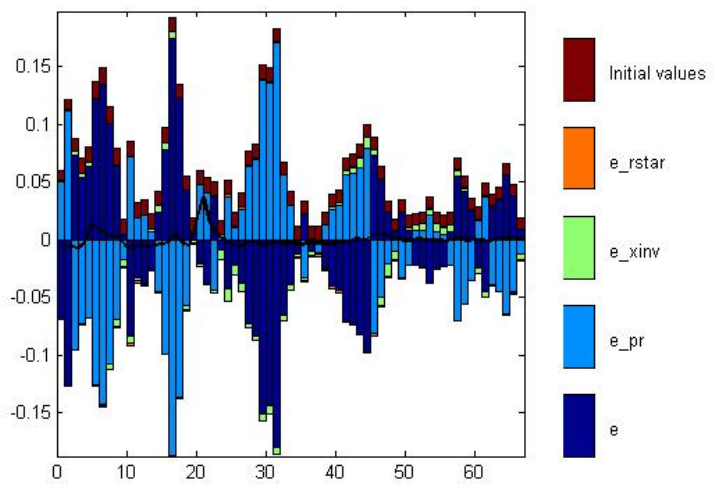

Figura 2.14: Converência multivariada Multivariate convergence diagnostic
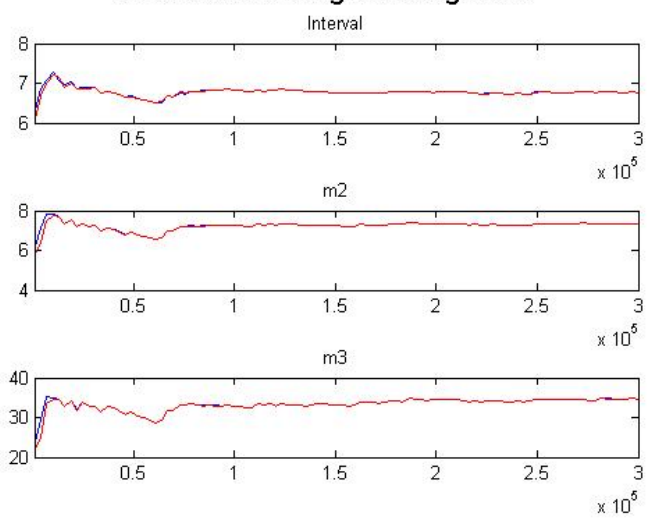
Figura 2.15: $\quad$ Choques suavizados Smoothed shocks
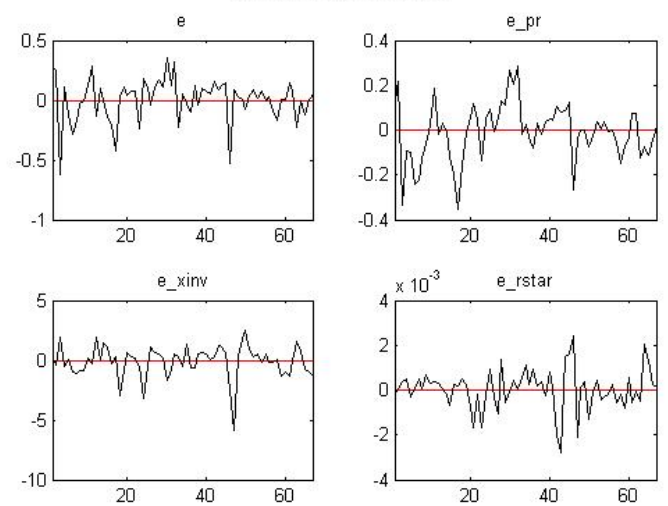

Em cima: choque tecnológico e no prêmio de risco.

Embaixo: choque específico no investimento e choque na taxa de juros real americana

Figura 2.16: Identificação

posterior_mean - Identification using info from observables

Identification strength with asymptotic Information matrix (log-scale)
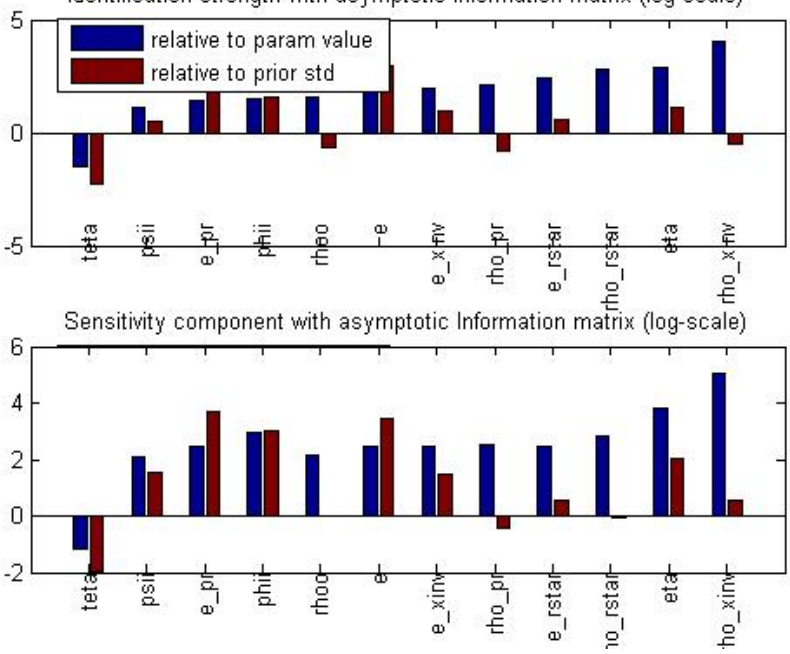


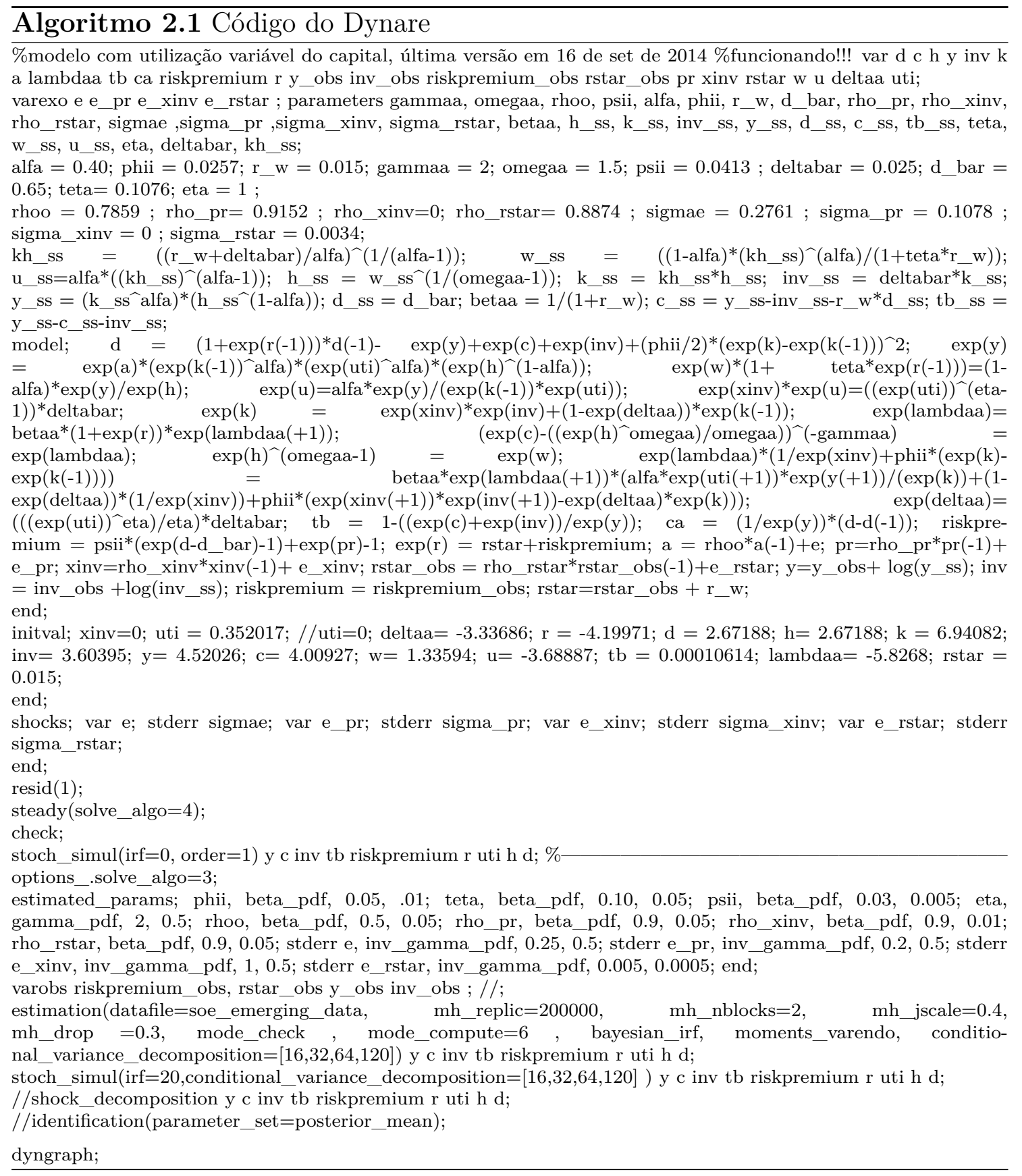




\section{Friç̧ões financeiras em um modelo de economia aberta estimado para o Brasil}

\subsection{Introdução}

O objetivo desta seção é analisar a importância de friç̧ões financeiras na economia brasileira, no contexto de uma economia aberta. A inclusão do acelerador financeiro em um modelo de economia aberta permite estudar o efeito da taxa de câmbio nas variáveis macroeconômicas, contribuindo para um maior entendimento dos efeitos das fricções financeiras, tendo em vista que a maior parte dos modelos que consideram este tipo de fricção é de economia fechada.

A crise financeira que se iniciou em 2007 motivou um esforço de pesquisa por parte dos macroeconomistas para melhor entender o papel de condições financeiras em agregados macroeconômicos. A partir de então, e resgatando pesquisas originalmente efetuadas na década de 90, os macroeconomistas passaram a incluir o setor bancário e variáveis financeiras nos modelos, principalmente em modelos de equilíbrio geral dinâmicos, no âmbito da modelagem DSGE.

Um dos trabalhos mais influentes neste sentido foi o conceito de acelerador financeiro, primeiramente desenvolvido por Bernanke e Gertler (1989) doravante BGG) e posteriormente incluído em um contexto de equilíbrio geral por Bernanke et al. (1999). Problemas de assimetria de informação entre os devedores e os credores, materializado pelo custo de monitoramento dos projetos daqueles por parte destes, dão origem a um prêmio de financiamento externo, que depende inversamente do razão entre o capital próprio e o capital de terceiros. Colocado de outra forma, quanto maior a alavancagem (a relação entre o capital de terceiros e o capital próprio), maior o prêmio de financiamento externo, dado pela diferença entre a taxa de retorno do capital próprio dos empreendedores e a taxa de juros livre de risco.

Partindo do arcabouço de BGG, recentemente diversos modelos têm sido desenvolvidos para aprimorar o entendimento sobre variáveis financeiras e macroeconômicas, com o interesse naturalmente se estendendo para os países emergentes.

Gertler, Gilchrist e Natalucci (2007) buscaram estudar as conexões entre regimes cambiais e crises financeiras. O modelo foi desenvolvido e aplicado para explicar 
a crise da Coréia do Sul de 1997 -98.O modelo foi calibrado com parâmetros representativos da economia sul coreana, com os autores encontrando que o modelo que inclui o prêmio de financiamento externo mais do que dobra o efeito do produto, investimento e emprego a um choque no prêmio de risco soberano, ilustrando a importância do acelerador financeiro no modelo.

López et al. (2008) examinaram o papel de imperfeições no mercado de crédito para a Colômbia, no período compreendido entre 1980 e 2005. Os autores concluíram pela relevância da fricção financeira em um modelo de economia aberta. A principal conclusão obtida foi que a fricção financeira aumenta a resposta de variáveis reais a um choque na taxa de juros, afetando principalmente o investimento.

Freystatter (2012) estudou o papel das fricções financeiras em um modelo de economia aberta para a Finlândia entre 1995 e 2008, encontrando uma grande importância de choques oriundos do setor financeiro para explicar a dinâmica do investimento naquele país.

Para o Brasil, o trabalho mais relacionado com esta seção é Silva Júnior e Divino (2013), que estimaram o modelo de Christiano et al. (2010) para a economia brasileira. Dentre os trabalhos que consideram economia aberta, Furlani estimou o modelo de Gali e Monacelli (2005) para o Brasil, usando dados de 2000 até 2007. Entretanto, uma importante limitação do modelo é a hipótese de mercados completos, uma vez que choques no prêmio de risco em geral são considerados como relevantes para a dinâmica do ciclo de negócios em economias emergentes.

Kanczuk (2013) desenvolveu um modelo que incorpora o acelerador financeiro para estudar o papel das medidas macro-prudenciais, com fricções financeiras nos estilo BGG tanto para os consumidores quanto para os empreendedores, no sentido que a taxa de juros com a qual estes agentes se deparam é função do seu nível de alavancagem. Dito de outra forma, o modelo contempla prêmios de financiamento do crédito às pessoas físicas e jurídicas.

Em face da ênfase no acelerador financeiro como peça para incorporar fricções financeiras nos modelos DSGE, esta seção contrapõe o papel do acelerador financeiro no contexto da literatura sobre ciclos em países emergentes, que em grande parte enfatiza o papel de choques no prêmio de risco, seja de forma exógena ou endógena -como função da produtividade-, seguindo os trabalhos de Neumeyer e Perri (2005) , Uribe e Yue (2006), García-Cicco et al. (2010), Chang e Fernández (2013) e Fernandez (2010) .

Além de uma estrutura mais rica para o papel de variáveis financeiras na economia, contemplando tanto choques tradicionais no prêmio de risco quanto o acelerador financeiro, a característica de economia aberta do modelo permite investigar o papel de algumas variáveis externas na economia brasileira, como choques na demanda externa e na inflação mundial, em conjunto com uma gama de outros choques. Em trabalho recente, Teles e Mendonça (2013) analisaram o efeito de choques nos termos de troca e nos fluxos de capitais para a economia brasileira para o período 20002012, encontrando uma grande importância para os termos de troca na variação do 
produto brasileiro, principalmente após a crise de 2007/2008. Embora os perídos sejam diferentes, os resultados contrastam com os obtidos por Silva (2008), que não encontrou grande relevância para os termos de troca nos ciclos brasileiros entre 1994 e 2007.

A contribuição deste trabalho se dá pela inclusão de fricções no mercado de crédito em um modelo de economia aberta, uma vez que o modelo estudado por Silva Júnior e Divino (2013) é de economia fechada, e modelos de grande porte construídos para o Brasil, como Castro et al. (2011) não consideram o papel de fricções financeiras.

\subsection{Modelo}

O modelo foi construído incorporando o acelerador financeiro ao modelo apresentado em Alendal (2008), que não considera o capital na função de produção. As alterações tornam o modelo semelhante ao de López et al. (2008), podendo ser considerado uma versão aberta do modelo de Christensen e Dib (2008).

A principal contribuição fica por conta da inclusão do acelerador financeiro no bloco de investimento em um modelo de economia aberta. Esta alteração permite a análise da interação da taxa de câmbio e de fatores externos na fricção financeira doméstica. A segunda contribuição decorre do fato do modelo ser estimado para o Brasil, com e sem a presença do custo de financiamento externo $(\psi)$, permitindo analisar o papel desta fricção financeira na dinâmica do modelo.

Além da inclusão de capital, o modelo difere de Alendal (2008) por considerar a rigidez nominal segundo a abordagem de Calvo, enquanto o modelo original considera a rigidez nominal segundo a abordagem de custos de ajustamento. Esta opção advém simplesmente do fato de que a maioria dos modelos que incorporam o acelerador financeiro, comparáveis com o estudado neste capítulo, consideram a rigidez nominal por meio da abordagem de Calvo (Christensen e Dib,2008; López et al., 2008; Freystatter, 2012; Gertler, Gilchrist e Natalucci ,2007).

O modelo inclui rigidez de preços, custos de ajustamentos de capital e hábito no consumo. As fricções financeiras são incorporadas no modelo por meio do acelerador financeiro, de forma que o financiamento externo por parte dos empreendedores depende da relação entre o capital próprio e o de terceiros. O investimento passa a ser afetado por choques que afetam o patrimônio líquido dos empreendedores.

A economia é composta por 4 tipos de agentes: consumidores, produtores de capital, empreendedores (que atuam no atacado) e varejistas (que são os responsáveis pela rigidez nominal do modelo). 


\subsubsection{Empreendedores}

Os empreendedores atuam no atacado, combinando capital e trabalho para produzir o seu bem, com base em uma função de produção Cobb-Douglas:

$$
y_{t}=A_{t} k_{t}^{\alpha}\left(h_{t}\right)^{1-\alpha}, \alpha \epsilon(0,1)
$$

onde $k_{t}$ é o capital,$h_{t}$ é o trabalho e $A_{t} e ́$ um choque tecnológico, dado por um $\operatorname{AR}(1)$.

$$
\log \left(A_{t}\right)=\rho_{A} \log \left(A_{t-1}\right)+\varepsilon_{A t}
$$

Cada empreendedor vende o seu produto em um mercado perfeitamente competitivo por um preço igual ao seu custo marginal nominal. Os empreendedores minimizam o custo escolhendo $k_{t}$ e $h_{t}$ sujeito à função de produção acima.

$$
\Pi_{t}=z_{t} k_{t}+w_{t} h_{t}+\xi_{t}\left(y_{t}-k_{t}^{\alpha}\left(A_{t} h_{t}\right)^{1-\alpha}\right)
$$

onde $\xi_{t}>0$ é o multiplicador de Lagrange associado à função de produção, e equivale ao custo marginal real; $w_{t}$ é o salário real e $z_{t}$ é a remuneração do capital em termos reais (produtividade marginal real do capital).

Derivando em relação a $k_{t}$ temos:

$$
z_{t}=\alpha \xi_{t} k_{t}^{\alpha-1}\left(A_{t} h_{t}\right)^{1-\alpha}=\alpha \xi_{t} \frac{y_{t}}{k_{t}}
$$

Derivando em relação a $h_{t}$ temos:

$$
w_{t}=A_{t}(1-\alpha) \xi_{t} k_{t}^{\alpha}\left(A_{t} h_{t}\right)^{-\alpha}=(1-\alpha) \xi_{t} \frac{y_{t}}{h_{t}}
$$

No final de cada período, os empreendedores compram, ao preço real $q_{t}$, o capital $\left(k_{t+1}\right)$ que será utilizado no próximo período, de forma que o custo do capital é $q_{t} k_{t+1}$. A compra do capital é financiada em parte pelo seu patrimônio líquido disponível no final do periodo t, $n_{t}$, e em parte pela emissão de titulos nominais $\left(B_{t+1}\right)$ junto aos intermediários financeiros. Estes se financiam com os consumidores e se deparam com um custo de oportunidade igual à taxa de juros livre de risco da economia entre $\mathrm{t}$ e $\mathrm{t}+1$. O financiamento do empreendedor pode ser expresso da seguinte forma:

$$
q_{t} k_{t+1}=n_{t+1}+\left(\frac{B_{t+1}}{P_{t}}\right)
$$


onde $q_{t}$ é o preço relativo de uma unidade de capital em unidades do bem de consumo. A demanda de capital do empreendedor depende do retorno marginal esperado do capital e do custo marginal esperado de financiamento externo. Denotando por $E_{t} f_{t+1} \mathrm{O}$ custo marginal esperado de financiamento externo (taxa de juros real esperada no financiamento externo), temos:

$$
E_{t} f_{t+1}=E_{t}\left[\frac{z_{t+1}+(1-\delta) q_{t+1}}{q_{t}}\right]
$$

O lado direito da equação acima dá o retorno marginal esperado do capital, onde $z_{t+1}$ é a produtividade marginal do capital em $\mathrm{t}+1$ e $(1-\delta) q_{t+1}$ é o valor de uma unidade de capital utilizada (não depreciada) em t+1.

BGG(1999) assumem imperfeições no mercado de crédito, que fazem com que o financiamento externo seja mais caro do que o interno, de forma que os tomadores de empréstimos pagam um prêmio acima da taxa de juros livre de risco caso eles demandem empréstimos externos. A imperfeição advém de um problema de informação. O produto dos empreendedores está sujeito a um choque aleatório, e os intermediários financeiros têm que pagar um custo para observar o produto, ao passo que os empreendedores não incorrem um custos para observar o produto. Após a produção, os empreendedores decidem se pagam o empréstimo ou não. No caso de inadimplência, os intermediários financeiros inspecionam e recuperam a produção do empreendedor, líquida dos custos de monitoramento. O contrato financeiro entre empreendedores e intermediários financeiros dá origem a um prêmio de financiamento externo, que por sua vez é função do nível de alavancagem do empreendedor.

O custo marginal de financiamento externo é dado por:

$$
E_{t} f_{t+1}=E_{t}\left[\frac{r_{t}}{\pi_{t}} S(.)\right]
$$

onde $E_{t}\left[\frac{r_{t}}{\pi_{t}}\right]$ é a taxa de juros real esperada, onde a taxa de juros nominal doméstica $\left(r_{t}\right)$ é determinada pela regra de Taylor da autoridade monetária. Seguindo Christensen e Dib (2008), o contrato entre os empreendedores e os intermediários financeiros é fixado em termos nominais, de forma que um aumento inesperado da inflação reduz o custo marginal esperado de financiamento externo por parte dos empreendedores. O prêmio de financiamento externo é função da alavancagem:

$$
S(.)=S\left(\frac{n_{t+1}}{q_{t} k_{t+1}}\right)
$$

onde $S^{`}()<$.0 e $S(1)=1$. Quando maior a fração de capital próprio em relação ao capital de terceiros, menor é o prêmio de financiamento externo. A intuição é que, 
quanto maior a alavancagem, maior é o incentivo do empreendedor em não relatar de forma precisa o resultado da sua produção, tornando o empréstimo mais caro e aumentando o custo do empréstimo. O prêmio de financiamento externo loglinearizado é dado por:

$$
f_{t+1}-\left(r_{t}-\pi_{t}\right)=\psi\left(q_{t}+k_{t+1}-n_{t+1}\right)
$$

onde $\psi$ representa a elasticidade do prêmio de financiamento externo com relação à alavancagem dos empreendedores, e indica a sensibilidade da demanda de capital dos empreendedores em relação à sua estrutura de capital. Pelo acelerador financeiro, o preço do capital $\left(q_{t}\right)$ afeta o patrimônio líquido dos empreendedores, e também é afetado pela fricção financeira. Um choque que reduz os preço do capital provoca, em consequência, uma redução do patrimônio líquido dos empreendedores, aumentando o custo de financiamento externo e em última instância deprimindo o investimento.

A evolução do patrimônio líquido dos empreendedores é dada por:

$$
n_{t+1}=\nu v_{t}+(1-\nu) g_{t}
$$

onde $v_{t}$ é o patrimônio líquido dos empreendedores líquidos dos custos de empréstimos do período anterior, $(1-\nu)$ é a parcela de novos empreendedores entrando na economia e $g_{t}$ é a transferência que os novos empreendedores recebem dos que morrem. A evolução de $v_{t}$ é dada por:

$$
v_{t}=\left[f_{t} q_{t-1} k_{t}-E_{t-1}\left[S(.) \frac{r_{t-1}}{\pi_{t}}\left(q_{t-1} k_{t}-n_{t}\right)\right]\right.
$$

O primeiro termo do lado direito é o retorno ex-post do capital em t, e o segundo termo é o custo do empréstimo, a taxa de juros real implícito no contrato tomado em t-1. Assim, os rendimentos das operações no período anterior se tornam o patrimônio líquido do próximo período. Aumentos inesperados da inflação afetam positivamente o patrimônio líquido dos empreendedores, pela redução da taxa de juros real.

Implicitamente, a estrutura do modelo assume que o financiamento externo dos empreendedores se dá em moeda local, e os intermediários financeiros que ofertam fundos para os empreendedores são em última instância os consumidores, que têm, em sua restrição orçamentária, a opção de adquirir títulos domésticos (em moeda local) ou externos.

A influência do setor externo e da taxa de câmbio se dá através da paridade descoberta de juros, que relaciona as taxas de juros doméstica e externa, o prêmio de risco e a taxa de câmbio. 


\subsubsection{Produtores de capital}

Os produtores de capital utilizam bens de consumo comprados dos varejistas como insumo para produzir capital novo. Eles combinam o bem de consumo (denotado por $i_{t}$ ) com o capital existente. Em linha com Christensen e Dib (2006) e López et al. (2008), assume-se que os produtores de capital são sujeitos a custos de ajustamento quadráticos. O problema dos produtores de capital é escolher a quantidade de investimento (que é expressa e bens de consumo) de forma a maximizar os lucros:

$$
\max _{i_{t}} E_{t}\left[q_{t} i_{t}-i_{t}-\frac{\chi}{2}\left(\frac{i_{t}}{k_{t}}-\delta\right)^{2} k_{t}\right]
$$

A condição de 1a ordem é :

$$
q_{t}-1-\chi\left(\frac{i_{t}}{k_{t}}-\delta\right)=0
$$

Assim, na ausência de custos de ajustamentos, o preço do capital $\left(q_{t}\right)$ é igual a 1. Conforme exposto em Christensen e Dib (2006), os custos de ajustamento do capital permitem que o preço do capital oscile, o que por sua vez gera volatilidade no patrimônio líquido dos empreendedores.A equação acima descreve a oferta de capital, ao passo que a demanda por capital é determinada pelas condições de 1a ordem dos empreendedores.

A evolução do estoque de capital é dada por:

$$
k_{t+1}=x i_{t}+(1-\delta) k_{t}
$$

Onde $x_{t}$ é um choque específico no investimento (preço relativo do investimento) que segue um processo $\operatorname{AR}(1)$.

\subsubsection{Varejistas}

Os empreendedores vendem toda a sua produção para os varejistas. Por sua vez, os varejistas diferenciam os produtos dos empreendedores e vendem os produtos diferenciados para os consumidores, os produtores de capital e o governo. 


\subsubsection{Bem doméstico}

Os varejistas compram o produto dos empreendedores, a um preço igual ao custo marginal nominal dos empreendedores, e o diferenciam sem custos. A diferenciação do produto por parte dos varejistas faz com que eles detenham poder de mercado em cada bem, de forma que os varejistas operam em um ambiente de competição monopolística. Seguindo a abordagem de Calvo (1983), uma fração $(1-\phi)$ dos varejistas podem mudar os seus preços em cada período. Por outro lado, caso o varejista não consiga reajustar os seus preços, ele segue uma regra de indexação, dada por uma ponderação entre a inflação passada e a meta de inflação.:

$$
p_{t+1}^{h}(j)=p_{t}^{h}(j)\left(1+\pi_{t}^{h}\right)^{\gamma_{h}}(1+\pi)^{\left(1-\gamma_{h}\right)}
$$

onde $\gamma_{h} \epsilon[0,1]$ é o grau de indexação à inflação passada, e $\pi$ é a meta de inflação. Se a firma não reajusta os seus preços por 1 períodos, então:

$$
p_{t+l}^{h}(j)=p_{t}^{h}(j) \Pi_{i=1}^{l}\left(1+\pi_{t-1+i}^{h}\right)^{\gamma_{h}}(1+\pi)^{l\left(1-\gamma_{h}\right)}
$$

A firma escolhe $p_{t}^{h}(j)$ para maximizar os lucros reais esperados descontados durante o período de tempo em que os preços se mantêm fixos:

$$
\max _{p_{j, t}} E_{t} \sum_{l=0}^{\infty}(\beta \phi)^{l} \lambda_{t+l} \frac{\Omega_{t+l}(j)}{p_{t+l}^{h}}
$$

sujeito à função de demanda da variedade $\mathrm{j}$ :

$$
y_{t+l}^{h}(j)=\left(\frac{p_{t+l}^{h}(j)}{p_{t+l}^{h}}\right)^{-\theta} y_{t+l}^{h}
$$

A função de lucro nominal do varejista é :

$$
\Omega_{t+l}(j)=\left(p_{t}^{h}(j) \prod_{i=1}^{l}\left(1+\pi_{t-1+i}^{h}\right)^{\gamma_{h}}(1+\pi)^{l\left(1-\gamma_{h}\right)}-p_{t+l}^{h} \xi_{t+l}\right) y_{t+l}^{h}(j)
$$

O preço ótimo do varejista $\left(p_{t}^{*}\right)$ é dado por:

$$
\frac{p_{t}^{*}}{p^{h}}=\frac{\theta}{\theta-1} \frac{E_{t} \sum_{l=0}^{\infty}(\beta \phi)^{l} \lambda_{t+l} \xi_{t+l}^{h} \prod_{i=1}^{l}\left\{\left(1+\pi_{t+i}^{h}\right)^{\theta}\left(1+\pi_{t-1+i}^{h}\right)^{-\theta \gamma_{h}}\right\}(1+\pi)^{-\theta l\left(1-\gamma_{h}\right)} y_{t+l}^{h}}{E_{t} \sum_{l=0}^{\infty}(\beta \phi)^{l} \lambda_{t+l} \prod_{i=1}^{l}\left\{\left(1+\pi_{t+i}^{h}\right)^{\theta-1}\left(1+\pi_{t-1+i}^{h}\right)^{(1-\theta) \gamma_{h}}\right\}(1+\pi)^{(1-\theta) l\left(1-\gamma_{h}\right)} y_{t+l}^{h}}
$$


A evolução do preço agregado é dada por uma composição do preço ótimo e do preço indexado, com os pesos dados pela fração das firmas que conseguem maximizar $(1-\phi)$ :

$$
p_{t}^{h(1-\theta)}=\left[(1-\phi)\left(p_{t}^{*}\right)^{(1-\theta)}+\phi\left[p_{t-1}^{h}\left(1+\pi_{t-1}^{h}\right)^{\gamma_{h}}(1+\pi)^{\left(1-\gamma_{h}\right)}\right]^{1-\theta}\right.
$$

Curva de Philps novo-keynesiana da inflação dos bens domésticos após a log-linearização:

$$
\pi_{t}^{h}=\frac{\beta}{1+\beta \gamma_{h}} \pi_{t+1}^{h}+\frac{\gamma_{h}}{1+\beta \gamma_{h}} \pi_{t-1}^{h}+\frac{(1-\beta \phi)(1-\phi)}{\phi\left(1+\beta \gamma_{h}\right)} \xi_{t}^{h}
$$

\subsubsection{Bem importado}

Os importadores, que operam no atacado, compram o bem importado ao preço internacional, valendo a lei do preço único:

$$
p_{t}^{f}=s_{t} p_{t}^{f^{*}}
$$

Em seguida, os importadores vendem o produto para os varejistas do bem importado, que diferenciam o produto e vendem no mercado doméstico. Assume-se que os varejistas têm poder de mercado no mercado do seu bem diferenciado. O problema de escolha do preço ótimo dos importadores varejistas é o mesmo dos varejistas do bem doméstico, com a diferença de que o custo marginal dos importadores é dado por $s_{t} p_{t}^{f^{*}}$, onde $s_{t}$ é a taxa de câmbio nominal. Assume-se que a rigidez nominal segue o procedimento de Calvo. O problema dá origem a uma curva de Philips para a inflação dos bens importados:

$$
\pi_{t}^{f}=\frac{\beta}{1+\beta \gamma_{f}} \pi_{t+1}^{f}+\frac{\gamma_{f}}{1+\beta \gamma_{f}} \pi_{t-1}^{f}+\frac{\left(1-\beta \phi^{f}\right)\left(1-\phi^{f}\right)}{\phi\left(1+\beta \gamma_{f}\right)} \xi_{t}^{f}
$$

onde $\pi_{t}^{f}=\frac{p_{t}^{f}}{p_{t-1} f}$

O custo marginal real é dado por:

$$
\xi_{t}^{f}=\frac{s_{t} p^{f *}}{p_{t}^{f}}
$$




\subsection{4 Índices de consumo e de preços}

O consumo é composto por bens domésticos e importados. A cesta de consumo é dada por:

$$
C_{t}=\left[(1-\alpha)^{\frac{1}{\eta}} C_{H, t}^{\frac{\eta-1}{\eta}}+\alpha^{\frac{1}{\eta}} C_{F, t}^{\frac{\eta-1}{\eta}}\right]^{\frac{\eta}{\eta-1}}
$$

onde $\alpha$ mede o grau de abertura da economia. $C_{H, t}$ e $C_{F, t}$ representam o consumo agregado de bens domésticos e importados, e são dados por CES de um contínuo de bens diferenciados, indexados por i.

$$
\begin{aligned}
& C_{H, t}=\left[\int_{0}^{1} C_{H, t}(i)^{\frac{\epsilon_{H}-1}{\epsilon_{H}}} d i\right]^{\frac{\epsilon_{H}}{\epsilon_{H-1}}} \\
& C_{F, t}=\left[\int_{0}^{1} C_{F, t}(i)^{\frac{\epsilon_{F}-1}{\epsilon_{F}}} d i\right]^{\frac{\epsilon_{F}}{\epsilon_{F-1}}}
\end{aligned}
$$

A elasticidade de substituição entre bens domésticos e importados é dada por $\eta>0$, e as elasticidades de substituição entre os diferentes tipos de bens domésticos e importados é dada por $\epsilon_{H}$ e $\epsilon_{F}$, respectivamente. A maximização do consumo sujeito à restrição orçamentária gera a demanda por cada tipo de bem:

$$
\begin{aligned}
C_{H, t} & =(1-\alpha)\left(\frac{P_{H, t}}{P_{t}}\right)^{-\eta} C_{t} \\
C_{F, t} & =\alpha\left(\frac{P_{F, t}}{P_{t}}\right)^{-\eta} C_{t}
\end{aligned}
$$

Os índices de preços dos bens domésticos e internacionais são definidos como:

$$
\begin{aligned}
& P_{H, t}=\left[\int_{0}^{1} P_{H, t}(i)^{1-\epsilon_{H}} d i\right]^{\frac{1}{\epsilon_{H, t^{-1}}}} \\
& P_{F, t}=\left[\int_{0}^{1} P_{F, t}(i)^{1-\epsilon_{F}} d i\right]^{\frac{1}{\epsilon_{F, t^{-1}}}}
\end{aligned}
$$


O índice de preços ao consumidor é dado por:

$$
P_{t} \equiv\left[(1-\alpha) P_{H, t}^{1-\eta}+\alpha P_{F, t}^{1-\eta}\right]^{\frac{1}{1-\eta}}
$$

A demanda ótima por cada bem individual dentro de cada categoria é dada por:

$$
\begin{aligned}
& C_{H, t}(i)=\left(\frac{P_{H, t}(i)}{P_{H, t}}\right)^{-\varepsilon_{H, t}} C_{H, t} \\
& C_{F, t}(i)=\left(\frac{P_{F, t}(i)}{P_{F, t}}\right)^{-\varepsilon_{F, t}} C_{F, t}
\end{aligned}
$$

\subsubsection{Economia externa}

Assume-se que a lei do preço único vale na economia para a qual o bem comercializável doméstico é exportado. Outra hipótese é que os consumidores desta economia têm preferências similares à dos consumidores domésticos pelo bem doméstico. Assim, a demanda externa para o bem doméstico é dada por:

$$
C_{H, t}^{f}=\alpha^{f}\left(\frac{P_{H, t}}{S_{t} P_{F, t}^{f}}\right)^{-\eta} C_{t}^{f}
$$

onde $C_{t}^{f}$ é a demanda externa, tomada como exógena.

O bem doméstico é vendido internamente, exportado, vendido para o governo ou para os produtores de bens de capital:

$$
C_{H, t}^{T}=C_{H, t}+C_{H, t}^{F}+G_{t}+I_{t}=(1-\alpha)\left(\frac{P_{H, t}}{P_{t}}\right)^{-\eta} C_{t}+\alpha^{f}\left(\frac{P_{H, t}}{S_{t} P_{F, t}^{f}}\right)^{-\eta} C_{t}^{f}+I_{t}+G_{t}
$$

\subsubsection{Consumidores}

A economia é povoada por um contínuo de consumidores, que consomem um compostos de bens domésticos e importados. Os consumidores maximizam a seguinte função de utilidade:

$$
E_{0} \sum_{t=0}^{\infty} \beta^{t}\left[\frac{\left(C^{j}-h C_{t-1}\right)^{1-\sigma}}{1-\sigma}-\frac{\left(N_{t+i}^{j}\right)^{1+\varphi}}{1+\varphi}\right]
$$


onde $\beta$ é o fator de desconto, $C_{t}^{j}$ é o consumo do indivíduo j, $C_{t-1}$ é o consumo agregado do período anterior e $h$ é o parâmetro associado ao hábito no consumo. $N_{t}$ é o trabalho do indivíduo j, e os parâmetros $\sigma$ e $\varphi$ representam o inverso da elasticidade de substituição intertemporal e da elasticidade Frisch da oferta de trabalho, respectivamente.

A restrição orçamentária do consumidor é dada por:

$$
C_{t}^{j}+\frac{B_{t}^{j}}{\left(1+r_{t}\right) P_{t}}+\frac{S_{t} B_{t}^{f, j}}{\left(1+r_{f}\right) \Phi\left(A_{t}\right) P_{t}}=\frac{B_{t-1}^{j}}{P_{t}}+\frac{S_{t} B_{t-1}^{f, j}}{P_{t}}+\frac{W_{t}}{P_{t}} N_{t}^{j}+X_{t}^{j}-T_{t}^{j}
$$

$B_{t}^{j}$ denota os títulos em moeda doméstica, $B_{t}^{f, j}$ denota os títulos em moeda estrangeira, $r_{t}$ é a taxa de juros nominall de curto prazo, $r_{t}^{f}$ é a taxa de juros externa de curto prazo, $T_{t}^{j}$ são impostos lump-sum,

O prêmio de risco é dado pela função $\Phi\left(A_{t}\right)=\exp \left(-\phi A_{t}+Z_{t}^{B}\right)$, onde $A_{t}$ é o ativo externo líquido agregado da economia, definidos por $A_{t} \equiv \frac{S_{t} B_{t}^{f}}{P_{t}}$. $Z_{t}^{B}$ é um choque no prêmio de risco que segue um $\mathrm{AR}(1)$.

Nas derivações que se seguem o operador esperança foi omitido em algumas passagens, apenas por simplificação.

Lagrangeano:

$L=E_{t} \sum_{i=0}^{\infty} \beta^{t}\left\{\left[\frac{\left(C_{t}^{j}-h C_{t-1}\right)^{1-\sigma}}{1-\sigma}-\frac{\left(N_{t}^{j}\right)^{1+\varphi}}{1+\varphi}\right]-\lambda_{t}\left[C_{t}^{j}+\frac{B_{t}^{j}}{\left(1+r_{t}\right) P_{t}}+\frac{S_{t} B_{t}^{f, j}}{\left(1+r_{t}^{f}\right) \Phi\left(A_{t}\right) P_{t}}-\frac{B_{t-1}^{j}}{P_{t}}-\frac{S_{t} B_{t-1}^{f, j}}{P_{t}}+-\frac{W_{t}}{P_{t}} N_{t}^{j}-X_{t}^{j}+T_{t}^{j}\right]\right\}$

Derivando em relação a $C_{t}^{j}$ :

$$
\begin{aligned}
& \beta^{t}\left(C_{t}^{j}-h C_{t-1}\right)^{-\sigma}-\beta^{t} \lambda_{t}=0 \\
& \lambda_{t}=\left(C_{t}^{j}-h C_{t-1}\right)^{-\sigma}
\end{aligned}
$$

Derivando em relação a $B_{t}^{j}$ :

$$
\begin{aligned}
& -\beta^{t} \frac{\lambda_{t}}{\left(1+r_{t}\right) P_{t}}+\beta^{t+1} \frac{\lambda_{t+1}}{P_{t+1}}=0 \\
& \beta\left(1+r_{t}\right) \frac{\lambda_{t+1}}{P_{t+1}} \frac{P_{t}}{\lambda_{t}}=1
\end{aligned}
$$


Chegamos na equação de Euler:

$$
\beta\left(1+r_{t}\right) E_{t}\left[\frac{\left(C_{t+1}^{j}-h C_{t}\right)^{-\sigma}}{\left(C_{t}^{j}-h C_{t-1}\right)^{-\sigma}} \frac{P_{t}}{P_{t+1}}\right]=1
$$

Derivando em relação a $B_{t}^{f, j}$ :

$$
\begin{aligned}
& -\lambda_{t} \beta^{t} \frac{S_{t}}{\left(1+r_{t}^{f}\right) \Phi\left(A_{t}\right) P_{t}}+\beta^{t+1} \lambda_{t+1} \frac{S_{t+1}}{P_{t+1}}=0 \\
& \beta \frac{\lambda_{t+1}}{\lambda_{t}} \frac{S_{t+1}}{S_{t}} \frac{\left(1+r_{t}^{f}\right) \Phi\left(A_{t}\right) P_{t}}{P_{t+1}}=1
\end{aligned}
$$

Utilizando a expressão 45:

$$
\frac{S_{t+1}}{S_{t}} \frac{\left(1+r_{t}^{f}\right) \Phi\left(A_{t}\right)}{\left(1+r_{t}\right)}=1
$$

Rearranjando os termos chegamos na paridade descoberta de juros:

$$
\frac{\left(1+r_{t}\right)}{\left(1+r_{t}^{f}\right)}=E_{t}\left[\frac{S_{t+1}}{S_{t}}\right] \Phi\left(A_{t}\right)
$$

Choques no prêmio de risco da forma usualmente modelada pela literatura de ciclos em países emergentes provocam um aumento na taxa de juros doméstica pela paridade descoberta de juros, e se refletem no custo marginal de financiamento externo dos empreendedores pela equação 8 .

Derivando em relação a $N_{t}^{j}$ :

$$
\begin{aligned}
& -\beta^{t}\left(N_{t}^{j}\right)^{\varphi}+\beta^{t} \lambda_{t} \frac{W_{t}}{P_{t}}=0 \\
& \frac{W_{t}}{P_{t}}=\frac{\left(N_{t}^{j}\right)^{\varphi}}{\left(C_{t}^{j}-h C_{t-1}\right)^{-\sigma}}
\end{aligned}
$$

onde a última expressão é a oferta de trabalho, que é determinada pela igualdade entre o salário real e a a taxa marginal de substituição entre lazer e consumo. 


\subsubsection{Governo}

O governo adquire apenas bens domésticos, e o gasto do governo é financiado por impostos lump-sum. O gasto do governo segue um processo $\mathrm{AR}(1)$, assim como todos os demais choques do modelo.

A política monetária é conduzida por meio de uma regra de Taylor:

$$
r_{t}=\omega_{r} r_{t-1}+\left(\frac{1-\omega_{r}}{R}\right)\left[\omega_{\pi} \pi_{t}+\omega_{y}\left(y-y_{t-1}\right)\right]+\xi_{t}^{r}
$$

\subsection{Modelo log-linearizado}

Os detalhes da derivação do modelo, exceto para o bloco do investimento, estão em Alendal (2008). São apresentadas a seguir as equações log-linearizadas.

$$
\begin{aligned}
& \hat{c}_{t}=\left(1-\gamma_{C}\right) \hat{c}_{H, t}+\gamma_{C} \hat{c}_{F, t} \\
& \hat{c}_{H, t}=\hat{c}_{t}-\eta \hat{p}_{H, t} \\
& \hat{c}_{F, t}=\hat{c}_{t}-\eta \hat{p}_{F, t} \\
& c_{H, t}^{f}=\hat{c}_{t}^{f}-\eta\left(\hat{p}_{H, t}-\hat{Q}_{t}\right) \\
& \hat{y}_{t}=\frac{C_{H}}{Y} \hat{c}_{H, t}+\frac{C_{H}^{f}}{Y} \hat{c}_{H, t}^{f}+\frac{G}{Y} \hat{g}_{t}+\frac{I}{Y} \hat{i}_{t} \\
& \hat{y}_{t}=\alpha \hat{k}_{t}+(1-\alpha) \hat{N}_{t}+z_{y, t} \\
& \hat{w}_{t}=\hat{y}_{t}+c m g_{t}-\hat{N}_{t} \\
& \hat{z}_{t}=\hat{y}_{t}+c m g_{t}-\hat{z}_{t}
\end{aligned}
$$




$$
\begin{aligned}
& \hat{k}_{t}=\delta\left(\hat{i}_{t}+\hat{x}_{t}\right)+(1-\delta) \hat{k}_{t-1} \\
& \hat{q}_{t}=\chi\left(\hat{i}_{t}-\hat{k}_{t}\right)-\hat{x}_{t} \\
& \hat{f}_{t+1}=\hat{r}_{t}-\hat{\pi}_{t+1}+\psi\left(\hat{q}_{t}+\hat{k}_{t+1}-\hat{n}_{t+1}\right) \\
& \hat{f}_{t}=\frac{z}{f} \hat{z}_{t}+\frac{1-\delta}{f} \hat{q}_{t}-\hat{q}_{t-1} \\
& \frac{\hat{n}_{t+1}}{\nu_{f}}=\frac{k}{n} \hat{f}_{t}-\left(\frac{k}{n}-1\right)\left(\hat{r}_{t-1}-\hat{\pi}_{t}\right)-\psi\left(\frac{k}{n}-1\right)\left(\hat{k}_{t}+\hat{q}_{t-1}\right)+\left(\psi\left(\frac{k}{n}-1\right)+1\right) \hat{n}_{t} \\
& r p=\psi\left(\hat{q}_{t}+\hat{k}_{t+1}-\hat{n}_{t+1}\right)
\end{aligned}
$$$$
\hat{c_{t}}=\frac{h}{1+h} \hat{c}_{t-1}+\frac{1}{1+h} E_{t}\left(\hat{c}_{t+1}\right)-\frac{1-h}{1+h} \frac{1}{\sigma}\left(\hat{r}_{t}-E_{t} \hat{\pi}_{t+1}\right)
$$$$
\hat{r}_{t}-\hat{r}_{t}^{f}=E_{t} \hat{Q}_{t+1}-\hat{Q}_{t}+E_{t} \hat{\pi}_{+1}-E_{t} \hat{\pi}_{t+1}^{f}-\phi A_{t}+Z_{t}^{B}
$$$$
\frac{Q \hat{b}_{t}^{f}}{R^{f}}-Q \hat{b}_{t-1}^{f}=p_{H} C_{H}^{f}\left(\hat{p}_{H, t}+\hat{c}_{H, t}^{f}\right)-Q C_{F}\left(\hat{Q}_{t}+\hat{C}_{F, t}\right)
$$$$
\frac{1}{\varphi} \hat{w}_{t}-\frac{\sigma}{\varphi(1-h)} \hat{c}_{t}+\frac{\sigma h}{\varphi(1-h)} \hat{c}_{t-1}=\hat{N}_{t}
$$$$
\hat{r}_{t}=\varpi_{r} \hat{r}_{t-1}+\left(\frac{1-\varpi_{r}}{R}\right)\left[\varpi_{\pi}+\varpi_{y}\left(\hat{y}_{t}-\hat{y}_{t-1}\right)\right]+\xi_{t}^{r}
$$$$
n x_{t}=\hat{p}_{H, t}+\hat{c}_{H, t}^{f}-\left(\hat{c}_{F, t}+\hat{Q}_{t}\right)
$$$$
\hat{\pi}_{F, t}=\hat{\pi}_{t}+\hat{p}_{F, t}-\hat{p}_{F, t-1}
$$ 


$$
\hat{\pi}_{H, t}=\hat{\pi}_{t}+\hat{p}_{H, t}-\hat{p}_{H, t-1}
$$

$$
\hat{\pi}_{F, t}=\frac{\beta}{1+\beta \gamma_{F}} \hat{\pi}_{F, t+1}+\frac{\gamma_{F}}{1+\beta \gamma_{F}} \hat{\pi}_{F, t-1}+\frac{\left(1-\beta \phi^{f}\right)\left(1-\phi^{f}\right)}{\phi^{f}\left(1+\beta \phi^{f}\right)}\left(\hat{Q}_{t}-\hat{p}_{F, t}\right)
$$

$$
\hat{\pi}_{H, t}=\frac{\beta}{1+\beta \gamma_{H}} \hat{\pi}_{H, t+1}+\frac{\gamma_{F}}{1+\beta \gamma_{H}} \hat{\pi}_{H, t-1}+\frac{\left(1-\beta \phi^{H}\right)\left(1-\phi^{H}\right)}{\phi^{H}\left(1+\beta \phi^{H}\right)}\left(c m g_{t}\right)
$$

Os gastos do governo, a inflação mundial, a demanda externa (consumo do bem doméstico pelo país estrangeiro), a taxa de juros mundial, o choque específico no investimento, o choque tecnológico, o choque no prêmio de risco e o choque na taxa de juros doméstica seguem um processo $\operatorname{AR}(1)$.

O inverso da elasticidade de substituição intertemporal $(\sigma)$ e o inverso da elasticidade da oferta de trabalho $(\varphi)$ também foram estimados. Para o primeiro parâmetro, foi obtido um valor próximo de 2 , enquanto para o segundo, as estimações resultaram em um valor próximo de 3,5, como será apresentado a seguir.

\subsection{Calibração}

Alguns parâmetros foram calibrados, por serem de difícil identificação ou serem mais consensuais na literatura. A descrição dos parâmetros, valores e justificativas é apresentada na tabela abaixo:

Além dos parâmetros apresentados na tabela, também foram calibrados os parâmetros relacionados ao choque na inflação mundial. Isto foi feito porque este parâmetro se mostrou de difícil identificação em estimações preliminares do modelo. O procedimento efetuado foi utilizar para a persistência e o desvio-padrão do choque os valores obtidos a partir da estimação de um modelo $\mathrm{AR}(1)$ por MQO para a inflação do G-20 (proxy da inflação mundial) da OCDE. Foi então obtido um valor para a persistência do choque de 0,97 e desvio-padrão de 0,53. 


\subsection{Dados}

Foram utilizadas séries de produto, taxa de juros Selic, inflação (IPCA), emprego (CAGED), consumo, investimento, câmbio real e salário real, HP-filtradas. Em linhas gerais estas séries são as recomendadas para a estimação de modelos DSGE por Guerrón-Quintana (2010). Seguindo De Graeve (2008) e Kanczuk (2013), não foram utilizadas séries financeiras nas estimações, apesar do bloco financeiro do modelo. Este procedimento difere do efetuado por Silva Júnior e Divino (2013), onde estes autores incluíram o crescimento das operações de crédito ao setor privado e o spread de crédito na estimação do modelo analisado.

Figura 3.1: $\quad$ Dados utilizados nas estimações
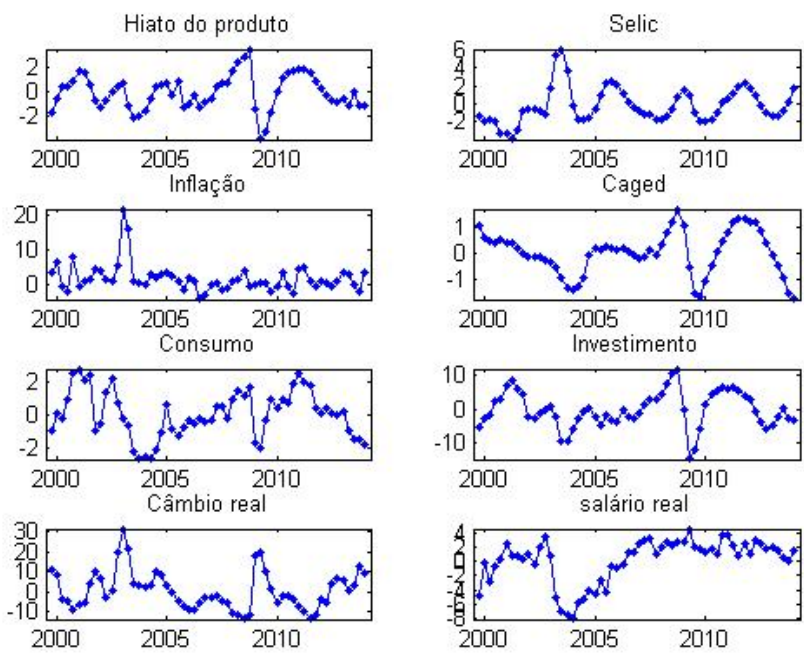

\subsection{Resultados}

\subsubsection{Parâmetros estimados}

$\mathrm{Na}$ estimação do modelo foram utilizadas duas cadeias com 500.000 iterações do algoritmo Metropolis-Hastings. Os resultados obtidos para os parâmetros são apresentados na tabela 2 .

A média da posterior do prêmio de financiamento externo foi inferior à prior $(\psi=0,0275$ contra 0,06). O resultado encontrado para o Brasil é inferior ao encontrado para os Estados Unidos por De Graeve (2008), que encontrou um valor de 0,05 para este parâmetro, em um modelo de economia fechada. No contexto de economia aberta, Freystatter (2012) encontrou um valor próximo de 0,04 para a Finlândia, enquanto López et al. (2008) encontrou um valor de 0.05 para a Colômbia. 
Todos os parâmetros associados à regra de Taylor foram inferiores às priors utilizadas. O grau de suavização da taxa de juros $\left(\omega_{r}\right)$ foi estimado em 0,41 , contra prior de 0,75 . O peso da inflação na regra de Taylor foi estimado em $\omega_{\pi}=1,5$ ante 2 da prior, ao passo que o peso do produto foi estimado em $\varpi_{y}=0,43$, contra 0,5 na prior.

O parâmetro de Calvo da curva de Philips dos bens domésticos $\left(\phi^{H}=0.43\right)$ aponta para uma relativa flexibilidade dos preços no Brasil, com frequência de reajustes estimada em torno de 1,7 trimestre. Curiosamente, o grau de indexação foi estimado em um valor baixo $\left(\gamma^{H}=0,03\right)$, mostrando uma maior importância da meta de inflação e das expectativas de inflação no processo inflacionário brasileiro.

Por outro lado, para a inflação dos bens importados, o valor estimado do parâmetro de Calvo foi superior ao dos bens domésticos $\left(\phi^{f}=0,54\right)$, implicando em uma frequência de reajustes a cada 2,7 trimestres. O grau de indexação estimado para os bens importados também foi bastante superior ao dos bens domésticos $\left(\gamma^{f}=0,70\right)$, mostrando uma inércia no repasse da variação cambial para os bens importados.

Conforme enfatizado por Casto et al. (2011, p.50), os resultados das estimações do parâmetro de Calvo dependem em alguma medida das especificidades de cada modelo, e não é possível uma mapeamento direto entre evidências micro e macroeconômicas. Entretanto, para efeito de comparação, o apêndice apresenta uma compilação das estimações do grau de rigidez de preços para o Brasil, obtidos em estudos anteriores.

A elasticidade do prêmio de risco em relação à divida foi estimada em um valor um pouco superior à prior $(\phi=0.07)$, enquanto o custo de ajustamento do capital se mostrou bastante superior ao valor da prior $(\lambda=2,06)$. Conforme exposto acima, os custos de ajustamentos do capital são importantes porque geram volatilidade no preço do capital -que na ausência de custos de ajustamento é igual à 1 no modelo-, e por consequência, no investimento.

O inverso da elasticidade de substituição intertemporal foi estimado em um valor próximo de $2(\sigma=1,98)$. Por sua vez, o inverso da elasticidade da oferta de trabalho foi estimado um um valor próximo de $4(\varphi=3,76)$, curiosamente apontando para uma baixa elasticidade da oferta de trabalho. Por fim, as elasticidades do consumo foram estimadas em $\eta=2,36$, valor bem superior ao do considerado na prior $(1,1)$.

O modelo também foi estimado sem a presença de friç̧ões financeiras (no sentido do prêmio de financiamento externo), e os resultados estão apresentados na última coluna da tabela em referência. O objetivo de se estimar o modelo sem o prêmio de financiamento externo foi averiguar a importância desta característica para os resultados encontrados. Outro objetivo foi ver como os demais parâmetros se alteram quando retirarmos o prêmio de financiamento do modelo.

Quando o prêmio de financiamento externo é zerado, a verossimilhança marginal se eleva em torno de 20 pontos logarítmicos, passando de -1.050 para -1.029, indicando um melhor ajuste do modelo nesta circunstância. Este resultado constrasta com o obtido por De Graeve (2008), que obteve evidências amplamente favoráveis a um 
modelo novo-keynesiano padrão com fricções financeiras em comparação com um modelo sem este tipo de fricção.

Em relação aos parâmetros, eles pouco se alteraram de uma estimação para outra. As principais diferenças ficam por conta da redução da persistência do choque tecnológico, que passa de 0,75 para 0,67, mas o seu desvio-padrão permance praticamente inalterado. O choque específico no investimento se torna menos persistente (de 0,69 para 0,60$)$ e menos volátil, com o desvio-padrão passando de 9,46 para 5,9. Por fim, o termo de suavização da taxa de juros na regra de Taylor se reduz, passando de 0,41 para 0,32 na média da posterior, mas o choque na taxa de juros doméstica se torna mais volátil, passando de 3,15 para 3,61. Observando a decomposição da variância do errro de previsão na tabela 3 , constata-se que o choque no prêmio de risco ganha importância na explicação das variáveis endógenas quando o prêmio de financiamento externo é retirado do modelo, passando a ser o choque de maior relevância.

Diante da maior importância do choque no prêmio de risco na ausência do prêmio de financiamento externo, a interpretação natural é que o modelo acaba compensando a ausência de um tipo de fricção financeira por outra, indicando que o choque no prêmio de risco pode ser interpretado como uma "forma reduzida" das fricções financeiras. Do ponto de vista da estrutura do modelo, os choques no prêmio de risco atuam ampliando a diferença entre a taxa de juros doméstica e a taxa de juros externa. Quando o prêmio de financiamento externo é zerado, os empreendedores se deparam com uma taxa de juros igual à fixada pela autoridade monetária, e independe do seu grau de alavancagem.

Especificamente em relação ao produto, quando o prêmio de financiamento externo é contemplado no modelo os choques de política monetária explicam cerca de $31 \%$ da sua variância, enquanto que quando o modelo é estimado sem prêmio de financiamento, a contribuição dos choques de política monetária se reduz para cerca de $1,6 \%$, ao passo que os choques no prêmio de risco passam a explicar cerca de $45 \%$ da variância do produto, ante $31 \%$ quando o prêmio de financiamento externo é inserido no modelo.

Para o investimento os resultados vão no mesmo sentido. Quando o modelo contempla o prêmio de financiamento externo, o choque na taxa de juros doméstica explica quase $60 \%$ da variância do investimento. No modelo estimado sem prêmio, o papel da política monetária doméstica se reduz para $1,36 \%$. Por outro lado, os choques no prêmio de risco passam a explicar $63 \%$ da variância do investimento, contra $27 \%$ quando o modelo foi estimado considerando o prêmio de financiamento.

A conclusão é que o prêmio de financiamento externo aumenta a potência dos choques na taxa de juros doméstica. Graficamente, isto pode ser ilustrado pelas funções de resposta ao impulso de um choque de política monetária, com e sem a presença do prêmio de financiamento externo. A figura 14 apresenta uma comparação das respostas a um choque de política monetária nestas circunstâncias. O produto e o investimento recuam em maior magnitude sob a presença do acelerador financeiro. 
Este maior efeito sobre as variáveis reais também foi documentado por López et al. (2008) para a Colômbia. A inflação também recua um pouco mais, embora graficamente a resposta seja quase igual.

Figura 3.2: $\quad$ Priors e posteriors-1

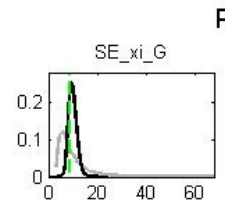
Priors and posteriors
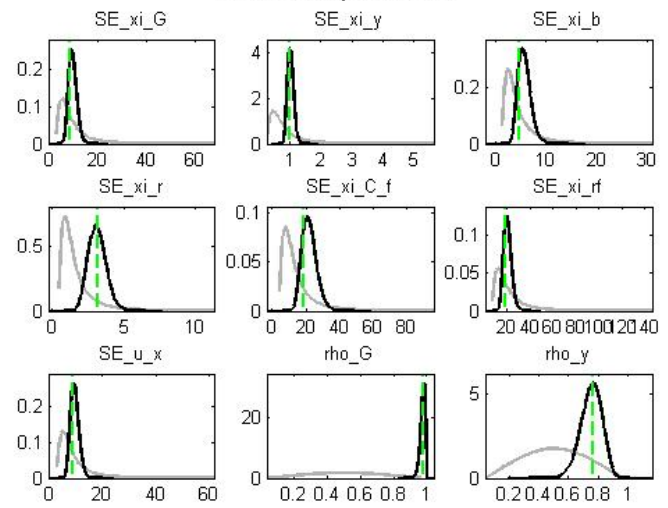

1a linha: desvio-padrão do choque nos gastos do governo, na produtividade, no prêmio de risco 2a linha: desvio-padrão do choque na taxa de juros doméstica, na demanda externa e na taxa de juros mundial

3a linha: desvio-padrão do choque específico no investimento, persistência do choque nos gastos do governo, persistência do choque da produtividade 
Figura 3.3: $\quad$ Priors e posteriors - 2

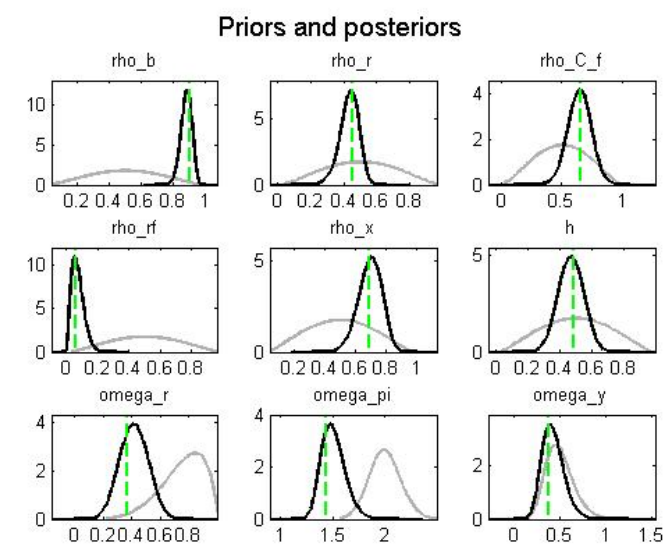

1a linha: persistência do choque no prêmio de risco, na taxa de juros e na demanda externa 2a linha: persistência do choque nos juros mundiais, persistência do choque especifico no investimento e hábito no consumo

3a linha: suavização da taxa de juros, peso da inflação na regra de Taylor, peso do produto na regra de Taylor

\subsubsection{Decomposição da variância}

Curiosamente, a decomposição da variância na média da posterior indica que os choques de produtividade não têm maior importância na explicação do produto.

Esta falta de importância de choques de produtividade no modelo decorre da presença de outros relacionados à variáveis financeiras (choque no prêmio de risco e na taxa de juros externa) e também em função da presença de choques no gastos do governo e choques específicos no investimento.

Somente quando o modelo foi simulado sem a presença de choques financeiros (zerando-se o parâmetro associado ao prêmio de financiamento externo e os choques no prêmio de risco), e com um baixo grau de rigidez nominal -fixando-se os parâmetros de Calvo em 0.01-, o choque de produtividade se mostrou mostrou de maior relevância para explicar o produto, 18\%. A interação da rigidez nominal com o bloco financeiro é fundamental para este resultado. Mesmo com flexibilidade de preços, a presença do acelerador financeiro faz com que os choques monetários tenham grande relevância no modelo, ie, quando o modelo foi simulado com preços flexíveis mas com o acelerador financeiro positivo, os choques na taxa de juros doméstica explicam $66 \%$ do produto, contra $7 \%$ do choque tecnológico.

Desta forma, os resultados indicam que choques de produtividade perdem relevância quando choques de origem no setor financeiro são incorporados em um modelo mais complexo, em que ao invés de apenas 1 bem comercializável (como no capítulo 2), a economia transaciona o bem doméstico comercializável e o bem externo importado, e com presença de rigidez nominal. Esta aumenta o poder dos choques monetários, 
Figura 3.4: $\quad$ Priors e posteriors - 3

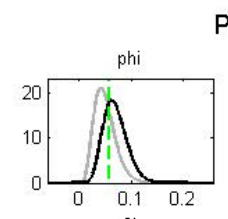

Priors and posteriors
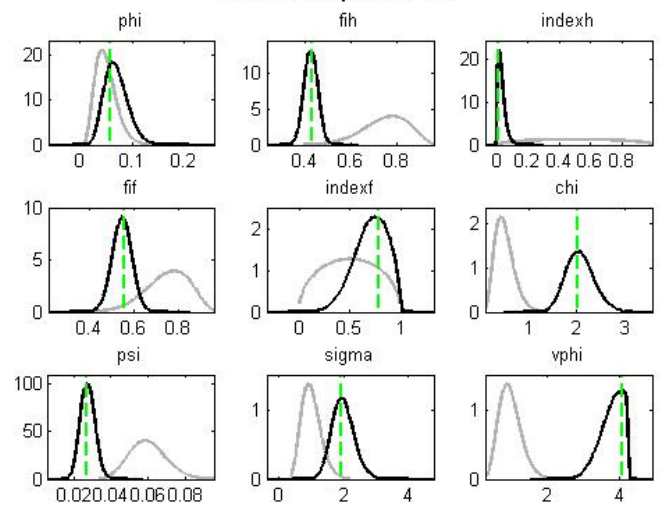

1a linha: elasticidade do prêmio de risco à dívida, Calvo da inflação dos bens domésticos, indexação da inflação doméstica

2a linha: Calvo da inflação dos bens importados, indexação da inflação dos bens importados, custo de ajustamento do capital

3a linha: elasticidade do prêmio de financiamento externo em relação à alavancagem, parâmetro da aversão ao risco e inverso da elasticidade da oferta de trabalho

Figura 3.5: $\quad$ Priors e posteriors -4

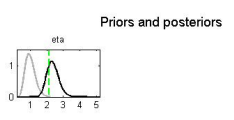

1a linha: elasticidades do consumo

mas não é fundamental para os resultados obtidos, como exemplificado acima.

Um resultado que emerge da decomposição da variância é que o prêmio de financiamento externo no modelo é basicamente explicado por choques na taxa de juros doméstica (84\%). Este resultado se constrasta com os obtidos por De Graeve (2008) para os Estados Unidos, que encontrou que os choques específicos no investimento são os principais determinantes do prêmio de financiamento externo naquele país, respondendo por $90 \%$ de sua variabilidade no longo prazo, embora os choques de política monetária também desempenhem um papel relevante no curto prazo. Desta forma, o modelo em consideração nesta seção atribui um papel fundamental para a política monetária na evolução do prêmio de financiamento externo, como pode ser observado na decomposição histórica apresentada na última figura do apêndice. 


\subsubsection{Funções de impulso resposta}

Figura 3.6: Choque de produtividade Orthogonalized shock to xi_y
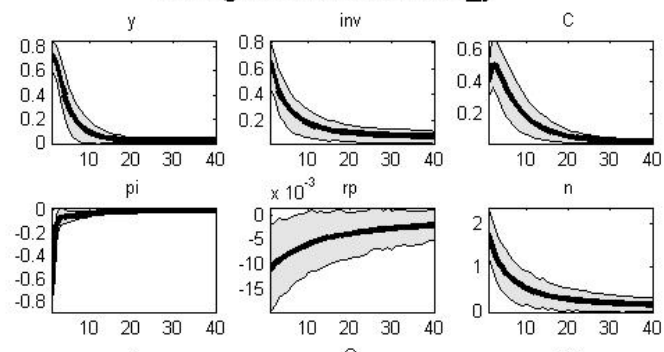

n
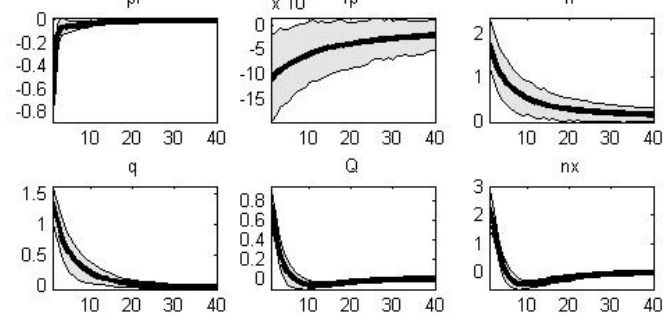

1a linha: resposta do produto, investimento e consumo

2a linha: resposta da inflação, do prêmio de financiamento externo e do patrimônio líquido 3a linha: resposta do preço do capital, do câmbio real e das exportações líquidas

Um choque na produtividade aumenta o produto, o consumo, o investimento e as exportações líquidas. A inflação se reduz, o que ajuda a depreciar o câmbio real. 
Figura 3.7: Choque na taxa de juros mundial

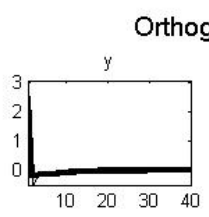

Orthogonalized shock to xi_rf
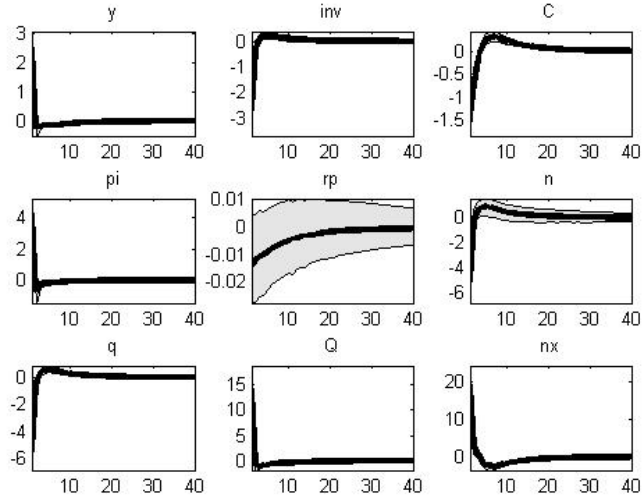

1a linha: resposta do produto, investimento e consumo

2a linha: resposta da inflação, do prêmio de financiamento externo e do patrimônio líquido 3a linha: resposta do preço do capital, do câmbio real e das exportações líquidas

Um choque na taxa de juros externa desvaloriza a taxa de câmbio real, que provoca um aumento das exportações líquidas. Em função disto, o produto acaba se elevando, embora o consumo e o investimento se deprimam.

\subsection{Conclusão}

A principal contribuição desta seção foi estimar um modelo de economia aberta com friç̧ões financeiras para o Brasil.

Os resultados indicam que, no âmbito de uma estrutura mais rica para representar a economia, os choques de produtividade perdem relevância para explicar o produto, em comparação com choques com origem no setor financeiro (prêmio de risco, taxa de juros externa) e outros (choques específicos no investimento e de gastos do governo).

Os choques específicos no investimento também não são de grande relevância no contexto dos demais, contribuindo para explicar de 8 a $16 \%$ da variância do investimento, em contraposição aos resultados encontrados por Araújo (2012) em um modelo RBC simples e com menos choques.

Os choques na inflação mundial e na demanda externa não se mostraram de maior relevância no contexto do modelo utilizado nesta seção, resultado em linha com Silva (2008) mas diferente do obtido por Teles e Mendonça (2013), que enfatizam o papel dos termos de troca após a crise de 2008 no âmbito de um modelo RBC de economia aberta.

Tendo em vista a significância do prêmio de financiamento externo nas estimações, conclui-se pela importância das fricções financeiras na economia brasileira. Mesmo quando o prêmio de financiamento externo não foi considerado no modelo, fixandose $\psi=0$, choques de origem financeira (prêmio de risco e taxa de juros externa) se 
Figura 3.8: Choque na taxa de juros doméstica

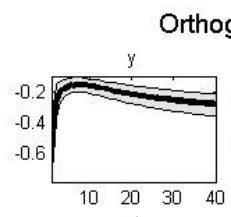

Orthogonalized shock to $x i \_r$
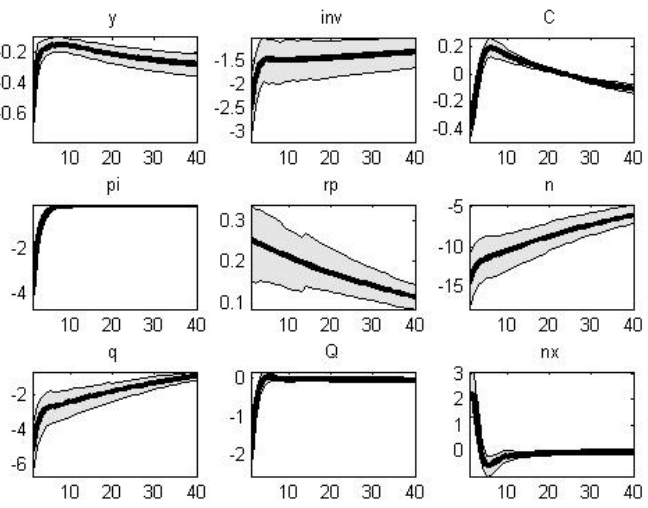

1a linha: resposta do produto, investimento e consumo

2a linha: resposta da inflação, do prêmio de financiamento externo e do patrimônio líquido

3a linha: resposta do preço do capital, do câmbio real e das exportações líquidas

Um choque na taxa de juros doméstica tem como efeitos a redução do produto, do investimento e do consumo. A inflação também se reduz. A taxa de câmbio real se valoriza. Mesmo assim, as exportações líquidas aumentam, refletindo seu caráter contra-ciclico.

mostraram de grande importância nas estimações.

Tendo em vista que a decomposição da variância apontou para choques no prêmio de risco e nos juros externos como os principais determinantes do câmbio real, concluise que a interação da taxa de câmbio com fatores financeiros desempenha um papel fundamental nos resultados obtidos.

Obteve-se evidências de que o prêmio de financiamento externo atua ampliando os efeitos da política monetária sobre o produto e o investimento, conforme observado pela comparação entre a decomposição da variância do modelo estimado com e sem prêmio de financiamento externo.

A despeito da significância do prêmio de financiamento externo no modelo estimado, a comparação da verossimilhança marginal mostrou que o modelo sem o acelerador financeiro logra obter um valor marginalmente maior da verossimilhança marginal, indicando um melhor ajuste aos dados. 
Figura 3.9: $\quad$ Choque na inflação mundial

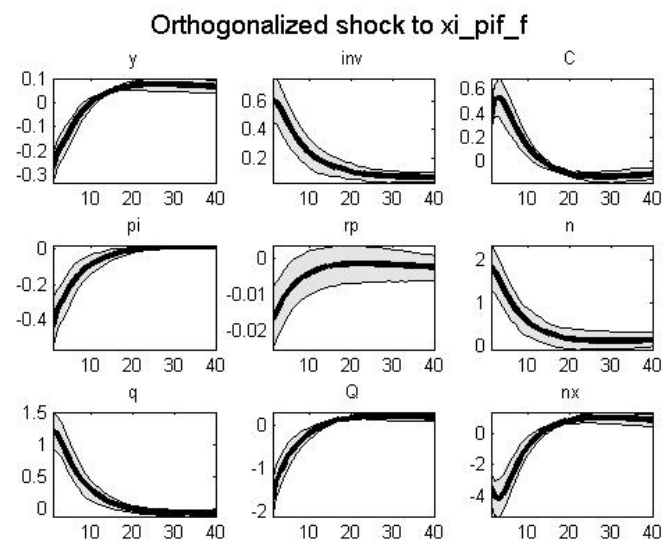

1a linha: resposta do produto, investimento e consumo

2a linha: resposta da inflação, do prêmio de financiamento externo e do patrimônio líquido 3a linha: resposta do preço do capital, do câmbio real e das exportações líquidas O choque provoca uma valorização da taxa de câmbio real BRL/USD, provocando uma queda na inflação via os bens importados e uma queda nas exportações líquidas. Muito embora o consumo e o investimento se elevem, o efeito nas exportações líquidas prevalece, provocando uma queda do produto.

Figura 3.10: Choque nos gastos do governo
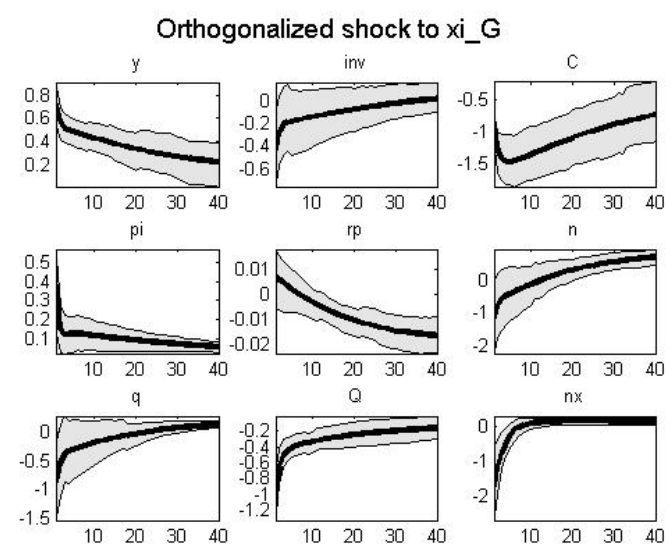

1a linha: resposta do produto, investimento e consumo

2a linha: resposta da inflação, do prêmio de financiamento externo e do patrimônio líquido

3a linha: resposta do preço do capital, do câmbio real e das exportações líquidas

O choque nos gastos do governo aumenta o produto,mas reduz o consumo e o investimento no curto prazo. A inflação também se eleva, contribuindo para a valorização do câmbio real BRL/USD. 
Tabela 3.1: $\quad$ Valores calibrados

\begin{tabular}{|c|c|c|c|}
\hline Parâmetro & Descrição & Valor & Justificativa/Fonte \\
\hline $\bar{\delta}$ & Depreciação & 0.025 & $\begin{array}{c}10 \% \text { a.a. , valor } \\
\text { consensual na } \\
\text { literatura }\end{array}$ \\
\hline$\beta$ & Fator de desconto & 0.985 & $\begin{array}{c}\text { Silva Júnior e Divino } \\
(2013)\end{array}$ \\
\hline$S$ & $\begin{array}{c}\text { Prêmio de } \\
\text { financiamento } \\
\text { externo de estado } \\
\text { estacionário, bruto }\end{array}$ & 1.0080 & $\begin{array}{c}\text { No relatório de } \\
\text { estabilidade } \\
\text { financeira do BC de } \\
\text { set11, pág.38, o } \\
\text { spread da taxa } \\
\text { preferencial do Brasil } \\
\text { em relação à Selic } \\
\text { para o período entre } \\
2005 \text { e } 2011 \text { foi de } \\
3,2 \% \text { a.a. }\end{array}$ \\
\hline$\nu$ & $\begin{array}{c}\text { Taxa de } \\
\text { sobrevivência dos } \\
\text { empreendedores }\end{array}$ & 0.9762 & $\begin{array}{l}\text { Silva Júnior e Divino } \\
(2013)\end{array}$ \\
\hline $\mathrm{k} \_\mathrm{n}$ & $\begin{array}{c}\text { Relação } \\
\text { capital/patrimônio } \\
\text { líquido em estado } \\
\text { estacionário }\end{array}$ & 2 & $\begin{array}{l}\text { Bernanke et al. } \\
\text { (1999) }\end{array}$ \\
\hline$\gamma_{c}$ & $\begin{array}{l}\text { Participação das } \\
\text { importações no } \\
\text { consumo }\end{array}$ & $17 \%$ & $\begin{array}{l}\text { Bens de consumo } \\
\text { representam cerca de } \\
17 \% \text { das importações. }\end{array}$ \\
\hline$C_{H} / Y$ & $\begin{array}{c}\text { Participação do } \\
\text { consumo de bens } \\
\text { domésticos no PIB }\end{array}$ & $62 \%$ & Castro et al. (2011) \\
\hline$I / Y$ & $\begin{array}{l}\text { Participação do } \\
\text { investimento no } \\
\text { PIB }\end{array}$ & $17 \%$ & Castro et al. (2011) \\
\hline$G / Y$ & $\begin{array}{l}\text { Participação dos } \\
\text { gastos do governo } \\
\text { no PIB }\end{array}$ & $20 \%$ & Castro et al. (2011) \\
\hline$\frac{C_{H}^{f}}{Y}$ & $\begin{array}{l}\text { Participação das } \\
\text { exportações no } \\
\text { PIB }\end{array}$ & $13 \%$ & Castro et al. (2011) \\
\hline$Q C_{F}$ & $\begin{array}{l}\text { Participação das } \\
\text { importações no } \\
\text { PIB }\end{array}$ & $12 \%$ & Castro et al. (2011) \\
\hline
\end{tabular}


Tabela 3.2: $\quad$ Resultado da estimação

\begin{tabular}{|c|c|c|c|c|c|c|}
\hline Parâmetro & Descrição & Média da prior & Desvio-padrão & Distribuição & $\begin{array}{l}\text { Média da } \\
\text { posterior - } \\
\text { Modelo com } \\
\text { friç̧ões } \\
\text { financeiras }\end{array}$ & $\begin{array}{l}\text { Média da } \\
\text { posterior - } \\
\text { Modelo sem } \\
\text { fricções } \\
\text { financeiras } \\
(p s i=0)\end{array}$ \\
\hline$\rho_{g}$ & governo & 0.500 & 0.2000 & beta & 0.9745 & 0.9645 \\
\hline$\rho_{y}$ & produtividade & 0.500 & 0.2000 & beta & 0.7528 & 0.6724 \\
\hline$\rho_{b}$ & prêmio risco & 0.500 & 0.2000 & beta & 0.8823 & 0.8800 \\
\hline$\rho_{r}$ & juros domésticos & 0.500 & 0.2000 & beta & 0.4305 & 0.4533 \\
\hline$\rho_{C_{f}}$ & demanda externa & 0.500 & 0.2000 & beta & 0.6420 & 0.6303 \\
\hline$\rho_{r f}$ & juros externos & 0.500 & 0.2000 & beta & 0.0714 & 0.0697 \\
\hline$\rho_{x}$ & específico investimento & 0.500 & 0.2000 & beta & 0.6959 & 0.6030 \\
\hline $\mathrm{h}$ & hábito & 0.500 & 0.2000 & beta & 0.4681 & 0.4627 \\
\hline$\omega_{r}$ & suavização & 0.750 & 0.1500 & beta & 0.4137 & 0.3257 \\
\hline$\varpi_{\pi}$ & peso inflação & 2.000 & 0.1500 & gamma & 1.5043 & 1.4816 \\
\hline$\varpi_{y}$ & peso produto & 0.500 & 0.1500 & gamma & 0.4262 & 0.4078 \\
\hline$\phi$ & elasticidade prêmio de risco & 0.050 & 0.0200 & beta & 0.0692 & 0.0697 \\
\hline$\phi^{h}$ & Calvo inflação dom & 0.750 & 0.1000 & beta & 0.4238 & 0.4345 \\
\hline$\gamma^{h}$ & indexação dom & 0.500 & 0.2500 & beta & 0.0311 & 0.0274 \\
\hline$\phi^{f}$ & Calvo inflação ext & 0.750 & 0.1000 & beta & 0.5436 & 0.5573 \\
\hline$\gamma^{f}$ & indexação ext & 0.500 & 0.2500 & beta & 0.7041 & 0.7171 \\
\hline$\chi$ & ajustamento capital & 0.500 & 0.2000 & gamma & 2.0621 & 1.5564 \\
\hline$\psi$ & prêmio financiamento ext & 0.060 & 0.0100 & gamma & 0.0274 & 0 \\
\hline$\sigma$ & inv elast subst & 1.000 & 0.3000 & gamma & 1.9800 & 1.9915 \\
\hline$\varphi$ & inv elast trab & 1.000 & 0.3000 & gamma & 3.7610 & 3.7788 \\
\hline$\eta$ & elasticidade cons & 1.000 & 0.3000 & gamma & 2.3610 & 2.3357 \\
\hline xi_G & dp governo & 12.000 & $\operatorname{Inf}$ & invg & 9.8533 & 9.5623 \\
\hline $\mathrm{xi} \_\mathrm{y}$ & dp produtividade & 1.000 & $\operatorname{Inf}$ & invg & 1.0245 & 0.9850 \\
\hline xi_b & dp prêmio risco & 5.500 & $\operatorname{Inf}$ & invg & 5.7620 & 5.8497 \\
\hline$x i \_r$ & dp juros domésticos & 2.000 & $\operatorname{Inf}$ & invg & 3.1570 & 3.6142 \\
\hline$x i \_C \_f$ & dp demanda externa & 17.000 & $\operatorname{Inf}$ & invg & 21.9430 & 21.3626 \\
\hline xi_rf & dp juros externos & 26.000 & $\operatorname{Inf}$ & invg & 20.1373 & 20.0995 \\
\hline $\mathrm{u} \_\mathrm{x}$ & dp específico investimento & 11.000 & $\operatorname{Inf}$ & invg & 9.4661 & 5.9776 \\
\hline Verossimilhança marginal & & & & & -1050.96 & -1029.08 \\
\hline
\end{tabular}


Tabela 3.3: Decomposição da variância

\begin{tabular}{|c|c|c|c|c|c|c|c|c|c|}
\hline \multicolumn{10}{|c|}{ Modelo com fricções financeiras } \\
\hline & Descrição & $x i \_y$ & xi_C_f & $\mathrm{xi} \_\mathrm{r}$ & xi_rf & xi_b & xi_pif_f & xi_G & $\mathrm{u} \_\mathrm{x}$ \\
\hline & & Produtividade & $\begin{array}{l}\text { Demanda } \\
\text { externa }\end{array}$ & $\begin{array}{l}\text { Juros do- } \\
\text { mésticos }\end{array}$ & $\begin{array}{c}\text { Juros } \\
\text { externos }\end{array}$ & $\begin{array}{l}\text { Prêmio } \\
\text { de risco }\end{array}$ & $\begin{array}{l}\text { Inflação } \\
\text { externa }\end{array}$ & $\begin{array}{c}\text { Gasto } \\
\text { do } \\
\text { governo }\end{array}$ & $\begin{array}{c}\text { Específico } \\
\text { no investi- } \\
\text { mento }\end{array}$ \\
\hline $\mathrm{y}$ & Produto & 3.36 & 1.07 & 31.64 & 13.43 & 31.44 & 0.94 & 12.53 & 5.61 \\
\hline inv & Investimento & 0.53 & 0.21 & 59.51 & 2.00 & 27.55 & 0.71 & 0.58 & 8.92 \\
\hline $\mathrm{C}$ & Consumo & 1.04 & 0.62 & 6.07 & 2.52 & 43.79 & 1.34 & 42.69 & 1.91 \\
\hline pi & Inflação & 0.69 & 1.96 & 24.95 & 23.62 & 47.09 & 0.70 & 0.75 & 0.24 \\
\hline $\mathrm{rp}$ & $\begin{array}{l}\text { Prêmio de fi- } \\
\text { nanciamento }\end{array}$ & 0.07 & 0.02 & 84.88 & 0.04 & 7.83 & 0.11 & 1.62 & 5.43 \\
\hline $\mathrm{n}$ & $\begin{array}{c}\text { Patrimônio } \\
\text { líquido }\end{array}$ & 0.25 & 0.07 & 77.91 & 0.58 & 16.02 & 0.35 & 1.11 & 3.70 \\
\hline $\mathrm{q}$ & $\begin{array}{l}\text { Preço do } \\
\text { capital }\end{array}$ & 0.84 & 0.56 & 32.34 & 5.50 & 47.37 & 1.10 & 0.67 & 11.63 \\
\hline $\mathrm{Q}$ & Câmbio real & 0.15 & 4.48 & 0.86 & 33.05 & 59.30 & 1.35 & 0.70 & 0.10 \\
\hline $\mathrm{nx}$ & $\begin{array}{c}\text { Exportações } \\
\text { líquidas }\end{array}$ & 0.24 & 4.75 & 0.24 & 9.76 & 82.27 & 2.51 & 0.13 & 0.11 \\
\hline \multicolumn{10}{|c|}{ Modelo sem fricções financeiras $(p s i=0)$} \\
\hline & & $\mathrm{xi} \_\mathrm{y}$ & $\mathrm{xi} \_\mathrm{C} \_f$ & $\mathrm{xi} \_\mathrm{r}$ & xi_rf & xi_b & xi_pif_f & xi_G & $\mathrm{u} \_\mathrm{x}$ \\
\hline $\mathrm{y}$ & Produto & 4.63 & 2.01 & 1.63 & 24.78 & 45.87 & 1.47 & 13.80 & 5.80 \\
\hline inv & Investimento & 0.85 & 0.91 & 1.36 & 8.24 & 63.45 & 1.72 & 6.70 & 16.77 \\
\hline $\mathrm{C}$ & Consumo & 0.79 & 0.76 & 0.53 & 3.07 & 54.18 & 1.70 & 37.94 & 1.02 \\
\hline $\mathrm{pi}$ & Inflação & 0.62 & 1.84 & 26.31 & 20.78 & 48.69 & 0.72 & 0.87 & 0.17 \\
\hline $\mathrm{n}$ & $\begin{array}{c}\text { Patrimônio } \\
\text { Líquido }\end{array}$ & 0.03 & 0.04 & 79.75 & 0.11 & 13.56 & 0.21 & 4.87 & 1.43 \\
\hline q & Preço capital & 0.88 & 1.14 & 1.73 & 10.83 & 78.06 & 1.81 & 2.90 & 2.65 \\
\hline $\mathrm{Q}$ & Câmbio real & 0.13 & 4.02 & 1.02 & 32.65 & 60.24 & 1.36 & 0.53 & 0.06 \\
\hline $\mathrm{nx}$ & $\begin{array}{c}\text { Exportações } \\
\text { líquidas }\end{array}$ & 0.20 & 4.73 & 0.25 & 9.63 & 82.47 & 2.51 & 0.15 & 0.06 \\
\hline
\end{tabular}


Figura 3.11: Choque na demanda externa

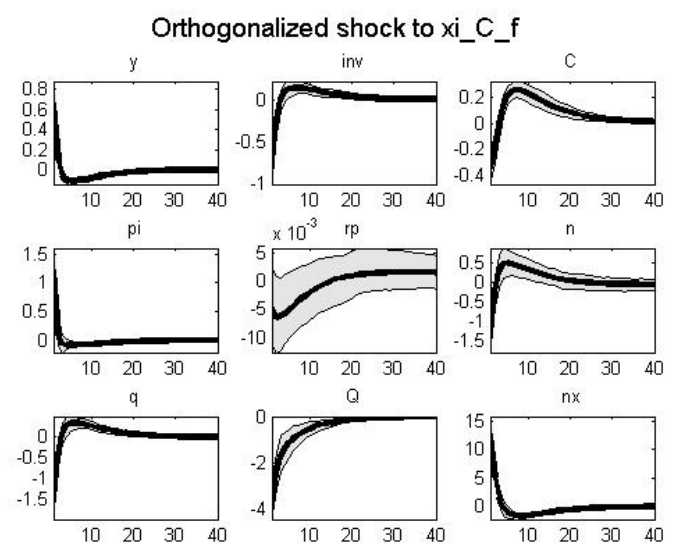

1a linha: resposta do produto, investimento e consumo

2a linha: resposta da inflação, do prêmio de financiamento externo e do patrimônio líquido

3a linha: resposta do preço do capital, do câmbio real e das exportações líquidas

Um choque positivo na demanda externa pelo bem doméstico tem como consequências uma elevação do produto, em decorrência do aumento das exportações líquidas. O aumento da inflação contribui para a valorização da taxa de câmbio real BRL/USD. O investimento é afetado negativamente no curto prazo.

Figura 3.12: $\quad$ Choque no prêmio de risco
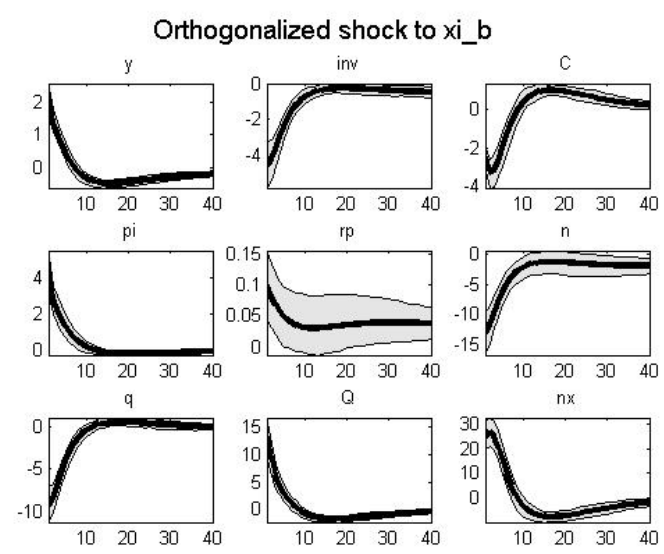

1a linha: resposta do produto, investimento e consumo

2a linha: resposta da inflação, do prêmio de financiamento externo e do patrimônio líquido

3a linha: resposta do preço do capital, do câmbio real e das exportações líquidas

O choque no prêmio de risco tem como efeitos a desvalorização da taxa de câmbio real BRL/USD. A inflação se eleva, em decorrência dos bens importados. O efeito na taxa de câmbio acaba aumentando as exportações líquidas no curto prazo, e por sua vez o produto. O consumo e o investimento são afetados negativamente após a incidência do choque. 
Figura 3.13: Choque específico no investimento

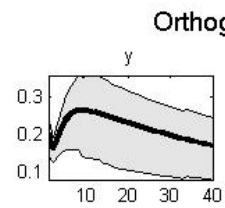
Orthogonalized shock to $u_{-} \mathrm{x}$
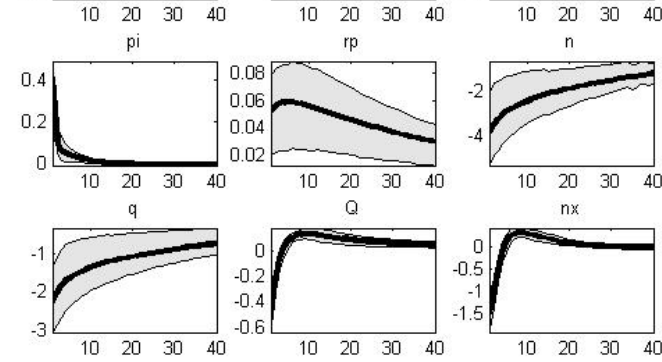

1a linha: resposta do produto, investimento e consumo

2a linha: resposta da inflação, do prêmio de financiamento externo e do patrimônio líquido 3a linha: resposta do preço do capital, do câmbio real e das exportações líquidas Após um choque específico no investimento, o investimento se eleva, assim como o produto, contudo em menor escala.

Figura 3.14: $\quad$ Funções de resposta ao impulso após um choque na taxa de juros, com e sem prêmio de financiamento externo
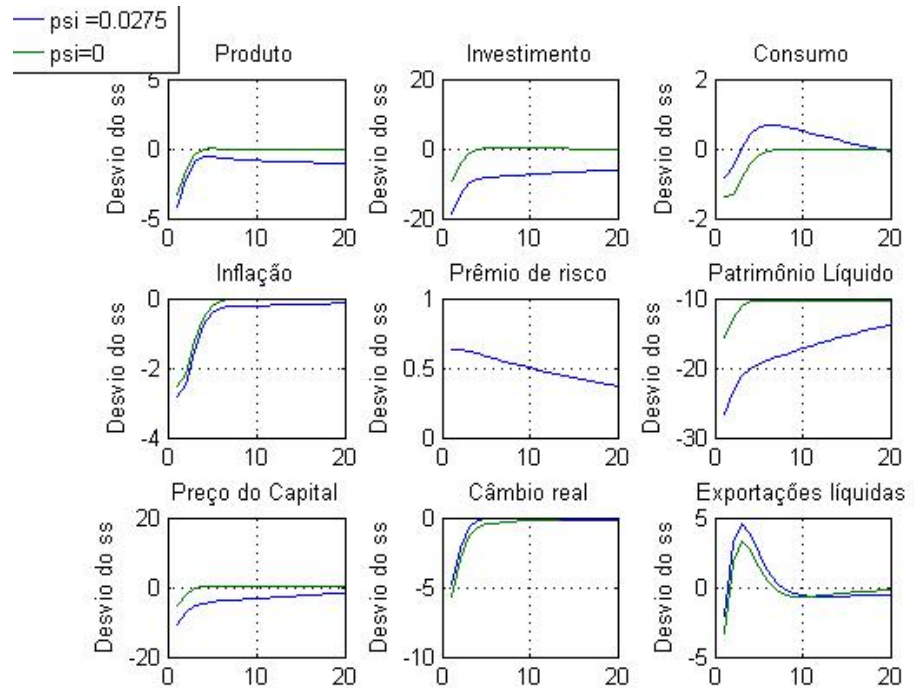
Figura 3.15: $\quad$ Identificação

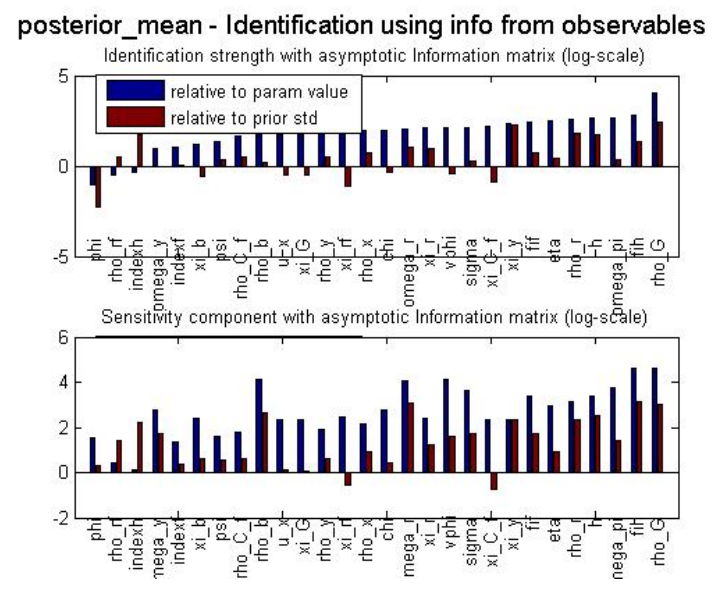

Figura 3.16: Convergência
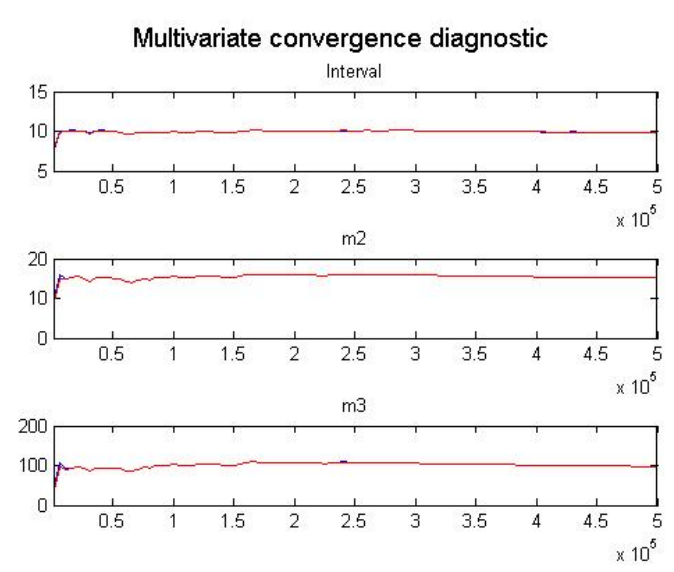


\section{Referências Bibliográficas}

[1] Alendal, L.A. (2008). Estimating the New Keynesian Phillips Curve in an Open Economy DSGE Framework. Dissertação de mestrado. Departamento de Economia da Universidade de Oslo. Link:https://www.duo.uio.no/handle/10852/17510 Acesso em 24 de agosto de 2014 .

[2] Araújo, E. (2012), 'Investment-specific shocks and real business cycles in emerging economies: Evidence from brazil', Economic Modelling 29(3), 671-678.

[3] Bernanke, Ben S. \& Gertler, Mark \& Gilchrist, Simon, 1999. "The financial accelerator in a quantitative business cycle framework, "Handbook of Macroeconomics, in: J. B. Taylor \& M. Woodford (ed.), Handbook of Macroeconomics, edition 1, volume 1, chapter 21, pages 1341-1393 Elsevier.

[4] Bernanke, Ben \& Gertler, Mark, 1989. "Agency Costs, Net Worth, and Business Fluctuations," American Economic Review, American Economic Association, vol. 79(1), pages 14-31, March.

[5] Chang, Roberto \& Andrés Fernández, 2013. "On The Sources Of Aggregate Fluctuations In Emerging Economies," International Economic Review, vol. 54, pages 1265-1293, November.

[6] Christensen, Ian \& Dib, Ali. 2008. "The Financial Accelerator in an Estimated New Keynesian Model," Review of Economic Dynamics, Elsevier for the Society for Economic Dynamics, vol. 11(1), pages 155-178, January.

[7] Christiano, L., Motto, R. \& Rostagno, M. (2010), Financial factors in economic fluctuations, Working Paper Series 1192, European Central Bank.

[8] De Graeve, F. (2008). The External Finance Premium and the Macroeconomy: U.S. Post-WWII Evidence. Journal of Economic Dynamics and Control, 32:3415-3440.

[9] Fernández, Andrés. 2010. "”Tropical” Real Business Cycles? A Bayesian Exploration." Ensayos sobre Política Económica, 28(61): 60-105.

[10] Fernández, Andrés \& Gulan, Adam, 2012. "Interest rates and business cycles in emerging economies: The role of financial frictions," Research Discussion Papers 23/2012, Bank of Finland.

[11] Freystatter, Hanna, 2012. "Essays on small open economy macroeoconomics". Manuscrito. 
[12] Furlani, L.G., 2008. "Flutuações cambiais e política monetária no Brasil: Evidências econométricas e de simulação. Dissertação de mestrado. UFRGS.

[13] Garcíla-Cicco, Javier, Roberto Pancrazi, and Martín Uribe. 2010. "Real Business Cycles in Emerging Countries?" American Economic Review, 100(5): $2510-31$.

[14] Gertler, Mark \& Gilchrist, Simon \& Natalucci, Fabio M. 2007. "External Constraints on Monetary Policy and the Financial Accelerator,"Journal of Money, Credit and Banking, Blackwell Publishing, vol. 39(2-3), pages 295-330, 03.

[15] Kanczuk, Fabio. (2013). Um Termômetro para as Macro-Prudenciais. Revista Brasileira de Economia, 67(4), 497-512.

[16] López , Martha R. \& Prada, Juan D. \& Rodríguez N., (2008) . "Financial Accelerator Mechanism in a Small Open Economy," Borradores de Economia 525, Banco de la Republica de Colombia.

[17] Neumeyer, Pablo A. \& Perri, Fabrizio, 2005. "Business cycles in emerging economies: the role of interet rates," Journal of Monetary Economics, Elsevier, vol. 52(2), pages 345-380, March.

[18] Ratto, Marco. (2011) Identification Analysis of DSGE models with Dynare. Disponível em: https://www.ifkcfs.de/fileadmin/downloads/events/conferences/monfispol2011/RATTO_IdentifFinal.pdfAce em 18 de julho de 2014 .

[19] Silva, Marcelo E. A. (2008) Accounting for Business Cycles in Emerging Market Economies. Manuscrito. Disponível em: http://www.unc.edu/ measilva/Paper_Marcelo_Silva_web.pdfAcesso em 4 de julho de 2014

[20] Silva Junior, Rogério Lúcio, \& Divino, José Angelo. (2013). Prêmio de risco e a política monetária no Brasil. Economia Aplicada, 17(2), 163-192.

[21] Teles, Vladimir K., \& Mendonça, Diogo de Prince. (2013). Política monetária em tempos de crise. Revista Brasileira de Economia, 67(4), 529-548.

\subsection{Apêndice}

Apresenta-se a decomposição histórica das principais variáveis do modelo. Adicionalmente, apresenta-se uma compilação das estimações do grau de rigidez de preços e salários obtidos em estudos anteriores para o Brasil. 
Figura 3.17: $\quad$ Decomposição histórica do produto Shock decomposition: $y$

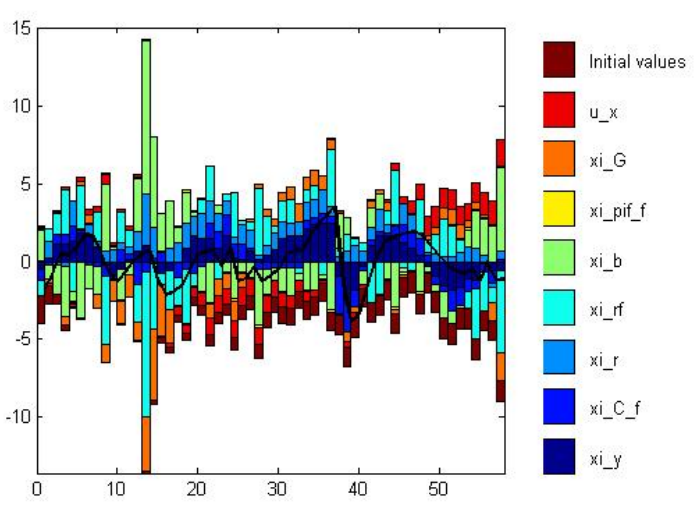

Figura 3.18: Decomposição histórica do consumo Shock decomposition: $\mathrm{C}$

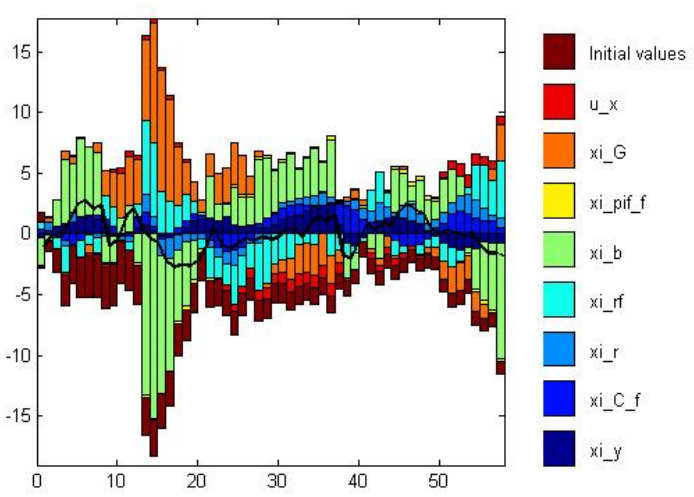


Figura 3.19: Decomposição histórica do investimento

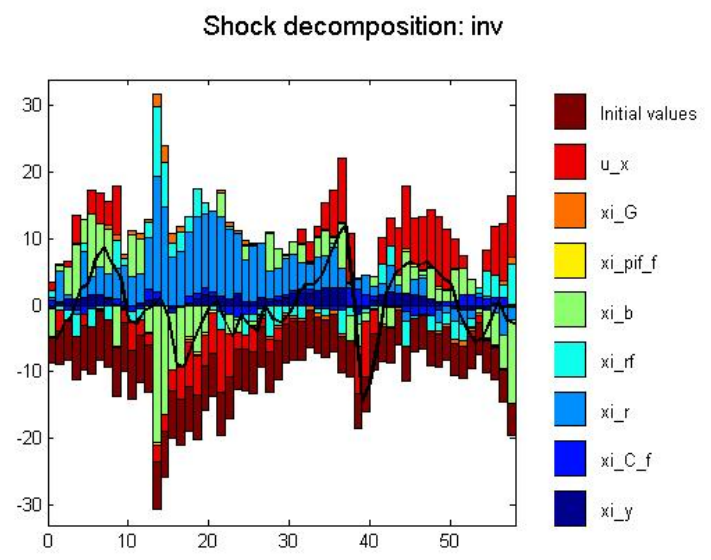

Figura 3.20: Decomposição histórica das exportações líquidas Shock decomposition: $\mathrm{nx}$

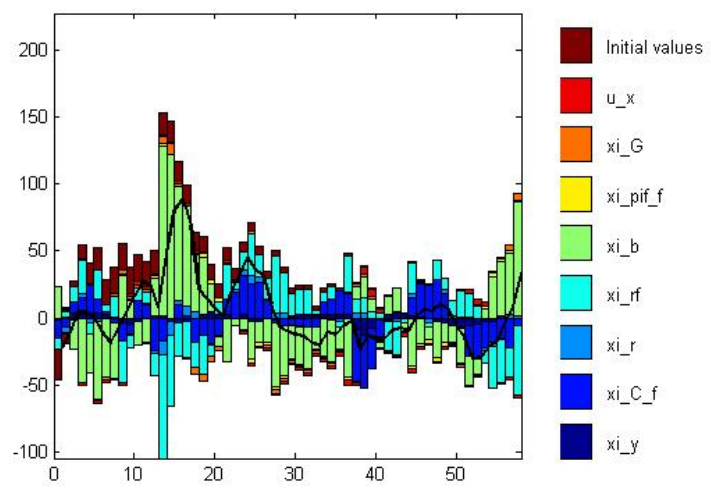

Figura 3.21: $\quad$ Decomposição histórica da inflação

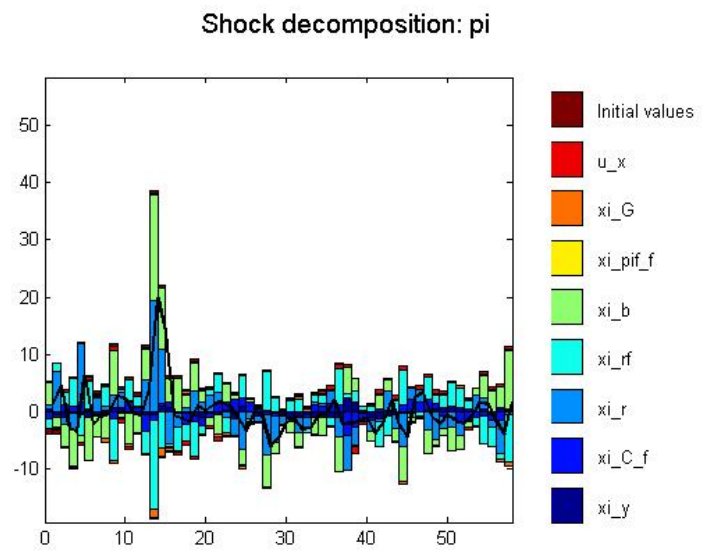


Figura 3.22: $\quad$ Decomposição histórica do prêmio de financiamento externo Shock decomposition: rp

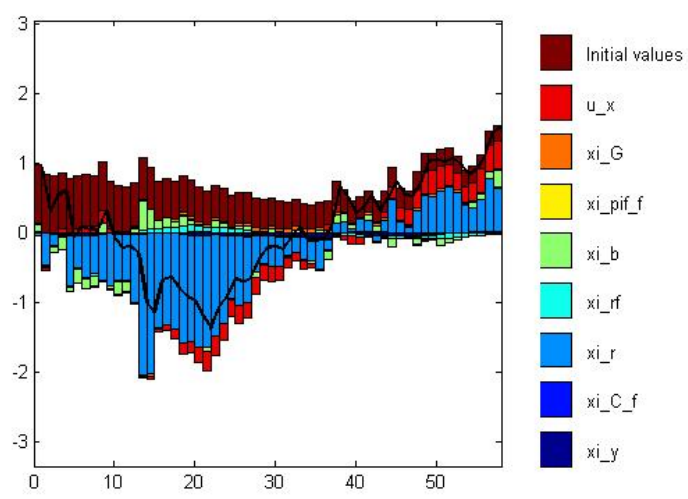

Tabela 3.4: $\quad$ Estimações da rigidez de preços e salários para o Brasil

\begin{tabular}{|c|c|c|c|c|c|c|}
\hline Estudo & $\begin{array}{l}\text { Rigidez } \\
\text { de } \\
\text { preços }\end{array}$ & $\begin{array}{l}\text { Indexação } \\
\text { de } \\
\text { preços }\end{array}$ & $\begin{array}{l}\text { Rigidez } \\
\text { de } \\
\text { salários }\end{array}$ & $\begin{array}{l}\text { Indexação } \\
\text { de } \\
\text { salários }\end{array}$ & Séries & Período \\
\hline $\begin{array}{c}\text { Vasconcelos } \\
\text { e Divino } \\
\text { (2012) }\end{array}$ & 0,63 & 0,23 & 0,32 & 0,51 & $\begin{array}{c}\text { Produto, Consumo, } \\
\text { Investimento, População } \\
\text { empregada da RMSP, } \\
\text { Salário Médio da RMSP, } \\
\text { Selic e IPCA }\end{array}$ & 2000Q1-2009Q4 \\
\hline $\begin{array}{c}\text { Castro et al. } \\
\quad(2011)\end{array}$ & $\begin{array}{c}0,74 \\
\text { (livres) }\end{array}$ & $\begin{array}{c}0,33 \\
\text { (livres) }\end{array}$ & 0,75 & 0,49 & Diversas ( 23 ao todo) & 1999Q3-2010Q2 \\
\hline $\begin{array}{c}\text { Sin e } \\
\text { Gaglianone } \\
(2006)\end{array}$ & 0,54 & 0,5 & 0,48 & 0,5 & $\begin{array}{c}\text { Produto, Consumo, } \\
\text { Investimento, Horas } \\
\text { trabalhadas, Salário Real, } \\
\text { Inflação e Taxa de Juros }\end{array}$ & $1992-2005$ \\
\hline $\begin{array}{l}\text { Silva Júnior } \\
\text { e Divino } \\
\text { (2013) }\end{array}$ & 0,468 & 0,5 & 0,3 & 0,499 & $\begin{array}{c}\text { PIB, Consumo, } \\
\text { Investimento, Inflação, } \\
\text { Salários Reais, Emprego e } \\
\text { Juros Nominais }\end{array}$ & 1995Q1-2010Q4 \\
\hline $\begin{array}{l}\text { Silveira } \\
(2008)\end{array}$ & 0,89 & 0,44 & & & $\begin{array}{c}\text { Produto, Inflação, Taxa } \\
\text { de juros de } 90 \text { dias, } \\
\text { Câmbio real }\end{array}$ & 1999Q3-2005Q3 \\
\hline $\begin{array}{c}\text { Gouvea } \\
(2007)\end{array}$ & \multicolumn{5}{|c|}{ Preços do IPC/FGV permanecem fixos entre 2,7 e 3,8 meses } & $1996-2006$ \\
\hline $\begin{array}{c}\text { Moura e } \\
\text { Rossi Júnior } \\
\text { (2010) }\end{array}$ & $\begin{array}{l}0,7(10 \\
\text { meses })\end{array}$ & & & & $\begin{array}{l}\text { Questionário para } 281 \\
\text { firmas em setembro de } \\
2007\end{array}$ & 2007 \\
\hline
\end{tabular}




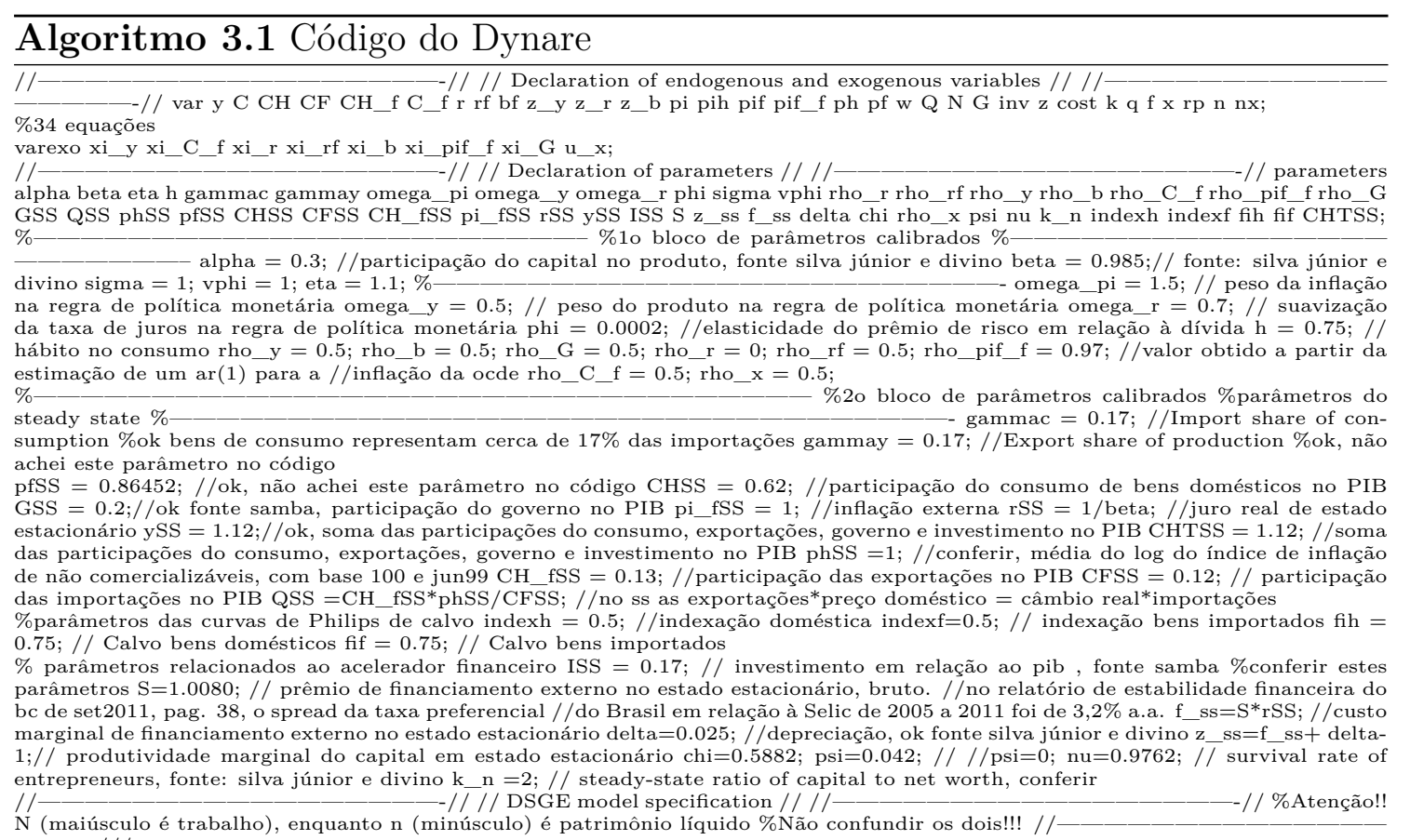

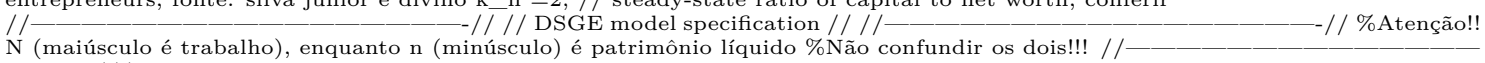
$-1 / /$

model(linear);

//Demand $\mathrm{C}=(1$-gammac $) * \mathrm{CH}+$ gammac ${ }^{*} \mathrm{CF} ; \%$ consumo total $\mathrm{CH}=\mathrm{C}$-eta* $(\mathrm{ph}) ; \%$ consumo dos bens domésticos $\mathrm{CF}=\mathrm{C}-$ eta $*(\mathrm{pf}) ;$ $\%$ consumo dos bens importados $\mathrm{CH} \_\mathrm{f}=\mathrm{C} \_\mathrm{f}-\mathrm{eta} *(\mathrm{ph}-\mathrm{Q}) ; \%$ demanda externa pelo bem doméstico

//Produção no modelo (Empreendedores) $\mathrm{y}=(\mathrm{CHSS} / \mathrm{CHTSS}){ }^{*} \mathrm{CH}+\left(\mathrm{CH} \_\right.$fSS $\left./ \mathrm{CHTSS}\right) * \mathrm{CH} \_\mathrm{f}+(\mathrm{GSS} / \mathrm{CHTSS}) * \mathrm{G}+(\mathrm{ISS} / \mathrm{CHTSS}) * \mathrm{inv}$; \%identidade contas nacionais $\mathrm{y}=$ alpha* $\mathrm{k}(-1)+(1-$ alpha $) * \mathrm{~N}+\mathrm{z} \_\mathrm{y} ; \%$ função de produção $\mathrm{w}=\mathrm{y}+\operatorname{cost}-\mathrm{N} ; \% \mathrm{FOC}$ para trabalho, cost é o custo marginal real (multiplicador de lagrange) $\mathrm{z}=\mathrm{y}+\operatorname{cost}-\mathrm{k}(-1)$; \% FOC para capital, cost é o custo marginal real (multiplicador de lagrange) $\mathrm{f}=\left(\mathrm{z} \_s s / f \_s s\right)^{*} \mathrm{z}+(1$-delta $) / \mathrm{f} \_s s^{*} \mathrm{q}-\mathrm{q}(-1)$; \%demanda por capital por parte dos empreendedores $\mathrm{f}(+1)=\mathrm{r}-\mathrm{pi}(+1)+\mathrm{psi}{ }^{*}(\mathrm{q}+\mathrm{k}-$ $\mathrm{n})$; \%custo marginal de financiamento externo (juro real + prêmio) rp=psi*(q+k-n); \%prêmio de financiamento externo (psi) $\mathrm{n} /\left(\mathrm{nu} * \mathrm{f} \_\mathrm{ss}\right)=\mathrm{k} \_\mathrm{n} *\left(\left(\mathrm{z} \_\mathrm{ss} / \mathrm{f} \_\mathrm{ss}\right)^{*} \mathrm{z}+(1\right.$-delta $\left.) / \mathrm{f} \_s s^{*} \mathrm{q}-\mathrm{q}(-1)\right)$ \%Evolução do patrimônio líquido $(\mathrm{n})$ dos empreendedores - $\left(\mathrm{k} \_\mathrm{n}-1\right) *(\mathrm{r}(-$ 1)-pi)-psi*(k_n-1)*(k(-1)+q(-1)) $+\left(\mathrm{psi}^{*}\left(\mathrm{k} \_\mathrm{n}-1\right)+1\right) * \mathrm{n}(-1)$

//Investimento (Capital producers) \% é o choque específico no investimento $\mathrm{q}=$ chi*(inv-k(-1))-x; \%relação entre o preço do capital(q de Tobin) e o custo de ajustament do capital $\mathrm{k}=$ delta*inv+delta* $\mathrm{x}+(1 \text {-delta })^{*} \mathrm{k}(-1)$; \%acumulação de capital

$/ /$ Euler $\mathrm{r}=(\operatorname{sigma} /(1-\mathrm{h}))^{*} \mathrm{C}(+1)-((1+\mathrm{h}) /(1-\mathrm{h}))^{*} \operatorname{sigma} *^{*} \mathrm{C}+\left(\mathrm{h}^{*} \operatorname{sigma} /(1-\mathrm{h})\right)^{*} \mathrm{C}(-1)+\mathrm{pi}(+1)$

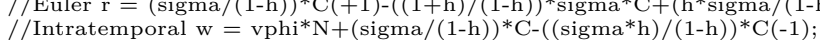

//Intratemporal w $=\operatorname{vphi}^{*} \mathrm{~N}+(\text { sigma } /(1-\mathrm{h}))^{*} \mathrm{C}^{*}\left(\left(\operatorname{sigma}^{*} \mathrm{~h}\right) /(1-\mathrm{h}\right.$
$/ / \mathrm{UIP} \mathrm{r}-\mathrm{rf}=\mathrm{Q}(+1)-\mathrm{Q}+\mathrm{pi}(+1)-$ pif $\mathrm{f}(+1)-\mathrm{phi}^{*} \mathrm{QSS} \mathrm{bf}_{\mathrm{z}} \mathrm{b}$;

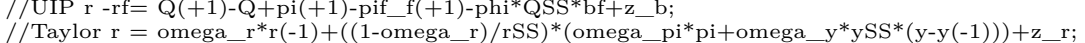

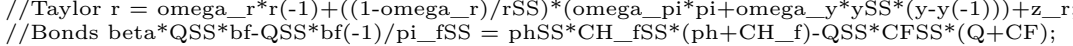

//Bonds beta* QSS*bf-QSS*bf(-1)/pi_fSS $=\mathrm{phSS}^{*} \mathrm{CI}$
$/ /$ exportações líquidas $\mathrm{nx}=\left(\mathrm{ph}+\mathrm{CH} \_\mathrm{f}\right)-(\mathrm{Q}+\mathrm{CF})$

$/ / \mathrm{Pi}$ pif $=$ pf-pf(-1)+pi; pih $=$ ph-ph(-1)+pi;

\%curvas de Philips de Calvo \%doméstica pih $=(\text { beta } /(1+\text { beta*indexh }))^{*} \operatorname{pih}(+1)+(\operatorname{indexh} /(1+\operatorname{beta} * \operatorname{indexh})) * \operatorname{pih}(-1)+(((1-$ beta*fih $) *(1-$ fih $)) /($ fih* $(1+$ beta*fih $)))^{*}$ cost;

\%bens importados pif $=$ (beta/(1+beta*indexf $))^{*} \operatorname{pif}(+1)+($ indexf $/(1+$ beta*indexf $)) * \operatorname{pif}(-1) \quad+\quad(((1-$ beta*fif $) *(1-$ fif) $) /($ fif*(1+beta*fif $)) *(\mathrm{Q}-\mathrm{pf})$;

//AR1-processes $\mathrm{G}=$ rho_G*G(-1)+xi_G; // gastos do governo z_y = rho_y*z_y(-1)+xi_y; //choque na produtividade z_b $=$ rho_b*z_b(-1)+xi_b; //choqe no prêmio de risco $z_{-} r=$ rho_r*z_r(-1)+xi_r; //choque na política monetária pif_f $=$ = rho_rf*rf(-1)+xi_rf; //choque na taxa de juros externa $\mathrm{x}=\mathrm{rho} \_\mathrm{x}^{*} \mathrm{x}(-1)+\mathrm{u} \_\mathrm{x} ; \overline{/} /$ choque específico no investimento

end;

shocks; var xi_G; stderr 0.012; // gastos do governo var xi_y; stderr 0.02;//produtividade var xi_b; stderr 0.01; // prêmio de risco var xi_r; stderr 0.0025; //política monetária var xi_pif_f; stderr 0.53; // inflação externa \%valor obtido a partir da \%estimação de var xi_r; stderr $\operatorname{ar}(1)$ para a inflação da ocde var xi_C f; stderr 0.01 ; // demanda externa var xi rf; stderr 0.01 ; // taxa de juros externa var um ar(1) para a infação da ocde var xi___f, stderr $0.01 ;$

// Compute steady state steady; // Compute eigenvalues and check Blanchard-Kahn conditions check; stoch_simul(irf=0)y inv C pi rp n q Q nx;

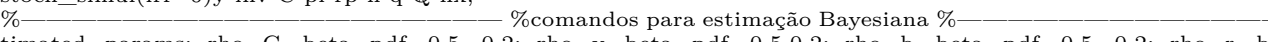
timated_params; rho_G, beta_pdf, 0.5, 0.2; rho_y, beta_pdf, 0.5,0.2; rho_b, beta_pdf, 0.5, 0.2; rho_r, beta_pdf, 0.5, 0.2 rho_C_f, beta_pdf, $\overline{0} .5,0.2$; rho_rf, beta_pdf, $\overline{0.5}, 0.2$; rho_x, beta_pdf, $0.5,0.2$; stderr xi_G, inv_gamma_pdf,12, inf; // gastos do governo stderr xi_y, inv_gamma_pdf,1, inf; //produtividade stderr xi_b, inv_gamma_pdf,5.5, inf; // prêmio de risco stderr xi_r, inv_gamma_pdf,2, inf; //política monetária stderr xi_C_f, inv_gamma_pdf,17, inf; // demanda externa stderr xi_rff inv gamma_pdf,26, inf; // taxa de juros externa stderr u_x, inv gamma_pdf,11, inf; // choque específico no investimento h beta_pdf, $0.5,0.2 ; / /$ habit formation (fonte: samba) omega_r, beta_pdf, $0.75,0.15 ; / /$ monetary policy parameter fonte:soto medina omega_pi, gamma_pdf, $2,0.15 ; / /$ monetary policy parameter fonte:samba omega_y, gamma_pdf, $0.50,0.15 ; / /$ monetary policy parameter fonte:samba phi, beta pdf, 0.05, 0.02; //elasticidade do prêmio de risco fih, beta_pdf, 0.75, 0.1; // Calvo prob. in domestic price (home goods) fonte: $\mathrm{ms}$ indexh, beta pdf, $0.5,0.25$; / indexation of domestic price (home goods)fonte: ms fif

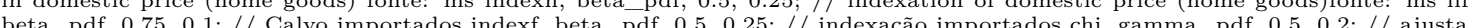
mento de capital psi, gamma pdf, $0.06,0.01 ; / /$ prêmio de financiamento externo em relação à alavancagem sigma, gamma_pdf, 1 , 0.3 ;// vphi, gamma pdf, $1,0.3 ; / /$ eta, gamma pdf, $1,0.3 ; / /$

$0.3 ; / /$
end;
$\%$

$\% 13$ variáveis observadas ao todo

varobs y r pi N C inv Q w;

\%Comando para a estimação Bayesian

estimation $\left(\right.$ datafile $=$ norges_data, prefilter $=1, \mathrm{mh} \_$jscale $=0.4, \mathrm{mh} \_$drop $=0.3, \mathrm{mh} \_$nblocks $=2$, mh_replic $=500000$, mode_check, mode_compute $=6$, moments_varendo,bayesian_irf, filtered_vars, smoother) y inv $\overline{\mathrm{C}}$ pi rp n q Q nx ; stoch_simul(nograph, irf $=40$, conditional_variance_decomposition $=[1,4,8,16,32])$ y inv C pi rp n q Q nx;

identification(parameter_set=posterior_mean); shock_decomposition y inv C pi rp n q Q nx;

dyngraph; 


\section{0 papel das variáveis externas no período 1999-2013 em um modelo DSGE estimado para o Brasil}

\subsection{Introdução}

O objetivo desta seção é analisar o papel das variáveis externas na economia brasileira, desde a introdução do regime de metas para a inflação em 1999 até 2013.

Para este objetivo, estima-se o modelo de Soto e Medina (2007) para o Brasil. O modelo em questão foi originalmente desenvolvido para a economia chilena. Apesar disso, a estimação do modelo para a economia brasileira é interessante, pois permite analisar o papel exercido pelas commodities e pelo petróleo na economia brasileira, tendo em vista a sua complexidade.

A análise do papel das commodities interessa pela importância deste segmento para a economia brasileira, em especial para o saldo da balança comercial, respondendo em média por quase $60 \%$ da pauta de exportações brasileira ao longo dos anos 2000.

Por outro lado, o estudo do efeito de choques no preço do petróleo na economia brasileira é de interesse, tendo em vista o crescente déficit na balança comercial do petróleo no Brasil, tendo alcançado US\$ 20 bilhões em 2013. A figura 1 apresenta a evolução recente da balança comercial do petróleo no Brasil.

A contribuição reside na análise do papel dessas e de outras variáveis de origem externa na dinâmica da economia brasileira, no contexto da modelagem DSGE.

Figura 4.1: Saldo comercial de produtos relacionados ao petroleo

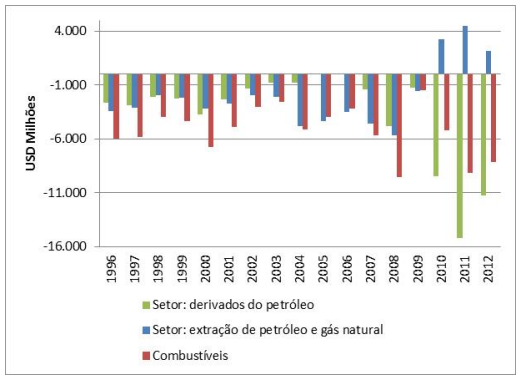

Nota: a fonte dos dados é a FUNCEX. Os dados foram coletados no IPEADATA. Elaboração do autor. 


\subsection{Revisão da Literatura}

\subsubsection{Termos de troca}

Mendoza (1995) encontrou que choques nos termos de troca respondem por 45 a $60 \%$ da variabilidade do PIB. Recentemente, Teles e Mendoça (2013) encontrarm um papel importante para os termos de troca na economia brasileira após a crise de 2008. No modelo utilizado neste capítulo, os termos de troca aparecem por meio do preço dos bens importados. e indiretamente por meio da inflação mundial.

\subsubsection{Petróleo}

A literatura sobre os efeitos de choques no preço do petróleo é extensa, em particular para os Estados Unidos. Em relação à origem dos choques, a literatura se divide entre a origem na oferta ou na demanda.

Sob o ponto de vista da oferta, o petróleo (ou a energia, de forma mais genérica) pode ser considerado como um fator de produção, assim como o capital e o trabalho, de forma que um aumento exógeno no preço do petróleo atua reduzindo a produtividade, como um choque negativo de oferta.

Kim e Lougant (2003) alteraram o modelo RBC para analisar choques no preço da energia, reduzindo a dependência do modelo RBC dos choques tecnológicos, que na prática não são observados. A função de produção do modelo leva em consideração trabalho, capital e energia, com a forma funcional de uma CES, e o modelo foi calibrado para os EUA. A inclusão de choques no preço da energia no modelo RBC resulta em um aumento do poder explicativo da volatilidade do produto e queda da correlação entre horas trabalhadas e o salário real. A conclusão alcançada no trabalho foi que, sem rigidez nominal, o impacto macroeconômico de choques no preço da energia é modesto.

Reconhecendo os efeitos de choques no preço do petróleo na atividade econômica, Rotemberg e Woodford (1997) se proporam a analisar os canais de transmissão pelos quais aumentos no custo de um fator de produção provocam um efeito significativo no produto, mesmo quando o fator de produção em consideração (energia) representa parcela pequena do custo marginal de produção da firma. Outro ponto em consideração foi a resposta do salário real a um choque do petróleo.

Com base em dados de 1947 a 1980, estimaram um VAR incluindo o logaritmo do preço real do petróleo, a taxa de crescimento dos preços nominais do petróleo, o salário real e o produto. Para o produto, o ponto de maior queda coincidiu com o nível máximo do preço real do petróleo. Os autores prosseguiram construindo e calibrando um modelo RBC com competição imperfeita para a analisar a resposta do produto e dos salários reais à um choque no preço do petróleo, conseguindo 
aproximar as respostas do produto e do salário real às obtidas a partir da análise empírica.

O papel da rigidez nominal - mais especificamente a rigidez de salários - na ampliação de um choque no preço do petróleo foi explicado por Brown e Yucel (2001). Um choque de oferta reduz a produtividade do trabalho, e como o salário nominal é rígido no curto prazo, o ajuste do mercado de trabalho ocorre nas quantidades, com consequente aumento do desemprego e queda do PIB. O único mecanismo pelo qual o salário real pode se ajustar é por meio do aumento inesperado da inflação. Sendo assim, se a política monetária não acomoda o choque, tentando evitar uma aceleração da inflação, a queda do produto pode ser ainda maior do que a inicialmente provocada pelo choque. O papel da política monetária no contexto de choques de oferta ganhou especial destaque na literatura, que será detalhado mais adiante.

É relativamente consensual na literatura que os choques no passado tiveram origem em uma súbita redução na produção mundial de petróleo, relacionada a guerras e fatores geopolíticos. Estes episódios incluem os choques de 73-74, 78-79, 80-81 e 90, os mais relevantes. O fato de que várias recessões foram precedidas por elevações do preço do petróleo, levou os economistas a associarem negativamente o aumento do preço da energia e a atividade econômica. Hamilton (2009) apresenta os principais choques no preço do petróleo, listando a redução da oferta durante o choque e o aumento do preço, reproduzidos parcialmente na Tabela 1.

Tabela 4.1: Principais choques do petróleo

\begin{tabular}{|c|c|c|}
\hline Episódio & $\begin{array}{c}\text { Redução } \\
\text { percentual } \\
\text { da oferta }\end{array}$ & $\begin{array}{c}\text { Aumento } \\
\text { percentual } \\
\text { no preço }\end{array}$ \\
\hline \hline Outubro 1973 - Março 1974 & 4.0 & 41.3 \\
\hline Novembro 1978 - Julho 1979 & 1.3 & 38.7 \\
\hline Outubro 1980 - Março 1981 & 1.2 & 25.8 \\
\hline Agosto 1990 - Outubro 1990 & 2.9 & 71.6 \\
\hline
\end{tabular}

Fonte: Hamilton (2010) página 223

Neste sentido, utilizando a causalidade no sentido de Granger, Hamilton (1983) não encontrou evidências de que as séries americanas de produto, desemprego, deflator do PIB, renda do setor não agrícolas, rendimento por hora e o M1 causaram o preço do petróleo para o período de 1948 a 1972, sugerindo que os choques no preço do petróleo no período foram exógenos, não podendo ser atribuídos a um conjunto de variáveis macroeconômicas. A conclusão foi de que frequentemente o aumento do preço da energia precedeu as recessões nos EUA, com o efeito se materializando entre 3 a 4 meses posteriores ao choque.

Uma exceção relevante para a interpretação de que os principais choques no preço do petróleo do passado foram causados pela interrupção da oferta é oferecida por Kilian (2009). Embora este autor não negue a importância da oferta, ele argumenta 
que apenas $20 \%$ da variação do preço real do petróleo decorre da oferta, sendo que parte relevante está ligada à demanda, por meio do ciclo econômico mundial.

Kilian (2009) decompõe o preço real do petróleo de 1975 a 2007 em três componentes: um choque na oferta de petróleo, um choque na demanda de todas as commodities e um choque de demanda específico para o mercado de petróleo, interpretado como um choque na demanda precaucionária de petróleo. A metodologia empregada foi um VAR estrutural.

Ao contrário do senso comum de que choques no preço do petróleo têm origem essencialmente na oferta, Kilian argumenta que sob um prisma histórico o preço do petróleo tem se movido em função de choques na demanda por commodities e na demanda precaucionária, ao invés de choques na oferta. Dessa forma, apesar de comumente os efeitos de uma elevação no preço do petróleo serem creditados à oferta, Kilian (2009) argumenta que na verdade boa parte dos choques se deveu ao aumento de demanda provocado por incertezas em relação à oferta futura de petróleo após guerras e conflitos políticos.

Hamilton (2009) argumenta que, além dos problemas imobiliários que estiveram na raiz da recessão que teve início em 2007 nos EUA, o choque no preço do petróleo teve papel relevante. Entretanto, em contraste com os episódios anteriores, em que o aumento do preço do petróleo foi largamente decorrente de súbitas interrupções na oferta, tendo como pano de fundo fatores geopolíticos, o aumento do preço do petróleo entre 2007 e 2008 foi motivado pela crescente demanda mundial (principalmente em função do aumento do consumo da China), com a produção mundial não tendo aumentado no mesmo ritmo.

Kilian (2007) sintetiza os canais pelos quais um choque no preço do petróleo afeta o consumo: i) preços maiores de energia reduzem a renda discricionária, pois os consumidores terão menos renda disponível para gastar em outros bens, este efeito sendo maior quando mais inelástica for a demanda por energia, e limitada pela proporção dos gastos com energia no consumo; ii)aumentos no preço da energia podem criar incerteza em relação à trajetória dos preços da energia, possivelmente provocando uma postergação do consumo de bens duráveis iii) esta incerteza pode afetar todas as formas de consumo, se supostamente os consumidores aumentarem a poupança como forma de precaução iv) o consumo de bens intensivos em energia tende a ser reduzido.

Blanchard e Galí (2008) estudaram o efeito de choques do petróleo desde a década de 70, utilizado vetores autoregressivos incluindo preços do petróleo (medido pelo West Texas Intermediate - WTI), inflação ao consumidor, deflator do PIB e salários nominais, além do PIB e das horas trabalhadas, incluindo todas as variáveis em variações percentuais trimestrais. Os modelos estimados também incluíram uma tendência quadrática. O modelo foi estimado para o período de 1960 a 1983, assim como de 1984 a 2007. Os fatores que contribuíram para os menores efeitos dos choques de oferta ao longo das décadas de 90 e 2000 foram: i) menor representatividade do petróleo no consumo e na produção, ii) mercados de trabalho mais flexíveis, com 
redução da rigidez real de salários e melhor condução da política monetária.

Outro ponto bastante abordado na literatura é a relação entre choques do petróleo e política monetária. Alguns autores argumentam que os choques de oferta ensejados pelo aumento do preço do petróleo no passado não justificam as recessões que se sucederam, de forma que as consequências do choque foram ampliadas pela resposta da política monetária.

O canal da política monetária é um meio de transmissão à parte em um choque do preço do petróleo. Como enfatizado por Hunt, Isard e Laxton (2001), o aumento dos custos de produção em função de choque podem levar as firmas e os trabalhadores a resistir a uma queda do salário real e das margens de lucro, provocando aumento do custo unitário do trabalho e aumento dos preços dos bens e serviços.

Bernanke, Gertler e Sims (1997) reconhecem os resultados Hamilton (1983), de que boa parte das recessões após a $2^{\text {a }}$ guerra, particularmente as de 1973-75, 1980-82 e 1990-91 foram precedidas por elevações no preço do petróleo. Entretanto, com base em uma análise vetores auto-regressivos na forma reduzida, encontram que a resposta endógena da política monetária respondeu pela maior parte dos efeitos recessivos provocados por um choque no preço do petróleo.

A resposta endógena da política monetária a um aumento no preço do petróleo constitui em uma explicação adicional para a queda do produto após um choque do petróleo. Conforme argumentado por alguns autores - Kim e Lougant (2003) e Hamilton (2010)-, os custos com energia são pequenos em relação aos custos de produção totais para explicar a queda do produto verificada após alguns choques, de forma que canais de transmissão que levam em consideração apenas a oferta não conseguem explicar recessões cuja causa primordial foi atribuída aos choques.

\subsubsection{Modelos DSGE aplicados à economia brasileira}

Silveira (2008) foi um dos primeiros aplicar modelos DSGE à economia brasileira. O autor construiu um modelo DSGE de economia aberta para dois países, com o objetivo de estudar o papel da persistência endógena gerada pela inclusão de hábito no consumo e indexação de preços no modelo. Os resultados encontrados dão suporte para a inclusão de hábito de consumo no modelo. Dentre os principais parâmetros estimados para o Brasil, o coeficiente de Calvo referente à rigidez de preço encontrado foi de 0,89 , resultando em uma duração média dos preços superior a 2 anos. Por sua vez, o grau de indexação à inflação passada foi estimado em 0,44.

Júnior e Portugal (2011) aplicam o modelo de Grith (2007) para o Brasil, com o objetivo de analisar o papel da política fiscal em uma economia aberta. O modelo contempla como variáveis de política fiscal a tributação sobre o consumo das famílias, sobre o capital e sobre o salário. Os autores encontram que, dentre as variáveis de política fiscal os gastos do governo produzem o maior efeito sobre a taxa de câmbio e sobre as exportações líquidas. Entretanto, o efeito dos gastos do governo sobre 
variáveis externas são inferiores aos produzidos pela política monetária, representada por um choque na taxa de juros.

Niquito et al. (2011) aplicam o modelo de Dib (2003) para o Brasil, se concentrando no papel da rigidez real e nominal na transmissão de choques monetários. A rigidez nominal do modelo foi modelada por meio de custos de ajustamentos de preços, enquanto a rigidez real é modelada por meio de custos quadráticos de ajustamento de capital e trabalho. A estimação utilizou dados de 2000 a 2010, por utilizando métodos bayesianos, utilizando as séries de PIB real per capita, deflator implícito do PIB e M2 real per capita. Os autores estimam diferentes versões do modelo, contemplando várias combinações com a presença ou ausência das distintas formas de rigidez. Um dos resultados encontrados é que a inclusão do custo de ajustamento do emprego no modelo resulta em um aumento do custo de ajustamento dos preços (rigidez nominal). Adicionalmente, as estimações apontaram para uma magnitude maior da rigidez de emprego em comparação com a do capital.

A análise da decomposição da variância das séries utilizadas na estimação mostram que os choques tecnológicos explicam a maior parte do produto, enquanto o crescimento monetário é explicado principalmente por choques na demanda de moeda. Já a taxa de inflação é explicada em parte por choques tecnológicos e também por choques na demanda por moeda. Entretanto, conforme reconhecido pelos autores, uma limitação do modelo utilizados em relação à realidade da economia brasileira é o fato do modelo ser de economia fechada, e da política monetária do modelo ser modelada por meio da utilização de agregados monetários, ao invés da taxa de juros.

Sin e Gablianone (2006) aplicam o modelo de Smets e Wouters (2003) para o Brasil, utilizando dados de 1992 a 2005. Apesar de utilizarem, para a estimação Bayesiana, dados de um período em que a economia brasileira passava por um período de instabilidade, os autores alcançam algumas conclusões. A rigidez de preços e de salários estimada foi inferior à prior considerada, com o parâmetro de Calvo recuando de 0,7 para 0,54 no caso dos preços e de 0,7 para 0,48 no caso dos salários. Outro parâmetro estimado que apresentou redução em relação à prior considerada foi o parâmetro de hábito no consumo, que passou de 0,7 para 0,52 na distribuição posterior.

Vasconcelos e Divino (2012) estimaram o modelo de economia fechada de Smets e Wouters (2007) para o Brasil, procurando investigar o desempenho da política monetária durante o regime de metas para a inflação, abrangendo os anos de 2000 a 2009.

Os autores testaram diversas regras de taxas de juros, envolvendo diferentes combinações entre inflação corrente, expectativas de inflação, hiato do produto e taxa de crescimento do produto, escolhendo a que proporcionava o maior valor para a verossimilhança condicional, cuja especificação embute a resposta dos juros à inflação corrente, às expectativas de inflação e ao crescimento do produto. As séries utilizadas nas estimações foram: produto, consumo, investimento, população empregada, salário, taxa de juros Selic e inflação medida pelo IPCA. Os resultados encontrados 
apontam que o Banco Central do Brasil reagiu às pressões inflacionárias do período, representado pelo coeficiente associado à inflação corrente no modelo estimado superior à unidade $(1,4)$. Adicionalmente, o modelo estimado aponta para uma resposta positiva do Banco Central ao crescimento do produto. O coeficiente da rigidez de preços de Calvo foi estimado em 0,63, implicando em uma duração de 2,7 trimestres dos preços no Brasil. Por último, o grau de indexação dos preços foi estimado em $25 \%$.

\subsection{Modelo}

Nesta parte da tese, o modelo utilizado será o de Soto e Medina (2007), um DSGE de médio/grande porte. A estrutura do modelo tem rigidez de preços e salários, custos de ajustamento do investimento e hábito no consumo. A economia exporta dois tipos de bens: um composto de variedades comercializáveis produzidas domesticamente e commodities. O bem doméstico comercializável também é vendido domesticamente. Por outro lado, a economia importa variedades produzidas no exterior e petróleo, que é utilizado tanto como um fator de produção pelas firmas doméstica quanto para consumo, neste caso capturando o papel dos combustiveis. Os bens importados, por sua vez, são utilizados para consumo e como bem de capital.

O setor de commodities é modelado como totalmente exportador. Para o Brasil, o propósito é analisar os efeitos das commodities em um modelo de equilíbrio geral, dado que quase $60 \%$ da pauta de exportações brasileira é composta por commodities (minério de ferro, soja, café, carnes, petroléo bruto, celulose, dentre outros). No modelo, a produção de commodities segue um processo $\mathrm{AR}(1)$, assim como os preços, que por hipótese são determinados no mercado internacional.

A rigidez nominal é modelada por meio da abordagem de Calvo, aparecendo de 4 formas: i) rigidez do preço do bem doméstico exportado, ii) rigidez do preço do bem doméstico vendido internamente, iii) rigidez de preço dos bens importados e iv) rigidez de salários.

\subsubsection{Estrutura geral do modelo}

Em alguns passos o operador esperança matemática foi omitido, por simplificação.

\subsubsection{Consumidores}

A economia é povoada por um contínuo de consumidores indexados por $j \epsilon(0,1)$, que maximizam a seguinte utilidade:

$$
E_{0} \sum_{t=0}^{\infty} \beta^{t}\left[\frac{\left(C_{t}(j)-h C_{t-1}\right)^{1-\sigma_{C}}}{1-\sigma_{C}}-\frac{l_{t}(j)^{1+\sigma_{L}}}{1+\sigma_{L}}\right]
$$


Figura 4.2: $\quad$ Firmas no modelo

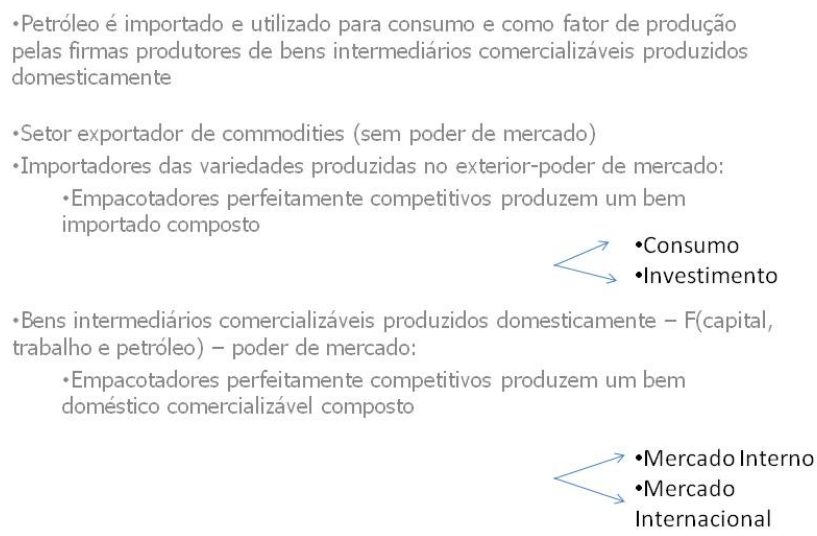

onde $l_{t}(j)$ é o trabalho, $C_{t}(j)$ é o consumo, $\sigma_{c}$ é o parâmetro da aversão ao risco (inverso da elasticidade de substituição intertemporal),$\sigma_{L}$ é o inverso da elasticidade da oferta de trabalho, $C_{t}$ é o consumo agregado, $h$ é o parâmetro associado ao hábito no consumo.

Os consumidores gastam a renda do trabalho $\left(W_{t}(j) l_{t}(j)\right)$, os lucros recebidos das frimas domésticas $\left(\Pi_{t}(j)\right)$ e a renda dos títulos de dívida em moeda local e estrangeira comprados no período anterior em consumo $\left(P_{c, t} C_{t}(j)\right)$ e novos títulos denominados em moeda local $(D(j))$ e estrangeira $\left(B_{t+1}^{*}(j)\right)$.

$$
P_{c, t} C_{t}(j)+E_{t}\left\{\frac{d(j)}{\left(1+i_{t}\right)}\right\}+\frac{\varepsilon_{t} B_{t+1}^{*}(j)}{\left(1+i_{t}^{*}\right) \Theta}=W_{t}(j) l_{t}(j)+\Pi_{t}(j)-T_{p, t}(j)+d_{t}(j)+\varepsilon_{t} B_{, t}^{*}(j)
$$

$\Theta$ é um prêmio que os consumidores domésticos têm que pagar para tomar empréstimos no exterior. Este prêmio, por hipótese constante no estado estacionário, é modelado como uma função da dívida líquida do país em proporção do PIB, ou seja:

$$
\Theta\left(\iota=\frac{\varepsilon_{t} B_{t}^{*}}{P_{Y, t} Y_{t}}\right)
$$

Lagrangeano: 


$$
L=E_{t} \sum_{t=0}^{\infty} \beta^{t}\left\{\left[\frac{\left(C_{t}(j)-h C_{t-1}\right)^{1-\sigma_{C}}}{1-\sigma_{C}}-\frac{l_{t}(j)^{1+\sigma_{L}}}{1+\sigma_{L}}\right]-\lambda_{t}\left[P_{c, t} C_{t}(j)+E_{t}\left\{\frac{D_{t+1}(j)}{\left(1+i_{t}\right)}\right\}+\frac{\varepsilon_{t} B_{t+1}^{*}(j)}{\left(1+i_{t}^{*}\right) \Theta}-W_{t}(j) l_{t}(j)-\Pi_{t}(j)+T_{p, t}(j\right.\right.
$$

Derivando em relação a $C_{t}(\mathrm{j})$ :

$$
\begin{aligned}
& \left(C_{t}(j)-h C_{t-1}\right)^{-\sigma_{c}}-\lambda_{t} P_{t}=0 \\
& \lambda_{t}=\frac{\left(C_{t}(j)-h C_{t-1}\right)^{-\sigma_{c}}}{P_{t}}
\end{aligned}
$$

Derivando em relação a $D_{t+1}(j)$ :

$$
\begin{aligned}
& -\beta^{t} \lambda_{t} \frac{1}{\left(1+i_{t}\right)}+\beta^{t+1} \lambda_{t+1}=0 \\
& \frac{1}{\left(1+i_{t}\right)}=E_{t}\left[\frac{\beta \lambda_{t+1}}{\lambda_{t}}\right]
\end{aligned}
$$

De 9 e 11:

$$
\begin{aligned}
\frac{1}{\left(1+i_{t}\right)} & =\frac{\beta\left(C_{t+1}(j)-h C_{t}\right)^{-\sigma_{c}}}{P_{t+1}} \frac{P_{t}}{\left(C_{t}(j)-h C_{t-1}\right)^{-\sigma_{c}}} \\
\frac{1}{\left(1+i_{t}\right)} & =\beta \frac{P_{t}}{P_{t+1}} \frac{\left(C_{t+1}(j)-h C_{t}\right)^{-\sigma_{c}}}{\left(C_{t}(j)-h C_{t-1}\right)^{-\sigma_{c}}}
\end{aligned}
$$

A equação de Euler fica da seguinte forma:

$$
E_{t}\left[\beta\left(1+i_{t}\right) \frac{P_{t}}{P_{t+1}} \frac{\left(C_{t+1}(j)-h C_{t}\right)^{-\sigma_{c}}}{\left(C_{t}(j)-h C_{t-1}\right)^{-\sigma_{c}}}\right]=1
$$

Derivando em relação a $B_{t+1}^{*}(j)$ :

$$
\frac{-\lambda_{t} \varepsilon_{t} \beta^{t}}{\left(1+i_{t}^{*}\right) \Theta}+\lambda_{t+1} \varepsilon_{t+1} \beta^{t+1}=0
$$


O papel das variáveis externas no período 1999-2013 em um modelo DSGE 4.3 Modelo

$$
\begin{aligned}
& \lambda_{t+1} \varepsilon_{t+1} \beta=\frac{\lambda_{t} \varepsilon_{t}}{\left(1+i_{t}^{*}\right) \Theta} \\
& \frac{\lambda_{t+1}}{\lambda_{t}} \frac{\varepsilon_{t+1}}{\varepsilon_{t}} \beta=\frac{1}{\left(1+i_{t}^{*}\right) \Theta}
\end{aligned}
$$

Substituindo a equação 9:

$$
\begin{aligned}
& \frac{1}{\beta\left(1+i_{t}\right)}=\frac{\varepsilon_{t}}{\varepsilon_{t+1} \beta\left(1+i_{t}^{*}\right) \Theta} \\
& \frac{\left(1+i_{t}\right)}{\left(1+i_{t}^{*}\right)}=\Theta E_{t}\left[\frac{\varepsilon_{t+1}}{\varepsilon_{t}}\right]
\end{aligned}
$$

A equação acima dá origem à paridade descoberta de juros no modelo.

Por último, derivando em relacão à $l_{t}(j)$ :

$$
-l_{t}(j)^{\sigma_{L}}+\lambda_{t} W_{t}(j)=0
$$

Substituindo a expressão para $\lambda_{t}$, dada em 9, temos a oferta de trabalho:

$$
\frac{W_{t}(j)}{P_{t}}=\frac{l_{t}(j)^{\sigma_{L}}}{\left(C_{t}(j)-h C_{t-1}\right)^{-\sigma_{C}}}
$$

\subsubsection{Consumo}

O consumo é dado por uma CES de petroleo $C_{o}$, e outros bens (core consumption bundle), $C_{z}$. A presença de petróleo no consumo pode ser interpretada como as despesas dos consumidores principalmente com transporte (gasolina):

$$
C_{t}(j)=\left[\alpha_{c}^{1 / \omega_{c}}\left(C_{z, t}(j)\right)^{\frac{\omega_{c-1}}{\omega_{C}}}+\left(1-\alpha_{C}\right)^{1 / \omega_{c}}\left(C_{o, t}(j)\right)^{\frac{\varpi_{c}-1}{\omega_{c}}}\right]^{\frac{\omega_{c}}{\varpi_{c}-1}}
$$

- $\omega_{c}$ determina o grau de substituição entre o consumo de petróleo e o consumo de outros bens, 
- $\alpha_{C}$ determina a proporção do consumo de petróleo e outros bens no consumo agregado.

O consumo de outros bens (não petróleo) é dado por uma CES de bens produzidos domesticamente $C_{H, t}(j)$ e no exterior $C_{F, t}(j)$ :

$$
C_{z, t}=\left[\gamma_{C}^{\frac{1}{\eta_{c}}}\left(C_{H, t}\right)^{\frac{\eta_{c}-1}{\eta_{c}}}+(1-\gamma c)^{\frac{1}{\eta_{c}}}\left(C_{F, t}\right)^{\frac{\eta_{c}-1}{\eta_{c}}}\right]^{\frac{\eta_{c}}{\eta_{c}-1}}
$$

Para encontrar as demandas para cada tipo de bem maximizamos o consumo, sujeito à restrição orçamentária dada por:

$$
P_{H, t} C_{H, t}+P_{F, t} C_{F, t}=Z
$$

Onde Z é um determinado nível de gastos.

O Lagrangeano é dado por:

$$
L=\left[\gamma_{C}^{\frac{1}{\eta_{c}}}\left(C_{H, t}\right)^{\frac{\eta_{c}-1}{\eta_{c}}}+\left(1-\gamma_{c}\right)^{\frac{1}{\eta_{c}}}\left(C_{F, t}\right)^{\frac{\eta_{c}-1}{\eta_{c}}}\right]^{\frac{\eta_{c}}{\eta_{c}-1}}-\lambda_{t}\left(P_{H, t} C_{H, t}+P_{F, t} C_{F, t}-Z\right)
$$

A condição de primeira ordem em relação a $C_{H, t}$ é:

$$
\left[\gamma_{C}^{\frac{1}{\eta_{c}}}\left(C_{H, t}\right)^{\frac{\eta_{c}-1}{\eta_{c}}}+\left(1-\gamma_{c}\right)^{\frac{1}{\eta_{c}}}\left(C_{F, t}\right)^{\frac{\eta_{c}-1}{\eta_{c}}}\right]^{\frac{1}{\eta_{c}-1}} \gamma_{C}^{\frac{1}{\eta_{c}}} C_{H, t} \frac{-1}{\eta_{c}}-\lambda_{t} P_{H, t}=0
$$

A condição de primeira ordem em relação a $C_{F, t}$ é análoga:

$$
\left[\gamma_{C}^{\frac{1}{\eta_{c}}}\left(C_{H, t}\right)^{\frac{\eta_{c}-1}{\eta_{c}}}+\left(1-\gamma_{c}\right)^{\frac{1}{\eta_{c}}}\left(C_{F, t}\right)^{\frac{\eta_{c}-1}{\eta_{c}}}\right]^{\frac{1}{\eta_{c}-1}}\left(1-\gamma_{C}\right)^{\frac{1}{\eta_{C}}} C_{F, t} \frac{-1}{\eta_{c}}-\lambda_{t} P_{F, t}=0
$$

Definição do índice de preços:

$$
P_{Z, t}=\left(\gamma_{C} P_{H, t}^{1-\eta_{C}}+\left(1-\gamma_{C}\right) P_{F, t}^{1-\eta_{C}}\right)^{\frac{1}{1-\eta_{C}}}
$$

Após algumas manipulações obtemos as demandas para $C_{H, t}$ e $C_{F, t}$ :

$$
C_{F, t}=(1-\gamma)\left(\frac{P_{F, t}}{P_{z, t}}\right)^{-\eta_{c}} C_{z}
$$




$$
C_{H, t}=\gamma\left(\frac{P_{H, t}}{P_{z, t}}\right)^{-\eta_{c}} C_{z}
$$

Os índices de preços são definidos da seguinte forma:

$$
\begin{aligned}
& P_{H, t}=\left[\int_{0}^{1} P_{H, t}(i)^{1-\varepsilon} d i\right]^{\frac{1}{1-\varepsilon}} \\
& P_{F, t}=\left[\int_{0}^{1} P_{F, t}(i)^{1-\varepsilon} d i\right]^{\frac{1}{1-\varepsilon}} \\
& P_{Z, t}=\left(\gamma_{C} P_{H, t}^{1-\eta_{C}}+\left(1-\gamma_{C}\right) P_{F, t}^{1-\eta_{C}}\right)^{\frac{1}{1-\eta_{C}}}
\end{aligned}
$$

O índice de cosumo é dado por:

$$
\begin{aligned}
C_{z, t} & =\left[\gamma_{C}^{\frac{1}{\eta c}}\left(C_{H, t}\right)^{\frac{\eta_{c}-1}{\eta_{c}}}+(1-\gamma c)^{\frac{1}{\eta_{c}}}\left(C_{F, t}\right)^{\frac{\eta_{c}-1}{\eta_{c}}}\right]^{\frac{\eta c}{\eta_{c}-1}} \\
C_{H, t} & =\left[\int_{0}^{1} C_{H, t}(i)^{\frac{\varepsilon-1}{\varepsilon}} d i\right]^{\frac{\varepsilon}{\varepsilon-1}} \\
C_{F, t} & =\left[\int_{0}^{1} C_{F, t}(i)^{\frac{\varepsilon-1}{\varepsilon}} d i\right]^{\frac{\varepsilon}{\varepsilon-1}}
\end{aligned}
$$

A demanda para um determinado bem é encontrada maximizando-se o consumo, sujeito à restrição orçamentária.

Demanda para o bem j:

$$
\begin{aligned}
& C_{H, t}(j)=\left(\frac{P_{H, t}(j)}{P_{H, t}}\right)^{-\varepsilon} C_{H, t} \\
& C_{F, t}(j)=\left(\frac{P_{F, t}(j)}{P_{F, t}}\right)^{-\varepsilon} C_{F, t}
\end{aligned}
$$




\subsubsection{Oferta de trabalho}

Cada consumidor $\mathrm{j}$ tem poder de mercado, ofertando um trabalho diferenciado. Estes são agregados por meio de um conjunto de "sindicatos" perfeitamente competitivos, que contratam os trabalhos diferenciados e combinam em um trabalho homogêneo:

$$
l_{t}=\left(\int_{0}^{1} l_{t}(j)^{\frac{\epsilon_{L}-1}{\epsilon_{L}}}\right)^{\frac{\epsilon_{L}}{\epsilon_{L-1}}}
$$

onde o parâmetro $\epsilon_{L}$ dá a elasticidade de substituição entre os diferentes tipos de trabalho. Este tipo de trabalho é posteriormente utilizado como insumo de produção através das firmas de produção de produtos intermediários.

A minimização de custo por parte dos sindicatos dá origem à seguinte demanda para cada tipo de trabalho:

$$
l_{t}(j)=\left(\frac{W_{t}(j)}{W_{t}}\right)^{-\epsilon_{L}} l_{t}
$$

onde $W_{t}(j)$ é o salário nominal fixado pelo consumidor $\mathrm{j}, W_{t}$ é o salário agregado e $l_{t}$ é a oferta de trabalho agregada.

O salário agregado é dado por:

$$
W_{t}=\left(\int_{0}^{1} W_{t}(j)^{1-\epsilon_{L}} d j\right)^{\frac{1}{1-\epsilon_{L}}}
$$

A rigidez de salários é introduzida por meio da modelagem de Calvo. Em cada período uma fração $\phi_{L}$ dos consumidores não conseguem fixar os salários de forma ótima, e indexam parcialmente o salário à inflação passada e à meta de inflação fixada pela autoridade monetária. A outra fração dos consumidores $\left(1-\phi_{L}\right)$ maximizam:

$$
\max _{W_{t}(j)}=E_{t} \sum_{i=0}^{\infty} \phi_{L}^{i}\left[\frac{W_{t+i}(j)}{P_{C, t}} l_{t+i}(j)-\zeta_{L, t} \frac{l_{t+i}(j)^{1+\sigma_{L}}}{1+\sigma_{L}}\left(C_{t+i}\right)\right]
$$

onde

$$
W_{t+i}(j)=\Gamma_{W, t}^{i} W_{t}(j)
$$


sujeito à demanda por trabalho (38) e à regra de atualização do salário nominal por parte dos consumidores que não consegem otimizar em um determinação período, que é dada por uma ponderação das inflação passada e da meta de inflação:

$$
\Gamma_{W, t}^{i}=\left(1+\pi_{C, t+i-1}\right)^{\chi_{L}}(1+\bar{\pi})^{1-\chi_{L}}
$$

onde $\chi_{L}$ é o peso da inflação passada na regra de indexação.

\subsubsection{Firmas}

- Produção doméstica de bens finais

Um grande número de firmas utiliza uma tecnologia CES para agregar bens domésticos produzidos pelas firmas intermediárias. Estas firmas vendem bens produzidos domesticamente internamente e no exterior. Seja $Y_{H, t}$ a quantidade de bens produzidos domesticamente vendidos internamente e $Y_{H, t}^{*}$ a quantidade vendida no exterior. As demandas para um bem intermediário $z_{H}$ são dadas por:

$$
Y_{H, t}\left(z_{H}\right)=\left(\frac{P_{H, t}\left(z_{H}\right)}{P_{H, t}}\right)^{-\epsilon_{H}} Y_{H, t} \quad Y_{H,}^{*}\left(z_{H}\right)=\left(\frac{P_{H, t}^{*}\left(z_{H}\right)}{P_{H, t}^{*}}\right)^{-\epsilon_{H}} Y_{H, t}^{*}
$$

- Firmas intermediárias

Os bens intermediários são produzidos por firmas que têm poder de mercado. Estas firmas maximizam os lucros escolhendo os preços do bem intermediário, sujeitos à demanda pela variedade intermediária e à tecnologia disponível. Seja $\mathbb{Y}_{H, t}\left(z_{H}\right) \mathrm{a}$ quantidade total produzida de uma variedade $z_{H}$.

$$
\mathbb{Y}_{H, t}\left(z_{H}\right)=A_{H, t}\left[\left(\alpha_{H}\right)^{\frac{1}{\omega_{H}}} V_{H, t}\left(z_{H}\right)^{\frac{\omega_{H}-1}{\omega_{H}}}+\left(1-\alpha_{H}\right)^{\frac{1}{\omega_{H}}} O_{H, t}\left(z_{H}\right)^{\frac{\omega_{H}-1}{\omega_{H}}}\right]^{\frac{\omega_{H}}{\omega_{H-1}}}
$$

onde $V_{H, t}\left(z_{H}\right)$ é um composto de capital e trabalho utilizado na produção e $O_{H, t}\left(z_{H}\right)$ é a quantidade de petroleo utilizada como insumo intermediário.

- $\alpha_{H}$ define o peso do composto de capital e trabalho an produção e

- $\omega_{H}$ determina a a elasticidade de substituição entre petróleo e outros fatores de produção.

- $A_{H, t}$ represente um choque de produtividade comum a todas as firmas. O composto de capital e trabalho é dado por uma tecnologia Cobb-Douglas: 


$$
V_{H, t}\left(z_{H}\right)=\left[l_{t}\left(z_{H}\right)\right]^{\eta_{H}}\left[K_{t}\left(z_{H}\right)\right]^{1-\eta_{H}}
$$

- $l_{t}\left(z_{H}\right)$ é a quantidade de trabalho utilizada, e

- $K_{t}\left(z_{H}\right)$ é a quantidade de capital fisico alugado

- $\eta_{H}$ define as proporção de capital e trabalho na produção.

Em cada período, as firmas conseguem reajustar os preços no mercado doméstico e externo, com probabilidades $1-\phi_{H_{D}}$ e $1-\phi_{H_{F}}$, respectivamente. Se a firma não reajusta o preço, ela segue uma regra de indexação à inflação passada e à meta de inflação. Assim, quando as firmas que reajustam os preços no mercado doméstico em um determinado período maximizam:

$$
\max _{P_{H, t}\left(z_{H}\right)}=E_{t}\left\{\sum_{i=0}^{\infty} \phi_{H_{D}}^{i}\left[\frac{P_{H, t+i}\left(z_{H}\right)-M C_{H, t+i}}{P_{C, t+i}} Y_{H, t+i}\left(z_{H}\right)\right]\right\}
$$

caso as firmas não consigam ajustar seus preços elas seguem:

$$
P_{H, t+i}\left(z_{H}\right)=\Gamma_{H_{D}, t}^{i} P_{H, t}\left(z_{H}\right)
$$

onde

$$
\Gamma_{H_{D}, t}^{i}=\Gamma_{H_{D, t}}^{i-1}\left(\frac{P_{H, t+1}}{P_{H, t+i-1}}\right)^{\chi_{H_{D}}}(1+\bar{\pi})^{1-\chi_{H_{D}}} e \Gamma_{H_{D}, t}^{0}=1
$$

e $\chi_{H_{D}}$ é o peso da inflação passada na regra de indexação.

As firmas que conseguem otimizar em um determinado período levam em consideração a probabilidade futura de não ser ser possivel ajustar os seus preços. Em cada período as firmas tambem recebem um sinal para reajustar os preços no mercado externo:

$$
\max _{P_{H, t}^{*}\left(z_{H}\right)}=E_{t}\left\{\sum_{i=0}^{\infty} \phi_{H_{F}}^{i}\left[\frac{\varepsilon_{t+i} P_{H, t+i}^{*}\left(z_{H}\right)-M C_{H, t+i}}{P_{C, t+i}} Y_{H, t+i}^{*}\left(z_{H}\right)\right]\right\}
$$

caso as firmas não consigam ajustar seus preços elas seguem:

$$
P_{H, t+i}^{*}\left(z_{H}\right)=\Gamma_{H_{F}, t}^{i} P_{H, t}^{*}\left(z_{H}\right)
$$


onde

$$
\Gamma_{H_{F}, t}^{i}=\Gamma_{F, t}^{i-1}\left(\frac{P_{F, t}^{*}}{P_{F, t-1}^{*}}\right)^{\chi_{H_{F}}}\left(\frac{P_{H, t+i}^{*}}{P_{H, t+i-1}^{*}}\right)^{1-\chi_{H_{F}}} \text { e } \Gamma_{F, t}^{0}=1
$$

O custo marginal de produção da variedade $z_{H}$ é dado por:

$$
M C_{H, t}=\frac{W_{t} l_{t}\left(z_{H}\right)+Z_{t} K_{t}\left(z_{H}\right)+P_{O, t} O_{H, t}\left(z_{H}\right)}{Y_{H, t}\left(z_{H}\right)}
$$

- A rigidez nominal do modelo é dada por 4 parâmetros de Calvo:

- Bens intermediários (vendidos internamente e no exterior). As mesmas firmas intermediárias vendem domesticamente e no exterior, mas elas recebem dois sinais diferentes para reajustar os seus preços, um para o mercado interno e outro para o externo.

- Bem importado

- Rigidez de salários

- Importadores:

A rigidez em moeda local é introduzida para permitir um pass-through incompleto da taxa de câmbio para os preços dos produtos importados em moeda local no curto prazo.

Um conjunto de "agregadores" perfeitamente competitivos utilizam uma tecnologia CES para combinar um contínuo de variedades importadas para produzir um bem final importado $Y_{F}$. Este bem pode ter duas finalidades: ou é consumido pelos consumidores ou é utilizado como insumo pelos produtores de bens de capital.

A minimização de custos por parte dos agregadores dá origem à demanda elas diferentes variedades importadas:

$$
Y_{F, t}\left(z_{F}\right)=\left(\frac{P_{F, t}\left(z_{F}\right)}{P_{F, t}}\right)^{-\epsilon_{F}} Y_{F, t}
$$

onde:

$\epsilon_{F}$ é a elasticidade de substituição entre as variedades importadas, $P_{F, t}\left(z_{F}\right)$ é o preço em moeda doméstica da variedade importada $z_{F}$ no mercado doméstico e $P_{F, t}$ é o preço agregado dos bens importados. 
Assim, se as firmas otimizam elas maximizam:

$$
\begin{aligned}
& \max _{P_{F, t}\left(z_{F}\right)}=E_{t}\left\{\sum_{i=0}^{\infty} \phi_{F}^{i}\left[\frac{\Gamma_{F, t}^{i} P_{F, t}\left(z_{F}\right)-\varepsilon_{t+i} P_{F, t+i}^{*}\left(z_{F}\right)}{P_{C, t+i}} Y_{F, t+i}\left(z_{F}\right)\right]\right\} \\
& \Gamma_{F, t}^{i}=\Gamma_{F, t}^{i-1}\left(1+\bar{\pi}_{t+i}\right)^{1-\chi_{F}}\left(\frac{P_{F, t+i}}{P_{F, t+i-1}}\right)^{\chi_{F}} \quad e \Gamma_{F, t}^{0}=1
\end{aligned}
$$

Neste arcabouço, mudanças na taxa de câmbio nominal não são imediatamente refletidas nos preços dos bens importados vendidos domesticamente, resultando em um pass-through incompleto.

\subsubsection{Investimento}

Uma firma representativa empresta bens de capital para as firmas produtoras de bens intermediários. Esta firma é responsável pela decisão de acumulação de capital. O investimento está sujeito a um custo de ajustamento. Os bens de capital são produzidos por uma CES que combina bens domésticos e estrangeiros :

$$
I_{t}=\left[\gamma_{I}^{\frac{1}{\eta_{I}}} I_{H, t}^{\frac{\eta_{I}-1}{\eta_{I}}}+(1-\gamma)^{\frac{1}{\eta_{I}}} I_{F, t}^{\frac{\eta_{I}-1}{\eta_{I}}}\right]^{\frac{\eta_{I}}{\eta_{I}-1}}
$$

- $\eta_{I}$ é a elasticidade de substituição entre bens domésticos e estrangeiros

- $\gamma_{I}$ é a proporção de bens domésticos no investimento

A maximização de $I_{t}$ em relação à restrição orçamentária $P_{I, t}=P_{H d, t} I_{H, t}+P_{F, t} I_{F, t}$ resulta nas seguintes demanda por cada tipo de bem:

$$
\begin{aligned}
& I_{H, t}=\gamma_{I}\left(\frac{P_{H, t}}{P_{I, t}}\right)^{-\eta_{I}} I_{t} \\
& I_{F, t}=\left(1-\gamma_{I}\right)\left(\frac{P_{F, t}}{P_{I, t}}\right)^{-\eta_{I}} I_{t}
\end{aligned}
$$

As derivações são análogas ao caso do bem de consumo.

$P_{I, t}$ é o índice de preços do investimento, dado por:

$$
P_{I, t}=\left[\gamma_{I} P_{H, t}^{1-\eta_{I}}+\left(1-\gamma_{I}\right) P_{F, t}^{1-\eta_{I}}\right]^{\frac{1}{1-\eta_{I}}}
$$


Problema da firma representativa:

$$
\max _{K_{t+1}, I_{t}} E_{t}\left\{\sum_{t=0}^{\infty} \Lambda_{t} \frac{Z_{t} K_{t}-P_{I, t} I_{t}}{P_{c, t}}\right\}
$$

sujeito à lei do movimento do capital:

$$
K_{t+1}=(1-\delta) K_{t}+\xi_{I, t} S\left(\frac{I_{t}}{I_{t-1}}\right) I_{t}
$$

Lagrangeano do problema:

$$
L=\sum_{t=0}^{\infty} \Lambda_{t}\left[\frac{Z_{t} K_{t}-P_{I, t} I_{t}}{P_{c, t}}-\frac{q_{t}}{P_{c, t}}\left(K_{t+1}-(1-\delta) K_{t}-\xi_{I, t} S\left(\frac{I_{t}}{I_{t-1}}\right) I_{t}\right]\right.
$$

Onde $q_{t}$ é o preço sombra do capital em termos nominais.

Derivando em relação a $K_{t+1}$ :

$$
\begin{aligned}
& \frac{\Lambda_{t+1} Z_{t+1}}{P_{c, t+1}}-\frac{\Lambda_{t} q_{t}}{P_{c, t}}+\frac{\Lambda_{t+1} q_{t+1}(1-\delta)}{P_{c, t+1}}=0 \\
& \frac{\Lambda_{t} q_{t}}{P_{c, t}}=\frac{\Lambda_{t+1} Z_{t+1}}{P_{c, t+1}}+\frac{\Lambda_{t+1} q_{t+1}(1-\delta)}{P_{c, t+1}} \\
& \frac{\Lambda_{t} q_{t}}{P_{c, t}}=E_{t}\left[\Lambda_{t+1}\left(\frac{Z_{t+1}}{P_{c, t+1}}+\frac{q_{t+1}(1-\delta)}{P_{c, t+1}}\right]\right. \\
& \frac{q_{t}}{P_{c, t}}=E_{t}\left[\frac{\Lambda_{t+1}}{\Lambda_{t}}\left(\frac{Z_{t+1}}{P_{c, t+1}}+\frac{q_{t+1}(1-\delta)}{P_{c, t+1}}\right]\right.
\end{aligned}
$$

Derivando em relaçao a $I_{t}$ :

$\frac{-\Lambda_{t} P_{I, t}}{P_{c, t}}+\frac{q_{t}}{P_{c, t}} \zeta_{I, t} S\left(\frac{I_{t}}{I_{t-1}}\right) \Lambda_{t}+\frac{q_{t}}{P_{c, t}} \xi_{I, t} S^{\prime}\left(\frac{I_{t}}{I_{t-1}}\right) \frac{I_{t}}{I_{t-1}} \Lambda_{t}+\frac{\Lambda_{t+1} q_{t+1}}{P_{c, t+1}} \xi_{I, t+1} I_{t+1} S^{\prime}\left(\frac{I_{t+1}}{I_{t}}\right)\left(-\frac{I_{t+1}}{I_{t}^{2}}\right)=0$ 


$$
\begin{aligned}
& \frac{\Lambda_{t} P_{I, t}}{P_{c, t}}=\frac{q_{t}}{P_{c, t}} \zeta_{I, t} S\left(\frac{I_{t}}{I_{t-1}}\right) \Lambda_{t}+\frac{q_{t}}{P_{c, t}} \xi_{I, t} S^{\prime}\left(\frac{I_{t}}{I_{t-1}}\right) \frac{I_{t}}{I_{t-1}} \Lambda_{t}+\frac{\Lambda_{t+1} q_{t+1}}{P_{c, t+1}} \xi_{I, t+1} S^{\prime}\left(\frac{I_{t+1}}{I_{t}}\right)\left(\frac{I_{t+1}^{2}}{I_{t}^{2}}\right) \\
& \frac{P_{I, t}}{P_{c, t}}=\frac{q_{t}}{P_{c, t}} \zeta_{I, t} S\left(\frac{I_{t}}{I_{t-1}}\right)+\frac{q_{t}}{P_{c, t}} \xi_{I, t} S^{\prime}\left(\frac{I_{t}}{I_{t-1}}\right) \frac{I_{t}}{I_{t-1}}+\frac{\Lambda_{t+1} q_{t+1}}{\Lambda_{t} P_{c, t+1}} \xi_{I, t+1} S^{\prime}\left(\frac{I_{t+1}}{I_{t}}\right)\left(\frac{I_{t+1}^{2}}{I_{t}^{2}}\right) \\
& \frac{P_{I, t}}{P_{c, t}}=\frac{q_{t}}{P_{c, t}} \zeta_{I, t}\left[S\left(\frac{I_{t}}{I_{t-1}}\right)+S\left(\frac{I_{t}}{I_{t-1}}\right) \frac{I_{t}}{I_{t-1}}\right]+E_{t}\left[\frac{\Lambda_{t+1} q_{t+1}}{\Lambda_{t} P_{c, t+1}} \xi_{I, t+1} S^{\prime}\left(\frac{I_{t+1}}{I_{t}}\right)\left(\frac{I_{t+1}^{2}}{I_{t}^{2}}\right)\right]
\end{aligned}
$$

\subsubsection{Setor produtor de commodities}

Uma única firma produz uma commodity homogênea que é exportada para o exterior. A produção deste bem não envolve insumos:

$$
Y_{S, t}=\left[Y_{S, t-1}\right]^{\rho_{y S}}\left[Y_{S, 0}\right]^{1-\rho_{Y S}} \exp \left(\varepsilon_{y S, t}\right)
$$

onde $\varepsilon_{y S, t} \sim N\left(0, \sigma_{y s}^{2}\right) \mathrm{e}^{\prime}$ um choque estocástico e $\rho_{Y s}$ captura a persistência do choque na produção de commodities. Um aumento na produção de commodities implica diretamente em um aumento do PIB.

\subsubsection{Setor externo}

Agentes externos demandam a commodity e o bem doméstico. A demanda pela commodity é completamente elástica ao preço internacional $P_{S, t}^{*}$, e a lei do preço único vale para este bem. O seu preço na moeda doméstica é dado por:

$$
P_{S, t}=\varepsilon_{t} P_{S, t}^{*}
$$

A oferta de petróleo deparada pelos agentes domésticos é completamente elástica a um determinado preço. Para o petróleo, a lei do preço único tambem vale no modelo, ou seja:

$$
P_{O, t}=\varepsilon_{t} P_{O, t}^{*}
$$


onde $P_{O, t}^{*}$ é o preço internacional do petróleo.

A taxa de câmbio real é definida como o preço relativo entre o índice de preço externo $P_{t}^{*}$ e o índice de preço dos bens de consumo na economia doméstica, $P_{C, t}$.

$$
R E R_{t}=\frac{\varepsilon_{t} P_{t}^{*}}{P_{C, t}}
$$

Por hipótese, o nível de preço externo $P_{t}^{*}$ cointegra com o preço dos bens importados. Assim:

$$
P_{F, t}^{*}=P_{t}^{*} \xi_{F, t}^{*}
$$

onde $\xi_{F, t}^{*}$ é um choque transitório estacionário no preço relativo dos bens importados. A demanda estrangeira pelo bem doméstico depende do preço relativo no exterior e da demanda total externa, $Y_{t}^{*}$ :

$$
Y_{H, t}^{*}=\varsigma^{*}\left(\frac{P_{H, t}^{*}}{P_{t}^{*}}\right)^{-\eta^{*}} Y_{t}^{*}
$$

onde $\varsigma^{*}$ corresponde à fatia dos bens intermediários domésticos na cesta de consumo dos agentes externos, e $\eta^{*}$ é a elasticidade preço da demanda.

\subsubsection{Governo}

A política monetária é conduzida por uma Regra de Taylor:

$$
\frac{1+i_{t}}{1+i}=\left(\frac{1+i_{t-1}}{1+i}\right)^{\psi_{i, 2}}\left(\frac{Y_{t}}{\bar{Y}_{t}} \frac{\bar{Y}_{t-1}}{Y_{t-1}}\right)^{\left(1-\psi_{i, 2}\right) \psi_{y, 2}}\left(\frac{1+\pi_{z, t}}{1+\bar{\pi}_{t}}\right)^{\left(1-\psi_{i, 2}\right) \psi_{\pi, 2}} \exp \xi_{m, t}
$$

onde $\pi_{z, t}=\frac{P_{z, t}}{P_{z, t-1}}-1$ e $\overline{\pi_{t}}$ é a meta de inflação para o período t. $\xi_{m, t}$ é um choque de política monetária i.i.d

\subsubsection{Equilíbrio:}

As exportações e importações são dadas respectivamente por:

$$
P_{X, t} X_{t}=\varepsilon_{t}\left(P_{H, t}^{*} Y_{H, t}^{*}+P_{S, t}^{*} Y_{S, t}\right)
$$




$$
P_{M, t} M_{t}=\varepsilon\left(P_{F, t}^{*} Y_{F, t}+P_{O, t}^{*}\left(C_{O, t}+O_{H, t}\right)\right.
$$

A quantidade de bens importados é dada por:

$$
Y_{F, t}=C_{F, t}+I_{F, t}
$$

\subsubsection{Modelo na forma log-linear:}

- Consumo dos consumidores Ricardianos:

$$
\hat{c_{t}}=-\frac{1-h}{1+h} E_{t}\left[\hat{i}_{t}-\hat{\pi}_{C, t+1}\right]+\frac{1}{1+h} E_{t}\left[\hat{c}_{t+1}^{R}\right]+\frac{h}{1+h} \hat{c}_{t-1}^{R}+\frac{1-h}{1+h}\left[\hat{\xi}_{C, t}-E_{t}\left[\hat{\xi}_{C, t+1}\right]\right]-\frac{1}{1+h}\left[h \hat{\xi}_{T, t}-E_{t}\left[h \hat{\xi}_{T, t+1}\right]\right]
$$

- Paridade descoberta de juros:

$$
\hat{i_{t}}=\hat{i}_{t}^{*}+\varrho \hat{b}_{t}^{*}+E_{t}\left[\Delta \hat{e}_{t+1}\right]
$$

- Oferta de trabalho:

$w r_{t}=\frac{1}{\left[\kappa_{L}+(1+\beta)\right]}\left[\kappa_{L}\left(\sigma_{L} l_{t}+\frac{1}{1-h} c_{t}-\frac{h}{1-h} c_{t-1}+\xi_{L, t}\right)+w r_{t-1}+\beta E_{t}\left[w r_{t+1}\right]-\left(1+\beta \chi_{L}\right) \pi_{C, t}+\chi_{L} \pi_{C, t-1}+\beta E_{t}\left[\pi_{C, t+1}\right]\right]$

$$
\kappa=\frac{\left(1-\beta \phi_{L}\right)\left(1-\phi_{L}\right)}{\phi_{L}\left(1+\sigma_{L} \epsilon_{L}\right)}
$$

- Cestas de consumo;

$$
\begin{aligned}
& \hat{c}_{Z, t}=\hat{c}_{t}-\varpi_{C} p \hat{r}_{Z, t} \\
& \hat{c}_{o, t}=\hat{c}_{t}-\varpi_{C} \hat{p r_{o, t}} \\
& \alpha_{C} \hat{p r}_{Z, t}+\left(1-\alpha_{C}\right) \hat{p r}{ }_{O, t}=0 \\
& \hat{c}_{H, t}=\hat{c}_{Z, t}-\eta_{C} p \hat{r}_{H_{d, t}}
\end{aligned}
$$


O papel das variáveis externas no período 1999-2013 em um modelo DSGE

$$
\hat{c}_{F, t}=\hat{c}_{Z, t}-\eta_{C} \hat{p r}_{F, t}
$$

$$
\hat{p r}_{Z, t}=\gamma_{C} \hat{p}{ }_{H d, t}+\left(1-\gamma_{C}\right) \hat{p r}_{F, t}
$$

- Acumulação de capital:

$$
\hat{k}_{t+1}=(1-\delta) \hat{k}_{t}+i \hat{n} v+\hat{\xi}_{I, t}
$$

- Cestas de investimento:

$$
\begin{aligned}
& \hat{i n v_{H, t}}=i \hat{n} v-\theta_{I}\left(\hat{p r}_{H D, t}-\hat{p r_{I, t}}\right) \\
& i \hat{n} v_{F, t}=i \hat{n} v-\theta_{I}\left(\hat{p r_{F t}}-\hat{p r} \hat{I, t}\right) \\
& \hat{p r}=\gamma_{I} p r_{H} d, t+\left(1-\gamma_{I}\right) \hat{p r} \hat{r}_{F, t}
\end{aligned}
$$

- Preço do investimento:

$\hat{p r_{I, t}}=\frac{Q_{r}}{\operatorname{PrI}}\left(\hat{q} \hat{r}_{t}+\varepsilon_{I, t}\right)-\frac{Q_{r}}{P r_{I}}\left(1+\frac{1}{1+r}\right) \mu_{S} i \hat{n} v_{t}+\frac{Q_{r}}{P r_{I}} \mu_{S} i \hat{n} v_{t-1}+\frac{Q_{r}}{P r_{I}} \mu_{S} \frac{1}{1+r} E_{t}\left[\hat{i n} v_{t+1}\right]$

- Preço sombra do capital:

$$
\hat{q \hat{r}_{t}}=E_{t}\left[\pi_{C, t+1}-i_{t}\right]+\frac{1}{1+r} \frac{Z_{r}}{Q_{r}} E_{t}\left[z \hat{r}_{t+1}\right]+\frac{1}{1+r}(1-\delta) E_{t}\left[\hat{q \hat{r}_{t+1}}\right]
$$

- Curva de Philips para os bens consumidos domesticamente:

$$
\hat{\pi}_{H D, t}=\frac{\beta}{1+\beta \chi_{H D}} E_{t}\left[\hat{\pi}_{H D, t+1}\right]+\frac{\chi_{H D}}{1+\beta \chi_{H D}} \hat{\pi}_{H D, t-1}+\frac{\kappa_{H D}}{1+\beta \chi_{H D}}\left[m \hat{c} r_{H, t}-\hat{p} \hat{r}_{H D, t}\right]
$$

- Curva de Philips para a inflação dos bens exportados:

$$
\hat{\pi}_{H F, t}=\frac{\beta}{1+\beta \chi_{H F}} E_{t}\left[\hat{\pi}_{H F, t+1}\right]+\frac{\chi_{H F}}{1+\beta \chi_{H F}} \hat{\pi}_{H F, t-1}+\frac{\kappa_{H F}}{1+\beta \chi_{H F}}\left[m \hat{c} r_{H, t}-r \hat{e} r-\hat{p} \hat{r}_{H F, t}\right]
$$


- Curva de Philips para os bens importados;

$$
\hat{\pi}_{F, t}=\frac{\beta}{1+\beta \chi_{H F}} E_{t}\left[\hat{\pi}_{H F, t+1}\right]+\frac{\chi_{F}}{1+\beta \chi_{F}} \hat{\pi}_{H F, t-1}+\frac{\kappa_{F}}{1+\beta \chi_{F}}\left[r \hat{e} r_{t}+\hat{\varsigma}_{F, t}^{*}-\hat{p} \hat{r}_{F, t}\right]
$$

onde:

$$
\begin{aligned}
& \kappa_{H D}=\frac{\left(1-\beta \phi_{H, D}\right)\left(1-\phi_{H, D}\right)}{\phi_{L}} \\
& \kappa_{H F}=\frac{\left(1-\beta \phi_{H, F}\right)\left(1-\phi_{H, F}\right)}{\phi_{H, F}} \\
& \kappa_{F}=\frac{\left(1-\beta \phi_{F}\right)\left(1-\phi_{F}\right)}{\phi_{F}}
\end{aligned}
$$

- Regra de Taylor:

$\hat{i}_{t}=\psi \hat{i}_{t-1}+(1-\psi)\left(\psi_{\pi} \hat{\pi}_{Z, t}+\psi_{y} \triangle \hat{y}_{t}\right)+\varsigma_{m, t}$

- Demanda externa pelo bem produzido domesticamente:

$\hat{y}_{H, t}^{*}=\hat{y}_{t}^{*}-\eta^{*} \hat{p r}{ }_{H F, t}$

- Lei do preço único para a commodity exportada e para o preço do petróleo:

$$
\hat{p r}{ }_{S, t}=r \hat{e} r_{t}+\hat{p} \hat{r}_{S, t}^{*}
$$

$$
\hat{p r_{O, t}}=r \hat{e} r_{t}+p \hat{r}_{O, t}^{*}
$$

- Lei de movimento dos preços relativos:

$\hat{\pi}_{Z, t}=\hat{p} \hat{r}_{Z, t}-\hat{p r}{ }_{Z, t-1}+\hat{\pi}_{C, t}$

$\hat{\pi}_{H D, t}=\hat{p} \hat{r}_{H D, t}-\hat{p} \hat{r}_{H D, t-1}+\hat{\pi}_{C, t}$

$\hat{\pi}_{H F, t}=\hat{p} \hat{r}_{H F, t}-\hat{p} \hat{r}_{H F, t-1}+\hat{\pi}_{t}^{*}$

$\hat{\pi}_{F, t}=\hat{p} \hat{r}_{F, t}-\hat{p} \hat{r}_{F, t-1}+\hat{\pi}_{C, t}^{*}$

$$
\triangle \hat{e}_{t}=r \hat{e} r_{t}-r \hat{e} r_{t-1}+\hat{\pi}_{C, t}-\hat{\pi}_{t}^{*}
$$


O papel das variáveis externas no período 1999-2013 em um modelo DSGE 4.3 Modelo

- Taxa de juros real::

$$
\hat{r}_{t}=\hat{i}_{t}-\hat{\pi}_{t}
$$

- Demanda dos bens produzidos domesticamente:

$$
\frac{P_{H} Y_{H}}{P_{Y} Y} \hat{y}_{H, t}=\gamma_{C} \frac{P_{C} C}{P_{Y} Y} \hat{c}_{H, t}+\frac{P_{G} G}{P_{Y} Y}\left(\hat{g}_{t}-\hat{p} \hat{r}_{H D, t}+\hat{p} \hat{r}_{Y, t}+\hat{y}_{t}\right)+\gamma_{I} \frac{P_{I} I}{P_{Y} Y} i \hat{n} v_{H, t}+\frac{P_{H} Y_{H}^{*}}{P_{Y} Y} \hat{y}_{H, t}^{*}
$$

- Oferta dos bens produzidos domesticamente:

$\hat{y}_{H, t}=\hat{a}_{H, t}+\gamma_{H}^{\frac{1}{\omega_{H}}}\left(A_{H} \frac{O_{H}}{Y_{H}}\right)^{\frac{\varpi_{H}-1}{\varpi_{H}}} \hat{o}_{H, t}+\left(1-\gamma_{H}\right)^{\frac{1}{\varpi_{H}}}\left(A_{H} \frac{V_{H}}{Y_{H}}\right)^{\frac{\varpi_{H}-1}{\varpi_{H}}} \eta_{H} \hat{l}_{t}+\left(1-\gamma_{H}\right)^{\frac{1}{\varpi_{H}}}\left(A_{H} \frac{V_{H}}{Y_{H}}\right)^{\frac{\varpi_{H}-1}{\varpi_{H}}}\left(1-\eta_{H}\right)\left(\hat{k}_{t-1}-\hat{\varsigma}_{T, t}\right)$

- PIB real:

$\hat{y}_{t}=\frac{P_{c} C}{P_{Y} Y} \hat{c}_{t}+\frac{P_{G} G}{P_{Y} Y}\left(\hat{g}_{t}-\hat{p r} \hat{r}_{H D, t}+\hat{p r} \hat{r}_{Y, t}+\hat{y}_{t}\right)+\frac{P_{I} I}{P_{Y} Y} i \hat{n} v+\frac{P_{X} X}{P_{Y} Y} \hat{x}_{t}-\frac{P_{M} M}{P_{Y} Y} \hat{m}_{t}$

- Exportações reais:

$$
\hat{x}_{t}=\frac{\varepsilon P_{S}^{*} Y_{S}}{P_{X} X} \hat{y}_{s, t}+\left(1-\frac{\varepsilon P_{S}^{*} Y_{S}}{P_{X} X}\right) \hat{c}_{H, t}^{*}
$$

- Importações reais:

$\hat{m}_{t}=\left(1-\gamma_{C}\right) \frac{P_{C} C}{P_{M} M} \hat{c}_{F, t}+\left(1-\gamma_{I}\right) \frac{P_{I} I}{P_{M} M} i \hat{n} v_{F, t}+\frac{P_{O}\left(C_{O}+O_{H}\right)}{P_{M} M}\left(\frac{C_{O}}{C_{O}+O_{H}} \hat{c}_{o, t}+\frac{O_{H}}{C_{O}+O_{H}} \hat{o}_{H, t}\right)$

- Preços das exportações:

$$
\hat{p} \hat{r}_{X, t}=\frac{\varepsilon P_{S}^{*} Y_{S}}{P_{x} X} \hat{p} \hat{r}_{S, t}+\left(1-\frac{\varepsilon P_{S}^{*} Y_{S}}{P_{x} X}\right)\left(\hat{p} \hat{r}_{H F, t}+r \hat{e} r_{t}\right)
$$

- Preços das importações:

$$
\hat{p} \hat{r}_{M, t}=r \hat{e} r_{t}+\left(1-\frac{P_{O}\left(C_{O}+O_{H}\right)}{P_{M} M}\right) \hat{\varsigma}_{F, t}^{*}+\frac{P_{O}\left(C_{O}+O_{H}\right)}{P_{M} M} \hat{r}_{O, t}^{*}
$$

Os choques exógenos seguem um processo $\mathrm{AR}(1)$. 


\subsection{Dados}

Nas estimação do modelo, foram utilizadas séries do produto, consumo, investimento, taxa de juros, emprego, inflação, conta-corrente, preço do petróleo e câmbio nominal. Assim, foram utilizadas 9 séries ao todo. Com exceção da conta-corrente, as demais séries são as recomendadas no estudo de Guerrón-Quintana (2007), e foram incluídas por serem variáveis relacionadas ao mercado externo, potencialmente informativas para um modelo de economia aberta, como o modelo em questão.

Em um primeiro momento, o modelo foi estimado considerando diferentes configurações de séries. Em adição às mencionadas acima, testou-se também a taxa de juros americana (FED FUNDS), a inflação externa - aproximada pela inflação dos países do G-20-, o crescimento da economia mundial - aproximado pelo crescimento dos países do G-20- e o preços das importações ( fonte FUNCEX). A configuração mencionada acima foi a que logrou obter maior verossimilhança marginal, indicando um melhor ajuste do modelo.

Figura 4.3: Séries utilizadas

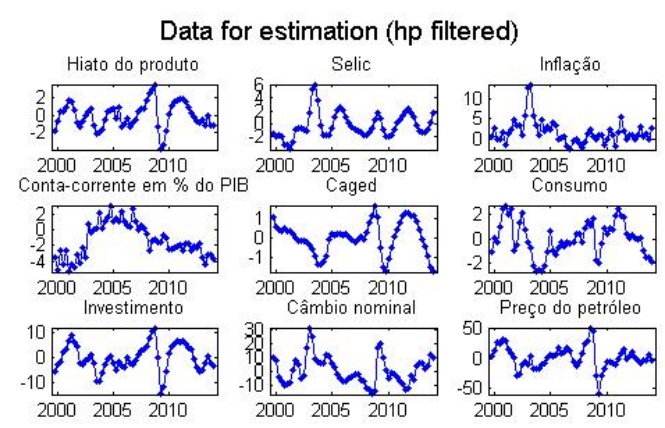

\subsection{Calibração}

Alguns parâmetros foram calibrados, por serem de difícil identificação ou serem mais consensuais na literatura. A descrição dos parâmetros, valores e justificativas se encontra na tabela abaixo: 
O papel das variáveis externas no período 1999-2013 em um modelo DSGE 4.5 Calibração estimado para o Brasil

\begin{tabular}{|c|c|c|c|}
\hline Parâmetro & Descrição & Valor & Fonte/Motivo \\
\hline Inflação de ss & - & $4,5 \%$ a.a., trimestralizado & Meta de inflação vigente no Brasil \\
\hline $\begin{array}{c}\text { Exportações líquidas de ss } \\
\text { em \% do PIB }\end{array}$ & & $1 \%$ & $\begin{array}{l}\text { No modelo SAMBA (Castro et. al } \\
\text { - 2011) as exportações líquidas são } \\
12 \% \text { e importações } 11 \%\end{array}$ \\
\hline $\begin{array}{l}\text { Conta-corrente em } \% \text { do } \\
\text { PIB no ss }\end{array}$ & & $-0,68 \%$ & $\begin{array}{l}\text { Calibrado com base no modelo } \\
\text { SAMBA (Castro et. al - 2011) }\end{array}$ \\
\hline Beta & Fator de desconto & 0.985 & $\begin{array}{l}\text { Vasconcelos e Divino (2012), } \\
\text { aproximadamente } 6 \% \text { real }\end{array}$ \\
\hline alpha_C & $\begin{array}{l}\text { Participação do petróleo } \\
\text { no consumo }\end{array}$ & $3 \%$ & Participação da gasolina no IPCA \\
\hline gamma_I & $\begin{array}{l}\text { Participação de bens } \\
\text { domésticos no } \\
\text { investimento }\end{array}$ & 0.80 & $\begin{array}{c}\text { Bens de capital representam cerca } \\
\text { de } 20 \% \text { das importações }\end{array}$ \\
\hline gamma_C & $\begin{array}{l}\text { Participação de bens } \\
\text { domésticos no consumo }\end{array}$ & 0.82 & $\begin{array}{l}\text { Bens de consumo representam } \\
\text { cerca de } 17 \% \text { das importações }\end{array}$ \\
\hline Ys_Y & $\begin{array}{l}\text { Participação da produção } \\
\text { de commodities no PIB }\end{array}$ & $6 \%$ & $\begin{array}{l}\text { Commodities representam cerca de } \\
58 \% \text { das exportações nos anos } 2000\end{array}$ \\
\hline delta_I & Depreciação & $10 \%$ a.a. & Vasconcelos e Divino (2012) \\
\hline gamma_H & $\begin{array}{l}\text { Participação do petróleo } \\
\text { na produção de bens } \\
\text { domésticos }\end{array}$ & & \\
\hline eta_H & $\begin{array}{l}\text { Participação do trabalho } \\
\text { na renda }\end{array}$ & $55 \%$ & SAMBA (Castro et. al - 2011) \\
\hline eps_L, eps_H, eps_F & $\begin{array}{c}\text { Elasticidades de } \\
\text { substituição (trabalho, } \\
\text { bens domésticos e bens } \\
\text { externos) }\end{array}$ & 11 & SAMBA (Castro et. al - 2011) \\
\hline sigma_C & $\begin{array}{c}\text { Elasticidade de } \\
\text { substituição intertemporal }\end{array}$ & 1 & \\
\hline sigma_L & $\begin{array}{l}\text { Elasticidade da oferta de } \\
\text { trabalho em relação ao } \\
\text { salário real }\end{array}$ & 1 & \\
\hline Gh_Y & $\begin{array}{c}\text { Participação do governo } \\
\text { no PIB }\end{array}$ & $20 \%$ & SAMBA (Castro et. al - 2011) \\
\hline $\mathrm{g} \_\mathrm{yF}$ & $\begin{array}{c}\text { Crescimento mundial no } \\
\text { ss }\end{array}$ & $2 \%$ & \\
\hline $\mathrm{piF}$ & Inflação de ss & $2 \%$ & \\
\hline $\mathrm{iF}$ & $\begin{array}{l}\text { Juros nominais no } \\
\text { exterior em ss }\end{array}$ & $5 \%$ & \\
\hline
\end{tabular}




\subsection{Resultados}

O modelo foi estimado ${ }^{1}$ considerando duas cadeias de 300.000 interações do algoritmo MCMC (Monte Carlo Markov Chain).

\subsubsection{Parâmetros estimados}

A tabela abaixo apresenta os resultados da estimação do modelo.

Em relação aos parâmetros de rigidez nominal do modelo, a de salários foi estimada em um valor baixo $\phi_{L}=0,11$, resultado um tanto quanto contra a intuição ${ }^{2}$. A rigidez de preços dos bens produzidos domesticamente e vendidos internamente foi estimada em $\phi_{H, D}=0,30$, correspondente a um reajuste médio a cada 1,4 trimestre. Por outro lado, a ridez de preços dos bens produzidos domesticamente e exportados foi estimada em um valor bem mais elevado, $\phi_{H, F}=0,97$, o que equivale a um reajuste médio a cada 8 anos. Para os bens importados, a rigidez também foi estimada em $\phi_{F}=0,42$, o que corresponde a uma frequência de reajustes de 1,7 trimestre. Outro ponto que se destaca é o baixo grau de indexação estimado para os preços dos bens domésticos vendidos internamente, $\chi_{H d}=0,10$, mostrando uma maior importância relativa das expectativas de inflação no processo inflacionário desses bens.

As elasticidades entre bens domésticos e importados no consumo e investimento $\left(\eta_{C}, \eta_{I}\right)$ foram estimadas em 0,85 e 0,95 na média da posterior, respectivamente, mostrando alguma dificuldade de substituição desses bens. Entretanto, o gráfico da prior e da posterior mostra que estes parâmetros são de difícil identificação, o que é reforçado pelo critério de identificação. A título de curiosidade, no caso Chileno estes parâmetros foram estimados em valores superiores à unidade, mostrando um maior grau de susbtituição.

Dos parâmetros relacionados à regra de Taylor, o grau de suavização da taxa de juros foi estimado em $\psi=0,65$. O peso da inflação foi estimado em $\psi_{\pi}=2,06$, um valor relativamente elevado e superior à prior considerada. Por sua vez, o peso do produto foi estimado em $\psi_{y}=0,48$, um pouco inferior à prior considerada.

O gráfico de substituição do petróleo no consumo e no investimento foi estimado em $\omega_{C}=0,64$ e $\omega_{H}=0,36$, respectivamente, mostrando um grau maior de substituição do lado da produção do que no consumo.

\footnotetext{
${ }^{1} \mathrm{O}$ código para a estimação do modelo foi retirado da base de dados http://www.macromodelbase.com/

${ }^{2}$ Mesmo quando o modelo foi estimado utilizando-se uma série de salário real, o parâmetro de Calvo de salários continuou apresentado um valor baixo, em torno de 0,19. Neste caso, o parâmetro de Calvo de preços dos bens domésticos vendidos internamente foi estimado em 0,29, o dos bens produzidos domesticamente e exportados em 0,93 e o Calvo das importações em 0,39 .
} 
O papel das variáveis externas no período 1999-2013 em um modelo DSGE 4.6 Resultados estimado para o Brasil

O parâmetro do hábito no consumo foi estimado em 0,70 , próximo do estimado em Castro et al. (2011).

\subsubsection{Distribuições posteriores}

Figura 4.4: $\quad$ Priors $\mathrm{x}$ posteriores dos parâmetros estimados - 1

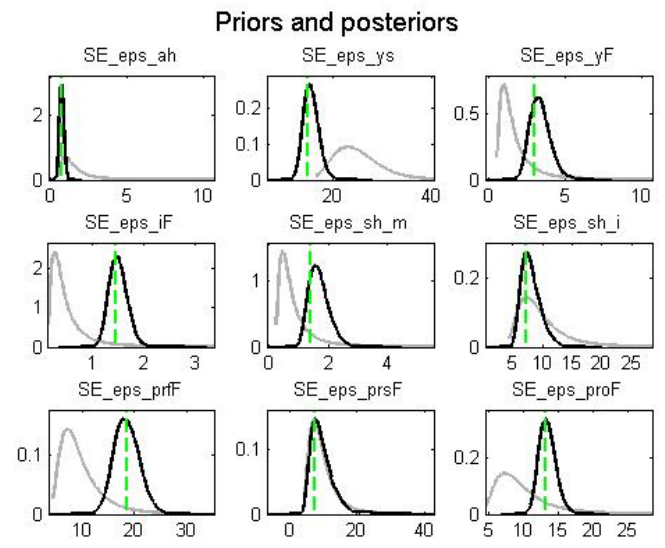

1a linha: desvio-padrão do choque de produtividade, desvio-padrão do choque na produção de commodities, desvio-padrão do choque do produto mundial

2a linha: desvio-padrão do choque na taxa de juros externa, desvio-padrão do choque na taxa de juros doméstica, desvio-padrao do choque no custo de ajustamento do investimento

3a linha: desvio-padrao do choque no preço das importações, desvio-padrao do choque no preço das commodities exportadas, desvio-padrão do choque no preço do petróleo 
Figura 4.5: $\quad$ Priors $\mathrm{x}$ posteriores dos parâmetros estimados - 2

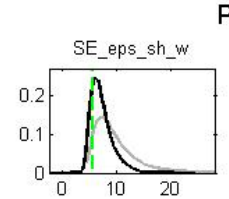

Priors and posteriors
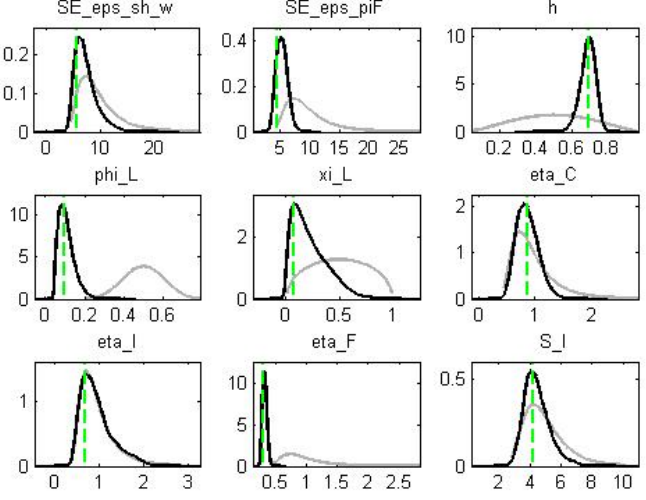

1a linha: desvio-padrão do choque na oferta de trabalho, desvio-padrão do choque na inflação mundial, hábito no consumo

2a linha: Calvo de salários, indexação de salários, elasticidade de substituição entre bens domésticos e importados no consumo

3a linha: elasticidade de substituição entre bens domésticos e importados no investimento, elasticidade-preço da demanda externa pelos bens domésticos, custo de ajustamento do investimento

\subsubsection{Decomposição da Variância}

A decomposição da variância mostra que, no modelo estimado, os choques de maior importância no período 1999-2013 foram os de origem externa, i.e, o choque no produto mundial e o choque na inflação mundial. Os choques na taxa de juros externa explicam cerca de $11 \%$ do câmbio nominal e $14 \%$ da conta-corrente. Choques na taxa de juros doméstica respondem por cerca de $40 \%$ da variabilidade da inflação e $8 \%$ do câmbio nominal. O choque no preço das importações, que pode ser interpretado como um choque negativo nos termos de troca, tem o seu maior efeito na inflação -explica 15\% da sua variabilidade - e indiretamente nos juros domésticos, respondendo por $20 \%$ da sua variação. Por último, os choques no preço do petróleo explicam em torno de $9 \%$ da variabilidade da inflação, $12 \%$ da taxa de juros doméstica e $11 \%$ da conta-corrente.

$\mathrm{Na}$ tabela 5 não foram apresentadas as contribuições dos choques na produção e no preço das commodities importadas, pois esses choques não explicaram mais do que $1 \%$ de nenhuma das variáveis endógenas consideradas. Entretanto, na decomposição da variância condicional o choque na produção de commodities tem importância. Para 1, 4, 8 , 16 e 32 períodos à frente, a contribuição do choque de produção de commodities para o produto é de 47, 24, 14, 6 e $2 \%$, respectivamente. Assim, quanto mais longo o período, menor a contribuição do choque na produção de commodities para o produto, até esta contribuição se tornar praticamente desprezível na decomposição da variância incondicional, apresentada na tabela 5. 
O papel das variáveis externas no período 1999-2013 em um modelo DSGE 4.6 Resultados estimado para o Brasil

Figura 4.6: $\quad$ Priors $\mathrm{x}$ posteriores dos parãmetros estimados -3

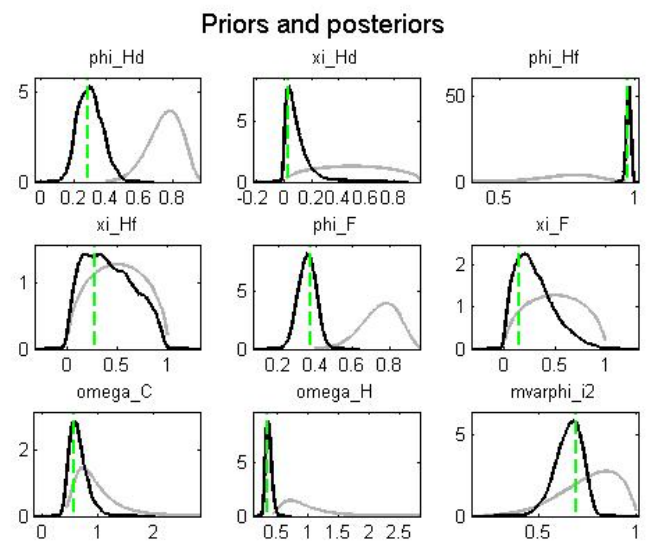

1a linha: Calvo dos bens domésticos vendidos internamente, indexação dos bens domésticos vendidos internamente, Calvo dos bens domésticos exportados

2a linha: indexação dos bens domésticos vendidos no exterior, Calvo dos bens importados, indexação dos bens importados

3a linha: elasticidade de substituição entre petróleo e outros bens no consumo, elasticidade de substituição entre petróleo e o composto de capital e trabalho na produção, suavização da taxa de juros na regra de Taylor

A evolução da variância condicional mostra que que o peso dos fatores externos no produto é crescente à medida em que o horizonte de previsão aumenta. Para 1 trimestre à frente, os choques associados à oferta do modelo respondem por mais de $80 \%$ da variação do produto, mas 4 anos à frente o peso da oferta recua para $26 \%$, enquanto o peso dos fatores externos alcança $72 \%$. Esta dinâmica contradiz com a do Chile, em que fatores associados à oferta e ao setor externo têm papel semelhante no longo prazo.

Para outras variáveis endógenas do modelo (inflação, salário real, conta-corrente), o peso de choques de origem externa também é bastante relevante, muito embora para a inflação os choques na taxa de juros doméstica exerçam um uma influência bastante significante, respondendo por cerca de $40 \%$ da sua variabilidade. Para o salário real, no curto prazo $14 \%$ da sua variabilidade é explicada por choques de oferta, mas esta contribuição declina significativamente ao longo do tempo, predominando os choques externos no longo prazo. Por sua vez, a taxa de câmbio e a conta-corrente são explicadas essencialmente por choques externos, tanto no curto quanto no longo prazo.

\subsubsection{Decomposição histórica}

Seguindo Soto e Medina (2007), os choques do modelo foram agrupados segundo o seu tipo. Esta opção permite uma visualização mais clara da decomposição histórica de cada variável endógena em função da contribuição de cada choque estrutural. Os 
Figura 4.7: $\quad$ Priors x posteriores dos parâmetros estimados - 4

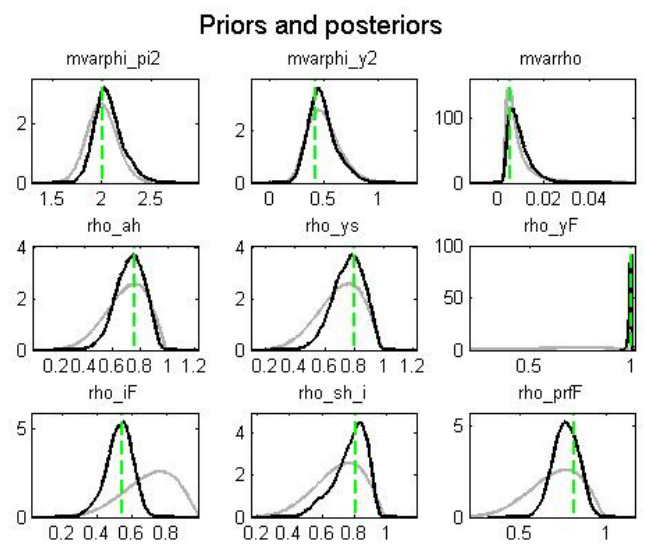

1a linha: peso da infação na regra de Taylor, peso do produto na regra de taylor, elasticidade do prêmio de risco 2a linha: persistência do choque na produtividade, persistência no choque na produção de commodities, eprsitência no choque no produto mundial

3a linha: persistência no choque na taxa de juros externa, persistência no choque no custo de ajustamento do investimento, persistência do choque no preço das importações

choques de produtividade, na produção de commodities, no custo de ajustamento do investimento e na oferta de trabalho foram agrupados como choques de oferta. Por sua vez, os choques no preço das commodities exportadas, no preço do petróleo, no produto mundial, na taxa de juros externa, na inflação externa e no preço das importações foram classificados como choques de origem externa.

Para a evolução histórica do produto, o modelo atribui às condições externas um papel expansionista entre 2001 e 2003, contrabalanceados por fatores da oferta doméstica. Entre 2004 e o início da crise em 2008, os papéis se invertem, com uma contribuição positiva dos choques associados à oferta doméstica e negativa dos fatores externos. Por sua vez, a desaceleração recente da economia brasileira é atribuída majoritariamente a choques de oferta.

Os choques na taxa de juros doméstica têm papel predominante na dinâmica da inflação. Até meados de 2005, o modelo os choques de política monetária contribuíram para o aumento da inflação, passando a ter papel contracionista daí em diante. Dentre os fatores externos, os choques no preço do petróleo e no preço dos bens importados foram os de maior relevância na dinâmica da inflação no período, contribuindo para pressionar a inflação. Por outro lado, choques na inflação externa, pelas funções de resposta ao impulso, levam a uma valorização da taxa de câmbio, o que acaba reduzindo a taxa de inflação nos períodos imediatamente posteriores ao choque

A dinâmica da conta-corrente é explicada majoritariamente por choques de origem externa, em especial os choques no produto mundial, na taxa de juros externa, na inflação mundial e no preço do petróleo. Entre 2006 e 2007, o superávit em 
O papel das variáveis externas no período 1999-2013 em um modelo DSGE 4.6 Resultados estimado para o Brasil

Figura 4.8: $\quad$ Priors $\mathrm{x}$ posteriores dos parâmetros estimados - 5

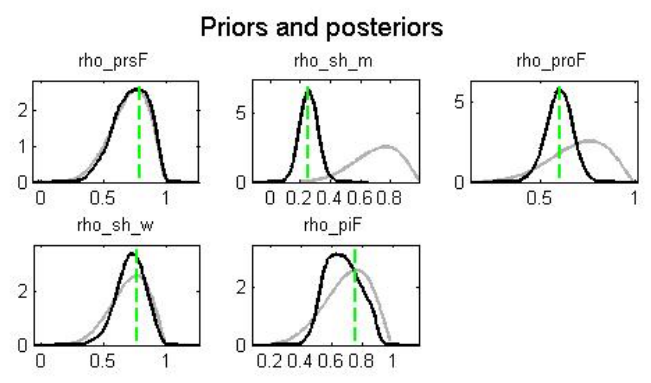

1a linha: persistência no choque no preço das commodities exportadas, persistência no choque na taxa de juros doméstica, persistência no choque no preço do petróleo

2a linha: persistência no choque na oferta de trabalho, persistência no choque na inflação mundial

transações correntes é explicado pelo modelo como função de choques no produto mundial, na taxa de juros externa e na inflação externa. Em termos quantitativos, choques nos termos de troca têm uma importância menor na evolução da contacorrente, de acordo com o modelo.

A taxa de câmbio real é explicada principalmente por fatores externos, especialmente por choques no produto mundial e na inflação externa. 


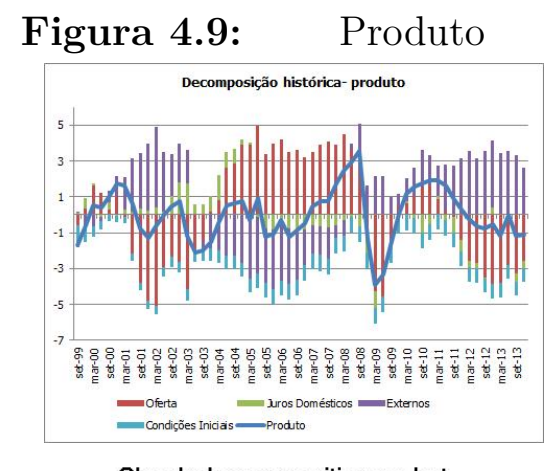

Shock decomposition: y_hat

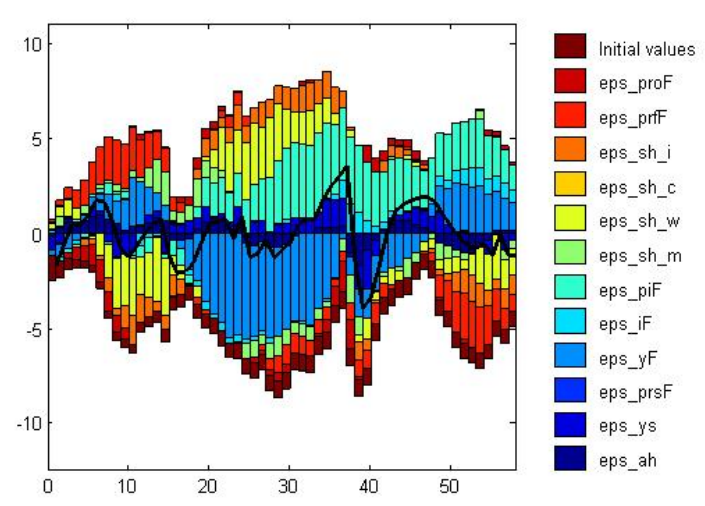

\subsubsection{Funções de impulso resposta}


O papel das variáveis externas no período 1999-2013 em um modelo DSGE 4.6 Resultados estimado para o Brasil

Figura 4.10: $\quad$ Inflação

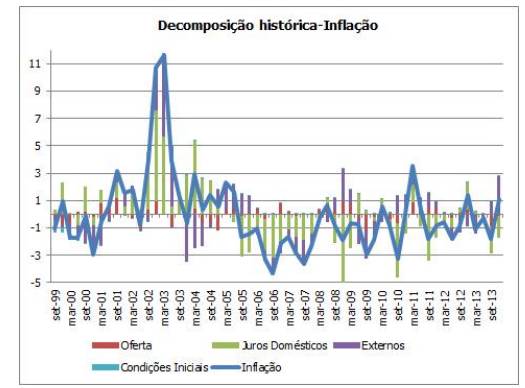

Shock decomposition: picz_hat

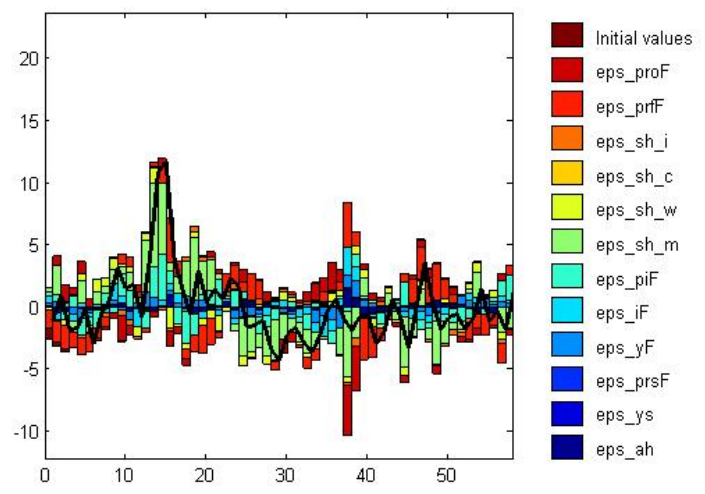

Figura 4.11: Conta-Corrente

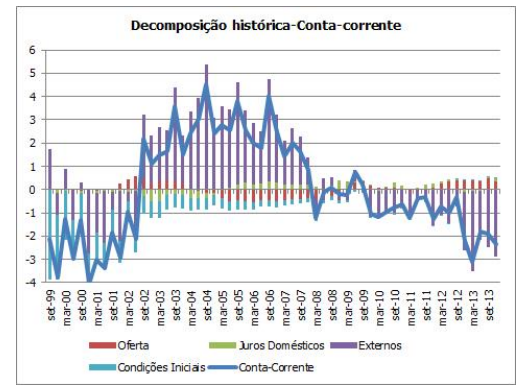

Shock decomposition: ca_y_hat

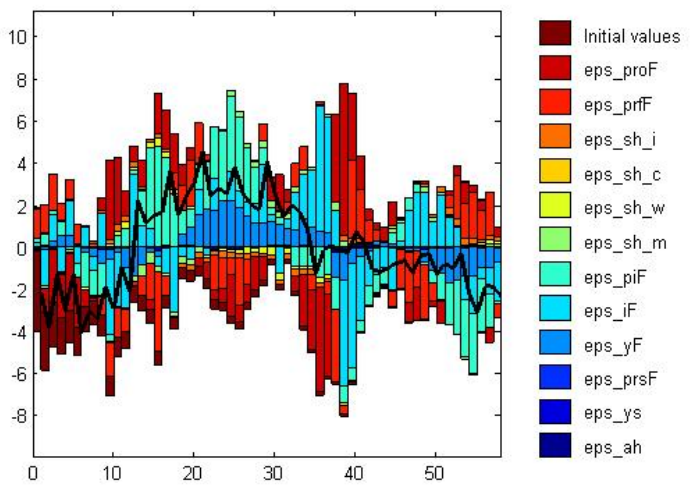


Tabela 4.2: Descrição das séries

\begin{tabular}{|c|c|c|}
\hline Série & Transformação & Fonte \\
\hline $\begin{array}{l}\text { PIB a trimestral a preços de } \\
\text { mercado. Série dessazonalizada } \\
\text { (média } 1995=100 \text { ) }\end{array}$ & $\begin{array}{c}\text { Diferença entre o log natural da série do seu filtro } \\
\text { HP }\end{array}$ & Ipeadata, fonte IBGE \\
\hline $\begin{array}{l}\text { Consumo final das famílias. Série } \\
\text { dessazonalizada (média } 1995= \\
100 \text { ) }\end{array}$ & $\begin{array}{c}\text { Diferença entre o log natural da série do seu filtro } \\
\text { HP }\end{array}$ & Ipeadata, fonte IBGE \\
\hline $\begin{array}{l}\text { Formação bruta de capital fixo. } \\
\text { Série dessazonalizada (média } 1995 \\
\qquad=100)\end{array}$ & $\begin{array}{c}\text { Diferença entre o log natural da série do seu filtro } \\
\text { HP }\end{array}$ & Ipeadata, fonte IBGE \\
\hline $\begin{array}{c}\text { Preço em dolares do barril de } \\
\text { petrélo West Texas Intermediate. }\end{array}$ & $\begin{array}{c}\text { Diferença entre logaritmo natural da média } \\
\text { trimestral do seu filtro HP }\end{array}$ & FED Saint Louis \\
\hline IPCA & Variaçao do IPCA no trimestre & Ipeadata, fonte IBGE \\
\hline Taxa Selic fixada pelo COPOM & Média no trimestre & Ipeadata, fonte BCB \\
\hline $\begin{array}{l}\text { Taxa de câmbio nominal - } \\
\text { BRL/USD }\end{array}$ & $\begin{array}{c}\text { Diferença entre o log natural da série do seu filtro } \\
\qquad \mathrm{HP}\end{array}$ & $\mathrm{BCB}$ \\
\hline Inflação Externa & Taxa de inflação trimestral ano/ano do G20 & OCDE \\
\hline Crescimento Mundial & Taxa de crescimento trimestral do G20 & OCDE \\
\hline Taxa de juros externa & FED Funds & FED Saint Louis \\
\hline Preço das importações & $\begin{array}{c}\text { Diferença entre o log natural da série do seu filtro } \\
\qquad \text { HP }\end{array}$ & Ipeadata, fonte FUNCEX \\
\hline Preços das commodities exportadas & $\begin{array}{c}\text { Diferença entre o log natural da série do seu filtro } \\
\text { HP }\end{array}$ & FMI \\
\hline Conta-corrente & $\begin{array}{l}\text { Déficit em conta-corrente no trimestre. Para } \\
\text { transformar a série em \% do PIB, calculei uma série } \\
\text { trimestral do PIB em dólares, dividindo o PIB em } \\
\text { reais pela taxa de câmbio média em um determinado } \\
\text { trimestre. }\end{array}$ & $\mathrm{BCB}$ \\
\hline Estoque de empregados formais. & $\begin{array}{l}\text { A partir do estoque de empregados disponível em } \\
\text { maio de } 2013 \text {, e considerando a série dos saldos } \\
\text { (admissões - demissões), construiu-se } \\
\text { retroativamente a série de estoque de empregados até } \\
\text { o início da série, em maio de 1999. Posteriormente a } \\
\text { série do estoque foi dessazonalizada, aplicou-se o log } \\
\text { natural e subtraiu-se o filtro HP. }\end{array}$ & $\begin{array}{c}\text { Ministério do Trabalho e } \\
\text { Emprego }\end{array}$ \\
\hline
\end{tabular}


Tabela 4.3: Descrição dos parâmetros estimados

\begin{tabular}{|c|c|}
\hline Parâmetro & Descrição \\
\hline sigma L & Inverso da elasticidade da oferta de trabalho \\
\hline $\mathrm{h}$ & Coeficiente de hábito no consumo \\
\hline phi_L & Probabilidade de Calvo de não reajuste dos salários nominais \\
\hline xi_L & Peso da inflação passada na indexação dos salários nominais \\
\hline eta_C & Elasticidade de substituição entre bens domésticos e importados no consumo \\
\hline eta_I & Elasticidade de substituição entre bens domésticos e importados no investimento \\
\hline S_I & Coeficiente do custo de ajustamento do investimento \\
\hline phi_Hd & Probabilidade de Calvo de não reajuste dos bens domésticos vendidos internamente \\
\hline xi_Hd & Peso da inflação passada na indexação dos preços dos bens vendidos domesticamente \\
\hline phi_Hf & Probabilidade de Calvo de não reajuste dos bens domésticos vendidos no exterior \\
\hline xi_Hf & Peso da inflação passada na indexação dos bens domésticos vendidos no exterior \\
\hline phi_F & Probabilidade de Calvo de não reajuste dos preços dos bens importados \\
\hline xi_F & Peso da inflação passada na indexação dos preços dos bens importados \\
\hline omega_C & Elasticidade de substituição entre petróleo e outros bens na cesta de consumo \\
\hline omega_H & Elastici3dade de substituição entre petróleo e composto de capital e trabalho na função de produção \\
\hline mvarphi_i2 & Coeficiente de suavização da taxa de juros \\
\hline mvarphi_pi2 & Peso da inflação na regra de política monetária \\
\hline mvarphi_y2 & Peso do produto na regra de política monetária \\
\hline eta_F & Elasticidade da demanda externa em relação aos bens domésticos \\
\hline mvarrho & Elasticidade do prêmio de risco em relação à relação dívida externa líquida-PIB \\
\hline rho_ah & Persistência do choque de produtividade \\
\hline rho_ys & Persistência do choque na produção de commodities \\
\hline rho_yF & Persistência do choque no produto mundial \\
\hline rho_iF & Persistência do choque na taxa de juros externa \\
\hline rho_piF & Persistência do choque na inflação mundial \\
\hline rho_sh_c & Persistência no choque nas preferências de consumo \\
\hline rho_sh_i & Persistência do choque no custo de ajustamento do investimento \\
\hline rho_prfF & Persistência no choque no preço das importações \\
\hline rho_prsF & Persistência do choque no preço das commodities exportadas \\
\hline rho_sh_m & Persistência do choque na taxa de juros interna \\
\hline rho_proF & Persistência do choque no preço do petróleo \\
\hline rho_sh_w & Persistência do choque na oferta de trabalho \\
\hline rho_e_hat & Persistência do choque na taxa de juros nominal \\
\hline eps_ah & Desvio-padrão do choque de produtividade \\
\hline eps_ys & Desvio-padrão do choque na produção de commodities \\
\hline eps_yF & Desvio-padrão do choque no produto mundial \\
\hline eps_iF & Desvio-padrão do choque na taxa de juros externa \\
\hline eps_piF & Desvio-padrão do choque na inflação mundial \\
\hline eps_sh_m & Desvio-padrão do choque nas preferências de consumo \\
\hline eps_sh_c & Desvio-padrão do choque no custo de ajustamento do investimento \\
\hline eps_sh_i & Desvio-padrão no choque no preço das importações \\
\hline eps_prfF & Desvio-padrão do choque no preço das commodities exportadas \\
\hline $114^{\text {ps__prsF }}$ & Desvio-padrão do choque na taxa de juros interna \\
\hline eps_proF & Desvio-padrão do choque no preço do petróleo \\
\hline eps_sh_w & Desvio-padrão do choque na oferta de trabalho \\
\hline eps_e_hat & Desvio-padrão do choque na taxa de juros nominal \\
\hline
\end{tabular}


Tabela 4.4: $\quad$ Parâmetros estimados

\begin{tabular}{|c|c|c|c|c|c|}
\hline Parâmetro & Prior & Distribuição & Desvio-Padrão & Descrição & Média da Posterior \\
\hline $\mathrm{h}$ & 0.500 & beta & 0.2000 & Hábito & 0.6889 \\
\hline phi_L & 0.500 & beta & 0.1000 & Rigidez salários & 0.1067 \\
\hline xi_L & 0.500 & beta & 0.2500 & Index salários & 0.2238 \\
\hline eta_C & 1.000 & invg & 0.5000 & Subst consumo & 0.8563 \\
\hline eta_I & 1.000 & invg & 0.5000 & Subst investimento & 0.9511 \\
\hline eta_F & 1.000 & invg & 0.5000 & Subst demanda externa & 0.3114 \\
\hline S_I & 5.000 & invg & 1.5000 & Ajust invest & 4.4438 \\
\hline phi_Hd & 0.750 & beta & 0.1000 & Rigidez preços dom & 0.2989 \\
\hline xi_Hd & 0.500 & beta & 0.2500 & Index preços dom & 0.0967 \\
\hline phi_Hf & 0.750 & beta & 0.1000 & Rigidez preços exp & 0.9777 \\
\hline xi_Hf & 0.500 & beta & 0.2500 & Index preços exp & 0.4210 \\
\hline phi_F & 0.750 & beta & 0.1000 & rigidez preços imp & 0.3535 \\
\hline $\mathrm{xi} \_\mathrm{F}$ & 0.500 & beta & 0.2500 & Index preços imp & 0.3001 \\
\hline omega_C & 1.000 & invg & 0.5000 & Elast petr consumo & 0.6491 \\
\hline omega_H & 1.000 & invg & 0.5000 & Elast petr produção & 0.3673 \\
\hline mvarphi_i2 & 0.750 & beta & 0.1500 & Taylor suavização & 0.6491 \\
\hline mvarphi_pi2 & 2.000 & gamma & 0.1500 & Taylor inflação & 2.0664 \\
\hline mvarphi_y2 & 0.500 & gamma & 0.1500 & Taylor produto & 0.4857 \\
\hline mvarrho & 0.010 & invg & 4.0000 & Elasticidade do prêmio & 0.0092 \\
\hline rho_ah & 0.700 & beta & 0.1500 & Pers produtividade & 0.7280 \\
\hline rho_ys & 0.700 & beta & 0.1500 & Pers prod commodities & 0.7588 \\
\hline rho_yF & 0.700 & beta & 0.1500 & Pers prod mundial & 0.9910 \\
\hline rho_iF & 0.700 & beta & 0.1500 & Pers juros mundiais & 0.5256 \\
\hline rho_sh_i & 0.700 & beta & 0.1500 & Pers ajustamento do inv & 0.7730 \\
\hline rho_prfF & 0.700 & beta & 0.1500 & Pers preço importações & 0.7650 \\
\hline rho_prsF & 0.700 & beta & 0.1500 & Pers preço commod exp & 0.7174 \\
\hline rho_sh_m & 0.700 & beta & 0.1500 & Pers juros domésticos & 0.2560 \\
\hline rho_proF & 0.700 & beta & 0.1500 & Pers preço petróleo & 0.5995 \\
\hline rho_sh_w & 0.700 & beta & 0.1500 & Pers oferta trab & 0.7129 \\
\hline rho_piF & 0.700 & beta & 0.1500 & Pers inflação mundial & 0.6728 \\
\hline eps_ah & 2.000 & invg & 5.0000 & DP produtividade & 0.7638 \\
\hline eps_ys & 25.000 & invg & 5.0000 & DP produção commodi & 15.4212 \\
\hline eps_yF & 2.000 & invg & 5.0000 & DP produto mundial & 3.3563 \\
\hline eps_iF & 0.600 & invg & 5.0000 & DP juros externos & 1.5063 \\
\hline eps_sh_m & 1.000 & invg & 5.0000 & DP juros domésticos & 1.6946 \\
\hline eps_sh_i & 10.000 & invg & 5.0000 & DP ajustamento inv & 8.0656 \\
\hline eps_prfF & 10.000 & invg & 5.0000 & DP preço das importa & 18.5062 \\
\hline eps_prsF & 10.000 & invg & 5.0000 & DP preço comm exp & 9.7365 \\
\hline eps_proF & 10.000 & invg & 5.0000 & DP preço petróleo & 13.3792 \\
\hline eps_sh_w & 10.000 & invg & 5.0000 & DP oferta trab & 7.2767 \\
\hline eps_piF & 10.000 & invg & 5.0000 & DP infla mundial & 5.2937 \\
\hline \multicolumn{3}{|c|}{ Taxa de aceitação - cadeia 1} & \multicolumn{3}{|c|}{$29.04 \%$} \\
\hline \multicolumn{3}{|c|}{ Taxa de aceitação - cadeia 2} & \multicolumn{3}{|c|}{$27.16 \%$} \\
\hline \multicolumn{3}{|c|}{ Verossimilhança Marginal } & \multicolumn{3}{|c|}{-1345.95} \\
\hline
\end{tabular}


O papel das variáveis externas no período 1999-2013 em um modelo DSGE 4.6 Resultados estimado para o Brasil

Tabela 4.5: $\quad$ Decomposição da Variância - contribuição \% de cada tipo de choque

\begin{tabular}{|c|c|c|c|c|c|c|c|c|c|}
\hline Série & Produtivid & $\begin{array}{l}\text { deProduto } \\
\text { Mundial }\end{array}$ & $\begin{array}{c}\text { Juros } \\
\text { externos }\end{array}$ & $\begin{array}{l}\text { Inflação } \\
\text { Externa }\end{array}$ & $\begin{array}{c}\text { Juros } \\
\text { domésti- } \\
\text { cos }\end{array}$ & $\begin{array}{c}\text { Oferta } \\
\text { de } \\
\text { trabalho }\end{array}$ & $\begin{array}{l}\text { Ajustamento } \\
\text { Investi- } \\
\text { mento }\end{array}$ & $\begin{array}{c}\text { Preço } \\
\text { das } \\
\text { importa- } \\
\text { ções }\end{array}$ & $\begin{array}{l}\text { Preço do } \\
\text { petróleo }\end{array}$ \\
\hline Produto & 0.15 & 54.52 & 0.15 & 42.86 & 0.03 & 0.43 & 0.90 & 0.41 & 0.20 \\
\hline Inflação & 2.42 & 2.61 & 3.77 & 22.20 & 39.29 & 3.60 & 1.67 & 15.59 & 8.79 \\
\hline Câmbio Nominal & 0.21 & 33.80 & 11.17 & 41.40 & 8.27 & 0.62 & 0.81 & 2.94 & 0.67 \\
\hline Câmbio Real & 0.02 & 43.28 & 0.31 & 54.74 & 0.02 & 0.08 & 1.13 & 0.24 & 0.17 \\
\hline Salário Real & 0.01 & 42.48 & 0.19 & 56.09 & 0.00 & 0.12 & 0.35 & 0.46 & 0.30 \\
\hline Consumo & 0.01 & 37.47 & 0.18 & 61.40 & 0.01 & 0.03 & 0.40 & 0.28 & 0.22 \\
\hline Investimento & 0.03 & 38.99 & 0.23 & 54.72 & 0.01 & 0.12 & 3.88 & 1.74 & 0.27 \\
\hline Juros domésticos & 1.40 & 6.85 & 4.55 & 40.71 & 0.77 & 2.89 & 9.06 & 20.89 & 12.51 \\
\hline Conta-Corrente & 0.04 & 21.46 & 14.45 & 44.81 & 0.09 & 0.13 & 0.95 & 7.32 & 10.74 \\
\hline
\end{tabular}

Figura 4.12: Câmbio Real

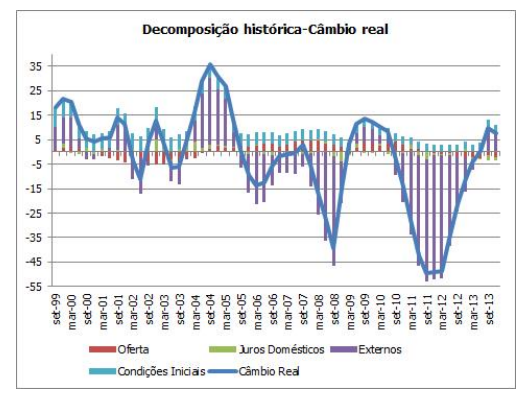

Shock decomposition: rer_hat

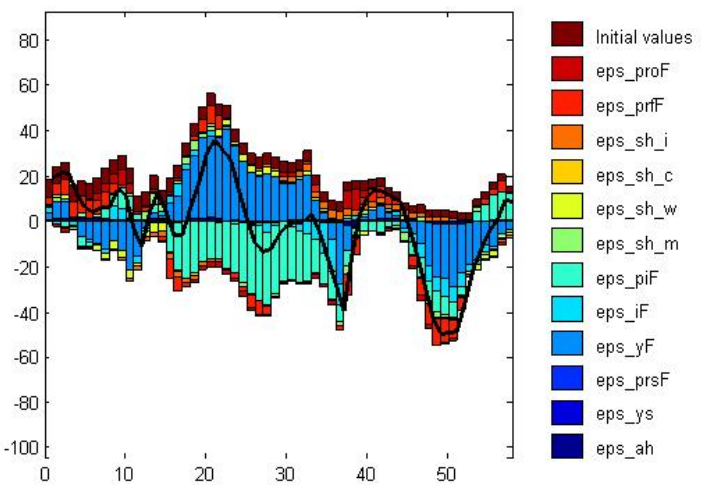


Tabela 4.6: $\quad$ Decomposição da variância condicional - contribuição \% de cada tipo de choque

\begin{tabular}{|c|c|c|c|}
\hline & Oferta & Juros Domésticos & Externos \\
\hline Trimestres & \multicolumn{3}{|c|}{ Produto } \\
\hline 1 & 80,26 & 6,35 & 13,38 \\
\hline 4 & 69,45 & 2,43 & 28,13 \\
\hline 8 & 51,43 & 1,21 & 47,36 \\
\hline 16 & 26,70 & 0,53 & 72,78 \\
\hline 32 & 10,13 & 0,20 & 89,68 \\
\hline Trimestres & \multicolumn{3}{|c|}{ Inflação } \\
\hline 1 & 7,00 & 37,88 & 55,13 \\
\hline 4 & 7,35 & 40,43 & 52,22 \\
\hline 8 & 7,74 & 40,15 & 52,12 \\
\hline 16 & 7,76 & 39,95 & 52,29 \\
\hline 32 & 7,81 & 39,80 & 52,41 \\
\hline Trimestres & \multicolumn{3}{|c|}{ Salário real } \\
\hline 1 & 14,35 & 0,04 & 85,60 \\
\hline 4 & 8,50 & 0,01 & 91,48 \\
\hline 8 & 4,19 & 0,01 & 95,80 \\
\hline 16 & 1,71 & 0,00 & 98,29 \\
\hline 32 & 0,82 & 0,00 & 99,19 \\
\hline Trimestres & \multicolumn{3}{|c|}{ Conta-Corrente } \\
\hline 1 & 0,23 & 0,27 & 99,48 \\
\hline 4 & 0,69 & 0,21 & 99,11 \\
\hline 8 & 1,29 & 0,16 & 98,55 \\
\hline 16 & 1,37 & 0,13 & 98,51 \\
\hline 32 & 1,21 & 0,11 & 98,66 \\
\hline
\end{tabular}

Choques de oferta: choque de produtividade, choque na produção de commodities, choque no custo de ajustamento do investimento, choque na oferta de trabalho

Choque monetário: choque na taxa de juros doméstica

Choques externos: choque no preço das commodities exportadas, choque no preço do petróleo, choque na demanda externa, choque na taxa de juros externa, choque na inflação externa, choque no preço das importações 
Figura 4.13: Choque de produtividade

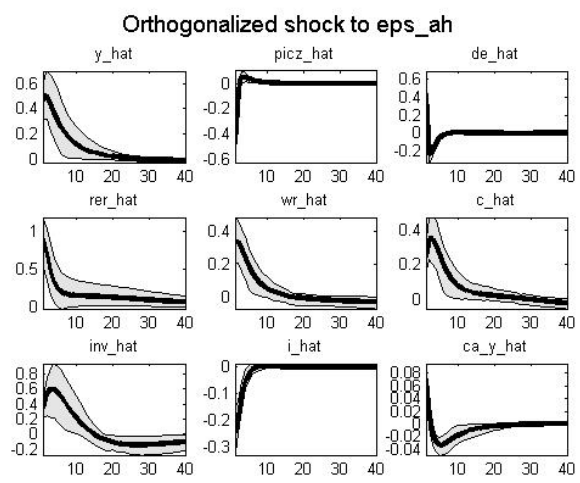

Após um choque de produtividade, o produto, o consumo e o investimento aumentam. A inflação cai, por conta da queda do custo marginal real. A reação endógena da política monetária leva a uma queda da taxa de juros. Com a queda da inflação, o câmbio real se deprecia, o que contribui para elevar o saldo em transações correntes.

Figura 4.14: Choque na produção de commodities

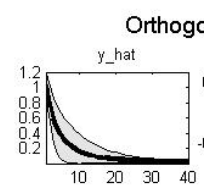

Orthogonalized shock to eps_ys
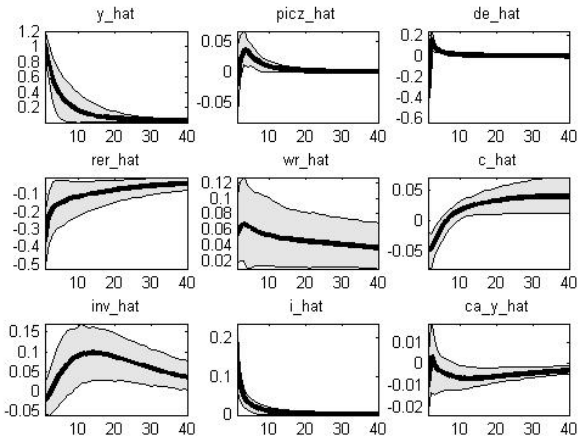

Um choque na produção de commodities leva imediatamente a um aumento do produto. A taxa de cãmbio, tanto real quanto nominal, se aprecia após o choque. 
Figura 4.15: $\quad$ Choque no preço das commodities exportadas

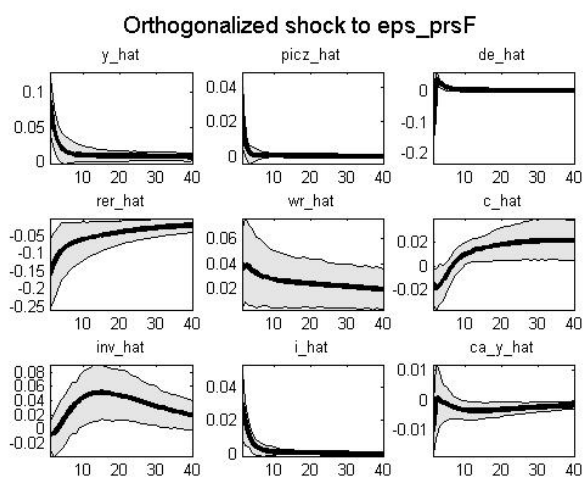

O choque no preço das commodities exportadas leva a um aumento do produto e investimento e a uma apreciação do câmbio real e nominal. A infalção se eleva no instante do choque, mas a valorização do câmbio reduz a inflação dos bens importados e da inflação em geral.

Figura 4.16: Choque no produto mundial

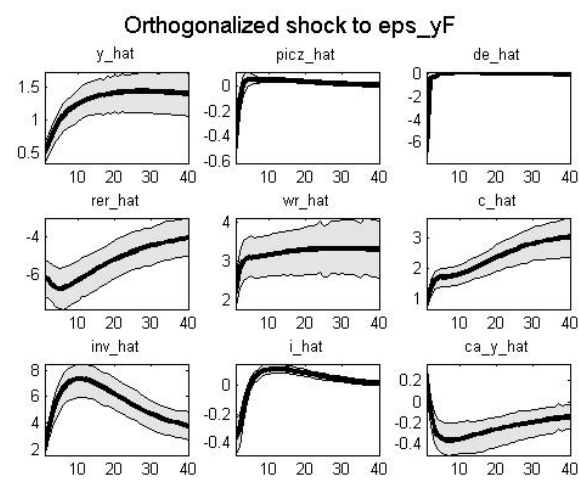


Figura 4.17: $\quad$ Choque na taxa de juros doméstica
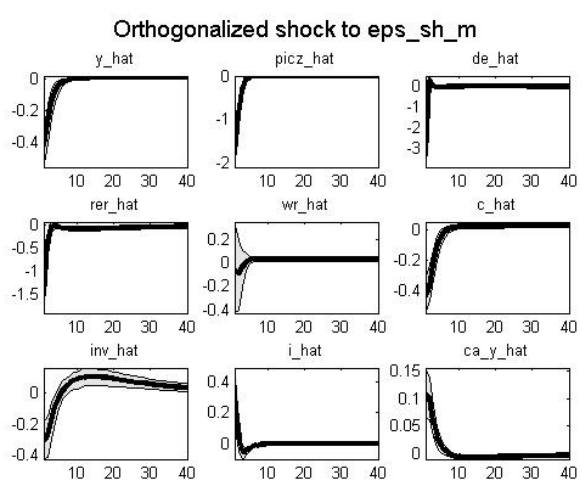

Um choque na taxa de juros doméstica leva a uma queda do produto, do consumo e do investimento. A taxa de câmbio se valoriza. Apesar disto, o saldo em transações correntes aumenta, atuando de forma contra-cíclica.

Figura 4.18: Choque na taxa de juros externa

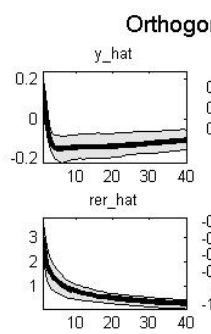
Orthogonalized shock to eps_iF
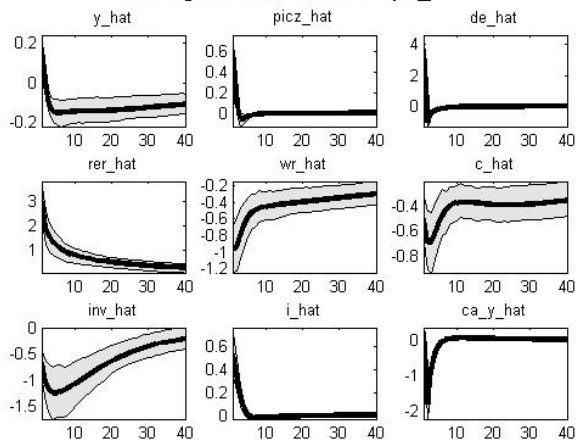

Um choque na taxa de juros externa leva a uma queda do produto, do consumo e do investimento. A inflação aumenta, e a taxa de câmbio sobre uma depreciação. O salário real recua, e a taxa de juros doméstica se eleva após o choque. O saldo em transações correntes sofre uma deterioração, que é rapidamente dissipada. 
Figura 4.19: Choque na oferta de trabalho
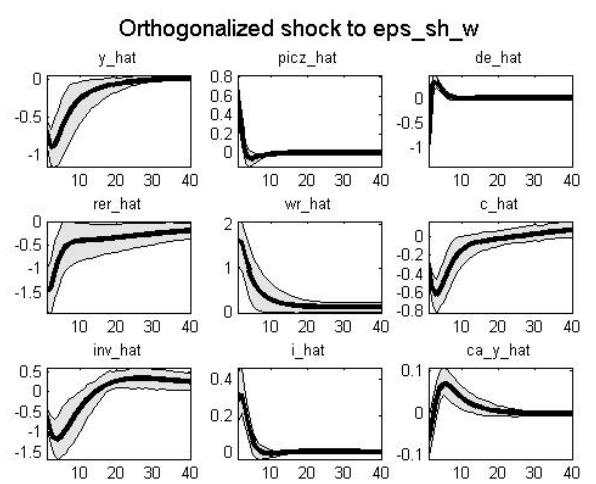

Figura 4.20: $\quad$ Choque no preço do petróleo

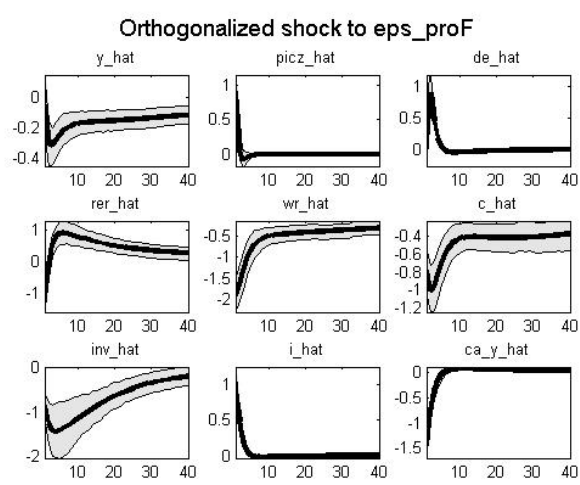

O choque no preço do petróleo provoca um aumento do custo marginal real, aumentando a inflação e reduzindo o produto, o consumo e o investimento. O aumento da inflação contribui para a apreciação da taxa de câmbio real e para queda do salário real. O saldo em conta-corrente sofre uma deterioração após o choque de oferta. 
Figura 4.21: Choque no custo de ajustamento do investimento

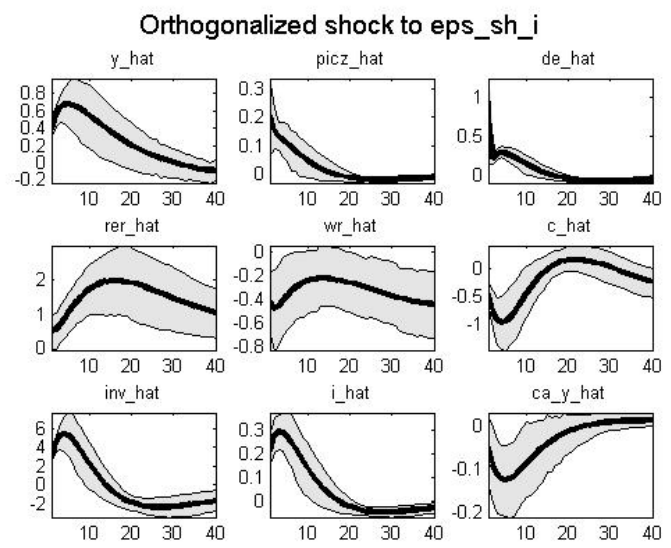

O choque no custo de ajustamento do investimento faz com que a mesma quantidade de investimento gere uma quantidade maior de capital, atuando como um choque específico no investimento. Após o choque o produto e o investimento aumentam. A inflação também se eleva, contribuindo para a queda do salário real. A taxa de câmbio real se deprecia, pois o investimento depende de bens importados. Com o aumento da inflação e do produto, a resposta endógena da política monetária leva a um aumento da taxa de juros. A resposta do consumo é ambígua, recuando logo após o choque mas se recuperando posteriormente.

Figura 4.22: $\quad$ Choque no preço das importações

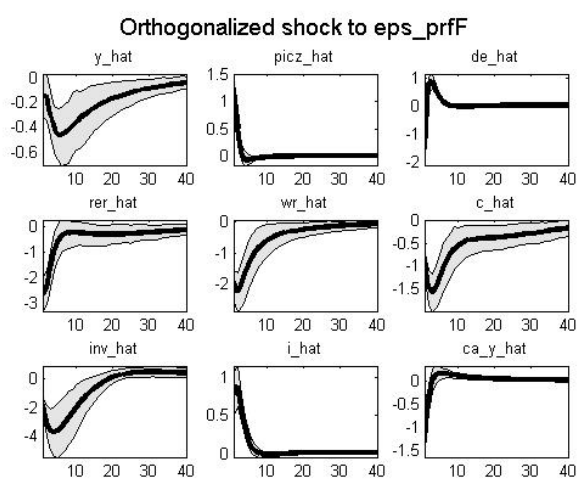

O choque no preço das importações atua como um choque negativo nos termos de troca do país. O produto, o consumo e o investimento sofrem uma queda após o choque. A inflação se eleva após o choque, contribuindo para a apreciação do câmbio real. A conta-corrente entra em déficit após o choque. 
Figura 4.23: Choque na inflação mundial
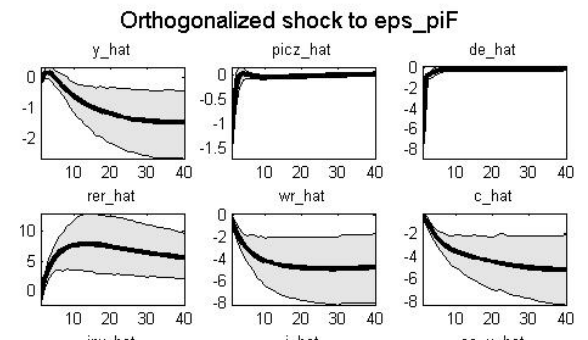

c_hat
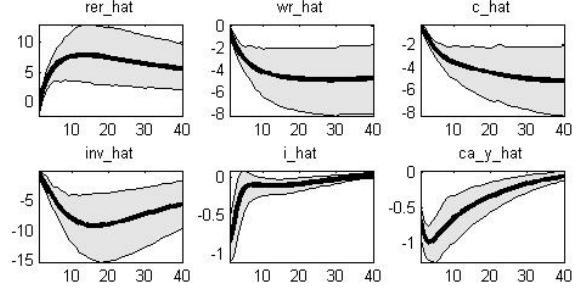

Um choque na inflação mundial leva a uma apreciação da taxa de câmbio nominal. Apesar da inflação doméstica recuar após o choque, o câmbio real se deprecia, refletindo o efeito do choque. O produto, o consumo e o investimento recuam ao longo do tempo, com a desvalorização do câmbio real, que também contribui para equilibrar o saldo em transações correntes.

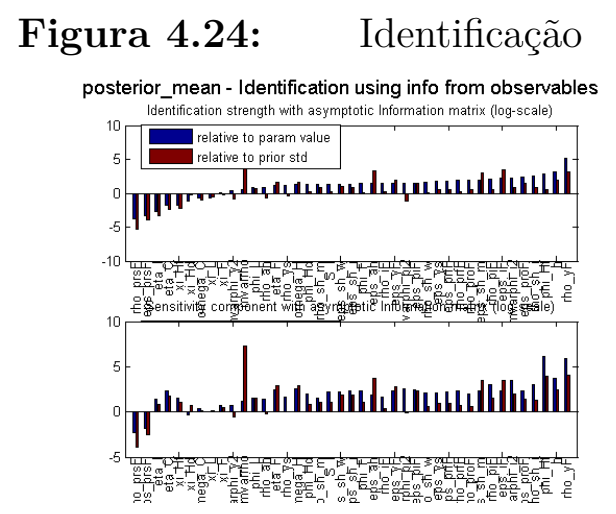

\subsection{Conclusão}

O objetivo desta seção foi analisar a contribuição de fatores externos na economia brasileira para o perído 1999-2003, utilizando um modelo DSGE de larga escala.

A estrutura do modelo utilizado permitiu a análise de choques nas commodities, que exercem uma grande contribuição para a balança comercial no Brasil, uma vez que em média $60 \%$ da pauta de exportações do Brasil é composta por commodities.

Outro objetivo foi analisar os efeitos de choques no preço do petróleo na economia brasileira, tendo em vista a importãncia da conta petróleo na balança comercial do Brasil nos últimos anos, e em face das poucas pesquisas sobre os efeitos do petróleo na economia brasileira, em contraponto com a ampla evidência disponível para os 
Estados Unidos. Por fim, o papel dos termos de troca, - representados por um choque no preço das importações - também pôde ser contemplado no modelo analisado.

Os resultados apontaram para um grande papel das variáveis externas na economia brasileira ao longo do período considerado. Embora os choques de oferta sejam predominantes na dinâmica do produto no curto prazo, como apresentado na decomposição do erro de previsão da variância, no longo prazo os choques de origem externa predominam.

O choque na produção de commodities se mostrou relevante na explicação do erro de previsão da variância do produto no curto prazo, embora no longo prazo (variância incondicional) a sua importância decline. O choque no preço das commodities exportadas não se mostrou de maior relevância no modelo.

Os preços das importações se mostraram importantes para explicar a inflação doméstica, em torno de $15 \%$ da sua variância, embora com impacto mais limitado na evolução do produto. Por sua vez, choques no preço do petróleo se mostraram relevantes para explicar a conta-corrente e a inflação.

A inflação foi explicada basicamente por choques na taxa de juros doméstica e choques de origem externa.

A titulo de comparação, os resultados obtidos no estudo original para o Chile mostraram que choques de origem externa e na oferta doméstica têm importância praticamente equivalente na evolução do produto no longo prazo. Os choques de origem externa também se mostraram bastate importantes para a dinâmica da taxa de câmbio real, do trabalho e da conta-corrente naquele país. Por outro lado, os choques na política monetária se mostraram de maior relevância para explicar a variância do Brasil do que no Chile.

À luz do grande papel explicativo de choques de origem externa nas variáveis endógenas do modelo, a interpretação é de que a dinâmica da taxa de câmbio exerceu papel fundamental na economia brasileira no período de tempo considerado, mesmo com a economia brasileira sendo relativamente fechada, com corrente de comércio em torno de $25 \%$ do PIB. Esta interpretação decorre do fato de que a dinâmica da taxa de câmbio no modelo é em grande parte explicada por choques de origem externa, que por sua vez foram os que tiveram maior relevância, de acordo com as estimações. 


\section{Referências Bibliográficas}

[1] Barsky, Robert B. \& Kilian, Lutz 2004. "Oil and the Macroeconomy Since the 1970s," Journal of Economic Perspectives, American Economic Association, vol. 18(4), pages 115-134, Fall.

[2] Bernanke, Ben S. \& Gertler, Mark \& Watson, Mark, 1997. "Systematic Monetary Policy and the Effects of Oil Price Shocks," Brookings Papers on Economic Activity, Economic Studies Program, The Brookings Institution, vol. 28(1), pages $91-157$.

[3] Blanchard, Olivier J. \& Gali, Jordi 2007. "The Macroeconomic Effects of Oil Shocks: Why are the 2000s So Different from the 1970s?," NBER Working Papers 13368, National Bureau of Economic Research, Inc.

[4] Brown, Stephen P. A. \& Yücel, Mine K. 2001. "Energy prices and aggregate economic activity: an interpretive survey," Working Papers 0102, Federal Reserve Bank of Dallas.

[5] Boivin, Jean \& Giannoni, Marc 2006. "DSGE Models in a Data-Rich Environment," NBER Working Papers 12772, National Bureau of Economic Research, Inc.

[6] Castro, M. R., Gouvea, S. N., Minella, A., Santos, R. C. e SouzaSobrinho, N. F. (2011) SAMBA: Stochastic Analytical Model with a Bayesian Approach. Banco Central do Brasil, WP Series \# 239. Disponível em: http://www.bcb.gov.br/pec/wps/ingl/wps239.pdfAcesso em 31 de janeiro de 2014 .

[7] Dhawan, Rajeev \& Jeske, Karsten 2007. "Taylor rules with headline inflation: a bad idea," Working Paper 2007-14, Federal Reserve Bank of Atlanta.

[8] DIB, A. An Estimated Canadian DSGE Model with Nominal and Real Rigidities. Canadian Journal of Economics, Canadá. Vol 36 No 4. November 2003.

[9] Divino, J. A. ; SILVA JUNIOR, R. L. S. . Prêmio de Risco e a Política Monetária no Brasil. Economia Aplicada (Impresso), v. 17, p. 163-192, 2013.

[10] GRITH, Maria. Monetary and Fiscal Policy in a Two Country Model with Sticky Prices. Dissertação do Mestrado em Economia e Ciências Administrativas da Escola de Comércio e Economia da Universidade de Berlim. Disponível em: <http://www2.wiwi.huberlin.de/wpol/html/diplom/pdf/DSGEThesis_Maria.pdf $>$. Acesso em: $22 / 03 / 2011$. 
[11] Gerron-Quintana, P.A. (2007) What you match does matter: The effects of observable variables on DSGE estimation Journal of Applied Econometrics, 25 (2010), pp: 774-804.

[12] Guerrón-Quintana, P., Nason, J. Bayesian Estimation of DSGE Models in M. Thornton and N. Hashimzade eds. Handbook of Empirical Methods in Macroeconomics, forthcoming, Edward Elgar Publishing, Ltd. (2012).

[13] Hamilton, James D, 1983. "Oil and the Macroeconomy since World War II," Journal of Political Economy, University of Chicago Press, vol. 91(2), pages 228-48, April.

[14] Hamilton, James D., 2003. "What is an oil shock?," Journal of Econometrics, Elsevier, vol. 113(2), pages 363-398, April.

[15] Hamilton, James D. 2009. "Causes and Consequences of the Oil Shock of 200708," Brookings Papers on Economic Activity, Economic Studies Program, The Brookings Institution, vol. 40(1 (Spring), pages 215-283.

[16] Hamilton, James D., 2011. "Nonlinearities And The Macroeconomic Effects Of Oil Prices," Macroeconomic Dynamics, Cambridge University Press, vol. 15(S3), pages 364-378, November.

[17] Hansen, G., 1985, Indivisible labor and the business cycle, Journal of Monetary Economics 16, 309-328.

[18] Hicks, Bruce \& Kilian, Lutz, 2009. "Did Unexpectedly Strong Economic Growth Cause the Oil Price Shock of 2003-2008?," CEPR Discussion Papers 7265, C.E.P.R. Discussion Papers.

[19] Isard, Peter \& Hunt, Ben \& Laxton, Douglas2001. "The Macroeconomic Effects of Higher Oil Prices," IMF Working Papers 01/14, International Monetary Fund.

[20] Junior, O. Portugal, M. (2012) Impacto da Política Fiscal sobre a Taxa de Câmbio: Análise para o caso brasileiro através de um modelo DSGE com economia aberta. Disponível em : http://www.lume.ufrgs.br/handle/10183/61931 Acesso em 11 de setembro de 2013.

[21] Kim, In-Moo \&Loungani, Prakash, 1992. "The role of energy in real business cycle models," Journal of Monetary Economics, Elsevier, vol. 29(2), pages 173189, April.

[22] Kilian, Lutz 2009. "Not All Oil Price Shocks Are Alike: Disentangling Demand and Supply Shocks in the Crude Oil Market," American Economic Review, American Economic Association, vol. 99(3), pages 1053-69, June.

[23] Mendoza, E.G. (1995) "The Terms of Trade, the Real Exchange Rate, and Economic Fluctuations". International Economic Review, Volume 36, N. 1, Feb.

[24] Mork, Knut Anton \& Hall, Robert E.1979. "Energy Prices, Inflation, and Recession, 1974-1975," NBER Working Papers 0369, National Bureau of Economic Research, Inc. 
[25] Niquito, T. Portugal, M. Tourrucôo, F. Nunes, A. (2012) Modelos DSGE com rigidez real e nominal: uma aplicação para o Brasil. Encontro ANPEC 2012. Disponível em : http://www.anpec.org.br/encontro/2012/inscricao/files_I/i31bdee431c29a593fd6f418c8d614c8a0.pdfAcesso em 11 de setembro de 2013

[26] Rasche, Robert H. \& Tatom, John A. 1977. "Energy resources and potential GNP," Review, Federal Reserve Bank of St. Louis, issue Jun, pages 10-24.

[27] Rotemberg, Julio J \& Woodford, Michael, 1996. "Imperfect Competition and the Effects of Energy Price Increases on Economic Activity," Journal of Money, Credit and Banking, Blackwell Publishing, vol. 28(4), pages 550-77, November.

[28] Silveira, M. A. (2008) Using a Bayesian Approach to Estimate and Compare New Keynesian DSGE Models for the Brazilian Economy: the Role for Endogenous Persistence Revista Brasileira de Economia, 2008, vol. 62, issue 3, pages 333-357

[29] Sin, H. L. e Gaglianone, W. P. (2006) Stochastic simulation of a DSGE model for Brazil. MPRA Paper \# 20853

[30] Solow, Robert M. 1980. "What to Do (Macroeconomically) When OPEC Comes," NBER Chapters, in: Rational Expectations and Economic Policy, pages 249-267 National Bureau of Economic Research, Inc.

[31] ROSSI JUNIOR, J. L. ; Moura, Marcelo . Price-Setting Policy Determinants: Micro Evidence from Brazil. Economia Aplicada (Impresso), v. 14, p. 201-210, 2010 .

[32] Silveira, M. A. (2008) Using a Bayesian Approach to Estimate and Compare New Keynesian DSGE Models for the Brazilian Economy: the Role for Endogenous Persistence Revista Brasileira de Economia, 2008, vol. 62, issue 3, pages 333-357

[33] Sin, H. L. e Gaglianone, W. P. (2006) Stochastic simulation of a DSGE model for Brazil. MPRA Paper \# 20853

[34] Smets, Frank \& Wouters, Raf, 2004. "Comparing shocks and frictions in US and euro area business cycles: a Bayesian DSGE approach," Working Paper Series 0391, European Central Bank.

[35] Soto, Claudio \& Medina, Juan Pablo \& Munro, Anella 2007. "The Chilean Business Cycles Through the Lens of a Stochastic General Equilibrium Model," Working Papers Central Bank of Chile 457, Central Bank of Chile.

[36] Vasconcelos, B.F.B. Divino, J.A. (2012) O desempenho recente da política monetária brasileira sob a ótica da modelagem DSGE. Working Paper do BCB No 291. Disponível em : http://www.bcb.gov.br/pec/wps/port/TD291.pdf Acesso em 11 de setembro de 2013 



\section{Apêndice - Estimação Bayesiana}

A estimação Bayesiana vem ganhando cada vez mais espaço na macroeconomia no últimos anos. Ela conjuga a calibração com o método da máxima verossimilhança, permitindo ao pesquisador incorporar nas estimações informações sobre as priors dos parâmetros de interesse, com base na teoria econômica ou na análise dos dados. A idéia subjacente é obter as informações sobre os parâmetros do modelo em função dos dados, conjugando esta informação com as priors dos parâmetros de interesse.

Por sua vez, as priors podem ser definidas como informações sobre os parâmetros que independem dos dados, mas que dependem do modelo considerado (Ermolaev et al., 2008). As priors podem ter origem em pesquisas anteriores sobre o assunto em questão, senso comum, restrições matemáticas, dentre outras. Na perspectiva Bayesiana, os parâmetros de interesse são uma variável aleatória, dependendo dos dados, que são fixos. Não existe um valor verdadeiro do parâmetro, mas sim uma distribuição de probabilidade dos parâmetros. Assim, a inferência da variável aleatoria é feita condicionando aos dados observados, de forma que a estimação Bayesiana busca o modelo que melhor descreve os dados observados. Como os modelos DSGE são vistos como abstrações da economia real, do ponto de vista Bayesiano todos os modelos são falsos. Por outro lado, na abordagem frequentista, a preocupação com a correta especificação do modelo é bem maior, no sentido de que dados adicionais ou poder computacional não resolve problemas ligados à correta especificação dos modelos DSGE (Guerrón-Quintana e Nason, p. 3)

Wether identification of DSGE models is a problem for Bayesians is not clear. For many Bayesians all that is needed for identification is a well posed prior. .. This problem differs from identification problems frequentists face. Identification of a model is a problem that arises in population for a frequentist estimatior, while for a Bayesian the source of equivalence is data interacting with the prior. (Guerrón-Quintana e Nason, p. 4)

Na estimação Bayesiana, a crença que o pesquisador tem sobre a prior é incorporada por meio de uma distribuição de probabilidade para determinados parâmetros do modelo, que pode ser ajustada conforme a convicção do pesquisados sobre o parâmetro de interesse, por meio do formato das distribuições e também através da sua variabilidade. Assim, é possivel ajustar o peso relativo atribuído aos dados ou à prior informada. Por meio da função de distribuição das priors e da função de verossimilhança dos dados, através do Teorema de Bayes é produzida a função de distribuição posterior. 
A estimação do modelo no programa Dynare compreende as seguintes etapas:

- Calculo do steady-stade;

- Linearização do modelo;

- Resolução do modelo linearizado;

- Cálculo da log-verossimilhança por meio do filtro de Kalman;

- Encontro do máximo da verossimilhança ou da moda da distribuição posterior;

- Simulação da distribuição posterior por meio do algoritmo Metropolis;

- Cálculo de várias estatisticas com base da distribuição posterior dos parâmetros;

O modelo é linearizado e colocado na forma de espaço de estados. O programa Dynare escreve o sistema da seguinte forma:

$$
\begin{aligned}
& s_{t}=\Phi s_{t-1}+R \epsilon_{t} \\
& y_{t}=A+B s_{t-1}+u_{t}
\end{aligned}
$$

onde $s_{t}$ é um vetor de estados e choques exógenos do modelo e $y_{t}$ é um vetor de controles, variáveis observáveis. A primeira equação é denominada de equação de transição, enquanto a segunda é chamada de equação de medida, que relacionada as variáveis observáveis aos estados. Na equação de transição, $\epsilon_{t}$ são os choques estruturais, com $E\left(\epsilon \epsilon^{\prime}\right)=\sum_{\epsilon}$, e na equação de medida $u_{t}$ são os erros de medida, com $E\left(u u^{\prime}\right)=H$, com ambos $\epsilon_{t} \mathrm{e} u_{t}$ supostos i.i.d. normais. $\Phi, R, B, H$ e $\sum_{\epsilon}$, são funções do vetor de parâmetros do modelo, ou seja:

$$
\Phi=\Phi(\theta), R=R(\theta), B=B(\theta), H=H(\theta) e \sum_{\epsilon}=\sum_{\epsilon}(\theta)
$$

O filtro de Kalman é utilizado para estimar a log-verossimilhança. O filtro de Kalman pode ser definido como um procedimento recursivo para calcular o estimador ótimo do vetor de estados no período $t$, baseado nas informações disponíveis em $t$. As informações observadas de $Y^{T}$ sao utilizadas para estimar as variáveis não observáveis em $s_{t}\left(s_{t} \mid Y^{T}\right)$. Seguindo Schorfheide (ano desconhecido), denote $E\left[s_{0}\right]=S_{0}$ e $\operatorname{Var}\left[s_{0}\right]=P_{0}$

- Inicialização: o procedimento é inicializado com uma distribuição prior para o estado inicial $s_{0}: s_{0} \sim N\left(S_{0}, P_{0}\right)$, de forma que $S_{0}$ e $P_{0}$ sejam a média e a variância da distribuição do vetor de estados.

- Previsão: após a observação de $y_{t-1}$, a crença sobre o vetor de estados tem a forma $s_{t-1} \mid Y^{t-1} \sim N\left(S_{t-1}, P_{t-1}\right)$. 
- Como $s_{t-1} \mathrm{e} u_{t}$ são variáveis aleatórias independentes com distribuição normal multivariada, segue que $s_{t} \mid Y^{t-1} \sim N\left(\hat{s}_{t \mid t-1}, P_{t \mid t-1}\right)$, onde:

$\hat{s}_{t \mid t-1}=\Phi s_{t-1}$

$$
P_{t \mid t-1}=\Phi P_{t-1} \Phi^{\prime}+R \sum R^{\prime}
$$

A distribuição condicional de $y_{t} \mid s_{t}, Y^{t-1}$ assume a seguinte forma:

$$
y_{t} \mid s_{t}, Y^{t-1} \sim N\left(A+B s_{t}, H_{t}\right)
$$

Do passo anterior, temos que $s_{t} \mid Y^{t-1} \sim N\left(\hat{s}_{t \mid t-1}, P_{t \mid t-1}\right)$. A distribuição marginal de $y_{t}$, condicional a $Y^{t-1}$ assume a seguinte forma:

$$
y_{t} \mid Y^{t-1} \sim N\left(\hat{y}_{t \mid t-1}, F_{t \mid t-1}\right)
$$

onde:

$$
\begin{aligned}
& \hat{y}_{t \mid t-1}=A+B \hat{s}_{t \mid t-1} \\
& F_{t \mid t-1}=B P_{t \mid t-1} B^{\prime}+H
\end{aligned}
$$

O passo seguinte é obter a distribuição posterior de $s_{t} \mid y_{t}, Y^{t-1}$. Redefinindo $y_{t} \mathrm{e}$ $s_{t}$ :

$$
\begin{aligned}
& s_{t}=\hat{s}_{t \mid t-1}+\left(s_{t}-\hat{s}_{t \mid t-1)}\right. \\
& y_{t}=\hat{y}_{t \mid t-1}+B\left(s_{t}-\hat{s}_{t \mid t-1}\right)+u_{t}
\end{aligned}
$$

A distribuição conjunta de $s_{t}$ e $y_{t}$ é dada por :

$$
\left[\begin{array}{l}
s_{t} \\
y_{t}
\end{array}\right] \mid Y^{t-1} \sim N\left(\left[\begin{array}{c}
\hat{s}_{t \mid t-1} \\
\hat{y}_{t \mid t-1}
\end{array}\right],\left[\begin{array}{cc}
P_{t \mid t-1} & P_{t \mid t-1} B^{\prime} \\
B P_{t \mid t-1} & F_{t \mid t-1}
\end{array}\right]\right)
$$


Aplicando o Teorema de Bayes, a interação do algoritmo é finalizando, com a posterior $s_{t} \mid Y^{t}$ passando a ser a prior da próxima interação:

$$
s_{t} \mid y_{t}, Y^{t-1} \sim N\left(S_{t}, P_{t}\right)
$$

onde:

$$
\begin{aligned}
& S_{t}=\hat{s}_{t \mid t-1}+P_{t \mid t-1} B^{\prime} F_{t \mid t-1}^{-1}\left(y_{t}-A-B \hat{s}_{t \mid t-1}\right) \\
& P_{t}=P_{t \mid t-1}-P_{t \mid t-1} B^{\prime} F_{t \mid t-1}^{-1} P_{t \mid t-1}
\end{aligned}
$$

O programa utilizado nas estimações (Dynare) calcula a moda posterior dos parâmetros $\theta$, encontrando um máximo de $\log L\left(Y^{T} \mid \theta\right)+\log P(\theta)$, ou seja:

$$
\theta^{\text {moda }}=\arg \max _{\theta}\left\{\operatorname { l o g } \left[p\left(Y^{T} \mid \theta\right]+\sum_{i=1}^{N} \log \left(\left[p_{i}\left(\theta_{i}\right)\right]\right\}\right.\right.
$$

O inverso do negativo da matriz hessiana calculada na moda posterior $\theta^{\text {moda }}$, calculado numericamente, é denotado de $\sum$, e assim definido:

$$
\sum \equiv\left[-\frac{\partial^{2} f(Y \mid \theta) f(\theta)}{\partial \theta \partial \theta^{\prime}}\right]_{\theta=\theta^{\text {moda }}}^{-1}
$$

Esta matriz de variância-covariância exercerá um papel no algoritmo de Cadeias de Markov Monte Carlo, para aproximar a distribuição posterior.

Seja $M$ um modelo especifico, $Y_{T}=\left\{y_{1}, \ldots, y_{T}\right\}$ os dados observados até a data $\mathrm{T}$, $\theta_{M}$ um vetor de parâmetros do modelo $M$, e $p\left(\theta_{M} \mid M\right)$ a densidade das priors.

A fórmula de Bayes é dada por:

$$
p(\theta \mid Y, M)=\frac{p(Y \mid \theta, M) p(\theta \mid M)}{p(Y \mid M)}
$$

onde $p(\theta \mid Y, M)$ é denominado de distribuição posterior de $\theta$, sendo a função densidade de probabilidade (fdp) de $\theta$ fixando os dados observados $Y$. 
A verossimilhança de um conjunto de parâmetros $\theta_{M}$ é definida como a probabilidade de observar o conjunto de dados $Y_{T}$ fixando os parâmetros $\theta_{M}$ no modelo, $p\left(Y_{T} \mid\right.$ $\left.\theta_{M}, M\right)$. Formalmente:

$$
\mathcal{L}\left(\theta_{M}, M\right) \equiv p\left(Y_{T} \mid \theta_{M}, M\right)=\prod_{t=1}^{T} p\left(y_{t} \mid Y^{t-1}, \theta\right)
$$

Na fórmula de Bayes, a informação que precisamos é posterior $p(\theta \mid Y, M)$, ou seja, qual a probabilidade de observar os parâmetros $\theta$, fixando os dados em $Y$ e o modelo $M$. A informação sobre as priors é representada por $p(\theta \mid M)$, que são informações sobre os parâmetros que independem dos dados observados $Y$.

O denominador da fórmula de Bayes, $p(Y \mid M)$, é a densidade marginal dos dados condicional ao modelo, sendo calculada por meio da seguinte expressão:

$$
p(Y \mid M)=\int p(Y \mid \theta, M) p(\theta \mid M) d \theta
$$

Esta expressão é uma constante, e depende das priors dos modelo, $p(\theta \mid M)$.Como a densidade marginal dos dados condicional ao modelo $\left(p\left(Y_{T}, M\right)\right)$ é constante, o kernel posterior é proporcional à densidade posterior:

$$
p\left(\theta_{M} \mid Y_{T}, M\right)=\frac{p(Y \mid \theta, M) p(\theta \mid M)}{p(Y \mid M)} \propto p\left(Y_{T} \mid \theta_{M}, M\right) p\left(\theta_{M}, M\right) \equiv \kappa\left(\theta_{M} \mid Y_{T}, M\right)
$$

Assim, a função de densidade de probabilidade posterior é proporcional à função de verossimilhança multiplicada pela função de densidade de propabilidade da prior, ou seja:

$$
f d p \text { posterior } \propto(\text { função de verossimilhança }) x(f d p \text { prior })
$$

Em logaritmos:

$$
\log (f d p \text { posterior }) \propto \log (\text { função de verossimilhança })+\log (f d p \text { prior })
$$

Geralmente o pesquisador está interessado em momentos da distribuição posterior:

$$
E[g(\theta) \mid Y]=\int g(\theta) P(\theta \mid Y) d \theta
$$


1. Para calcular a média de $\theta, g(\theta)=\theta$

2. Para calcular a probabilidade que $\theta \epsilon \theta^{*}, g(\theta)=1$ se $\theta \epsilon \theta^{*}$ e $g(\theta)=0$ caso contrário

3. Para calcular a posterior do j-ésimo elemento do vetor de parâmetros $\theta, g(\theta)=$ $\theta_{j}$

A equação acima pode ser interpretada como uma média ponderada de $g(\theta)$, onde os pesos são dados pela distribuição posterior $P(\theta \mid Y)$, que por sua vez é função da função de verossimilhança e da prior.

Em geral as integrais acima não podem ser calculadas analiticamente, sendo necessário a utilização de métodos numéricos, retirando elementos da distribuição posterior $P(\theta \mid Y)$ para calcular $E[g(\theta) \mid Y]$. O procedimento consiste então em gerar $\left\{\theta_{i}\right\}_{i=1}^{N}$ que converge para $P(\theta \mid Y)$ quando $N \rightarrow \infty$, e, uma vez que a convergência tenha sido atingida, calcular o momento de interesse, após descartar a parte da amostra anterior à convergência.

A distribuição posterior é simulada por meio do algoritmo Metropolis-Hastings, que é um caso especial de Cadeias de Markov Monte Carlo (MCMC) para simular a distribuição posterior. Este algoritmo produz uma aproximação da distribuição posterior de um parâmetro de interesse. Intuitivamente, consiste em aproximar a distribuição posterior por meio de uma distribuição conhecida, por exemplo, uma normal. Múltiplas cadeias são simuladas, sendo que parte de cada cadeia é rejeitada, sendo a regra de aceitação o algoritmo Metropolis-Hasting, descrito a seguir:

1. Seja $\theta_{i-1}$ um vetor de parâmetros iniciais, e $q(\theta)$ a distribuição de saltos ("jumping distribution"). Geralmente a distribuição utilizada é a Normal multivariada, escalada por um valor c na matriz de variância-covariância, com o objetivo de garantir que a distribuição tem caudas pesadas: $N\left(\theta^{\text {moda }} ; c^{2} \sum\right)$. A matriz $\sum$ é a inversa do negativo da matriz hessiana na moda, definida acima.

2. Retire aleatoriamente um valor $\theta^{*}$ de $q\left(\theta \mid \theta_{i-1}\right)$

3. Cálculo das as posteriores $p\left(\theta^{*} \mid Y^{T}\right)$ e $p\left(\theta_{i-1} \mid Y^{T}\right)$, por meio da verossimilhança por meio do filtro de Kalman multiplicada pela prior

4. Calcule $\nu=\min \left\{\frac{p\left(\theta^{*} \mid Y^{T}\right)}{p\left(\theta_{i-1} \mid Y^{T}\right)}, 1\right\}$.

5. Retirar um número aleatório $\alpha$ da distribuição uniforme $U(0,1)$.Então, se $\nu$ por maior do que $\alpha$, a distribuição de saltos ("jumping distribution") é atualizada para $\theta_{i}=\theta^{*}$ com probabilidade $v$. Por outro lado, se $\nu$ for menor do que $\alpha$, manter $\theta_{i}=\theta_{i-1}$. Entretanto, o valor proposto $\theta^{*}$ é mantido com certa probabilidade. O motivo para este procedimento é que podem existir máximos locais e globais na distribuição. Caso fossem mantidos apenas valores propostos para os parâmetros com probabilidade elevada, este procedimento poderia atingir um máximo local. Dessa forma, algums valores propostos para os parâmetros são mantidos, mesmo quando têm probabilidade inferior ao do 
último periodo, pois isto pode levar a uma densidade ainda mais alta ao longo da cadeia. A regra de aceitação tem como objetivo percorrer todo o domínio da distribuição posterior.

6. O procedimento é repetido até atingir o nível desejado de interações.

7. Em geral o valor de $c$ é escolhido de tal forma a se obter uma taxa de aceitação de $23 \%$ a $27 \%$, onde a taxa de aceitação é definida da seguinte forma: Taxa de aceitação $=\frac{N^{o} \text { de elementos aceitos }}{N^{\circ} \text { de elementos retirados da distribuição de saltos }}$ 



\section{Referências Bibliográficas}

[1] Christiano, L. (2008) Econometrics Methods for the Analysis of Dynamic General Equilibrium Models. Notas de aula disponíveis em: http://dev3.cepr.org/meets/wkcn/1/1692/papers/handout_22.pdf. Acesso em 10 de setembro de 2013.

[2] Deen Hann, W.(2003) Introduction to Bayesian Estimation. Notas de aula disponíveis em http://www.wouterdenhaan.com/numerical/slidesbayesian.pdf. Acesso em 10 de setembro de 2013.

[3] I. Ermolaev, C. Freedman, M. Juillard, O. Kamenik, D. Korshunov, D. Laxon (2008) Estimating GPM with Dynare

[4] Griffoli, Tommaso. (2007-2008) Manual do Dynare. Disponível em: http://www.dynare.org/documentation-and-support/user-guide/DynareUserGuide-WebBeta.pdf Acesso em 10 de setembro de 2013.

[5] Guerrón-Quintana, P., Nason, J. Bayesian Estimation of DSGE Models in M. Thornton and N. Hashimzade eds. Handbook of Empirical Methods in Macroeconomics, forthcoming, Edward Elgar Publishing, Ltd. (2012).

[6] Ho, Tai-kuang. Bayesian Estimation of Linearized DSGE Models. Notas de aula.

[7] Kurmann, A. (2010) Short Course on DSGE Modeling

[8] Ripatti, A. (2013) Macroeconometrics Course. University of Helsinki

[9] Schorfheide, F. Estimation and Evaluation of DSGE Models. Notas de aula. 